\title{
Estudo comparativo estrutura-mecanismo de ação da Labaditina e seu análogo linear: aplicação de técnicas biofísicas e simulação molecular.
}

\section{Simone Cristina Barbosa}

Tese apresentada à Faculdade de Filosofia, Ciências e Letras de Ribeirão Preto da Universidade de São Paulo, como parte das exigências para a obtenção do título de Doutor em Ciências, Área: Química 


\section{Estudo comparativo estrutura-mecanismo de ação da Labaditina e seu análogo linear: aplicação de técnicas biofísicas e simulação molecular.}

\section{Versão Corrigida}

Simone Cristina Barbosa

Orientador: Prof. Dr. Pietro Ciancaglini

Tese apresentada à Faculdade de Filosofia, Ciências e Letras de Ribeirão Preto da Universidade de São Paulo, como parte das exigências para a obtenção do título de Doutor em Ciências, Área: Química 
Autorizo a reprodução e divulgação total ou parcial deste trabalho, por qualquer meio convencional ou eletrônico, para fins de estudo e pesquisa, desde que citada a fonte.

\section{FICHA CATALOGRÁFICA}

Barbosa, Simone Cristina

Estudo Comparativo Estrutura-Mecanismo de Ação da Labaditina e seu Análogo Linear: Aplicação de Técnicas Biofísicas e Simulação Molecular. Ribeirão Preto, 2014. p. 99

Tese de Doutorado, apresentada à Faculdade de Filosofia, Ciências e Letras de Ribeirão Preto/USP. Área de Concentração: Química

Orientador: Ciancaglini, Pietro

1. Labaditina. 2. Síntese de peptídeos. 3. Interação peptídeo-membrana. 4. Modelos de membrana. 5. Conformação. 
BARBOSA, S. C. Estudo comparativo estrutura-mecanismo de ação da Labaditina e seu análogo linear: aplicação de técnicas biofísicas e simulação molecular. Tese apresentada à Faculdade de Filosofia, Ciências e Letras de Ribeirão Preto da Universidade de São Paulo, como parte das exigências para a obtenção do título de Doutor em Ciências, Área: Química

Aprovado em: 25 de junho de 2014

\author{
Banca Examinadora
}

Prof. Dr. Pietro Ciancaglini Instituição: FFCLRP-USP

Julgamento Assinatura

Prof. Dr. Osvaldo Novais de Oliveira Júnior Instituição: IFSC - USP

Julgamento Assinatura

Prof. Dr. Eduardo Maffud Cilli Instituição: UNESP/ Araraquara Julgamento Assinatura

Prof. Dr. Antônio José da Costa Filho Instituição: FFCLRP-USP Julgamento Assinatura

Prof. Dr. Ana Paula Ramos Instituição: FFCLRP-USP

Julgamento Assinatura 


\section{Dedicatória}

À minha mãe Isabel Felippe Barbosa pela constante ajuda, amor pleno. Não hesitou em educar!

Aos meus irmãos pelo companheirismo, pelas críticas, pela compreensão e amor.

E principalmente à JESUS, por estar presente em todos os momentos da minha vida, por me dar força em todos os momentos... sem seu amor, graça e misericórdia eu não conseguiria viver.

Enfim, Muito obrigada a todos vocês. 


\section{Agradecimentos}

Ao Prof. Dr. Pietro Ciancaglini pela disponibilidade e orientação. Sou muito grata pelo acolhimento.

Ao Prof. Dr. Eduardo Maffud Cilli pela colaboração na obtenção dos peptídeos.

Aos colegas do laboratório: Amanda, Ana Maria, Bruno, Carol, Daniela, Heitor, Juliana, Marcelle, Maytê, Thuany.

Ao Niltinho, Ivana e Mércia pela disposição, profissionalismo e amizade.

Á Priscila Cerviglieri Ciancaglini pela correção dos textos em inglês.

Ao Dr. Carlos Fuzo, muito obrigada pela colaboração nas simulações por Dinâmica Molecular.

Ao Prof. Dr. Osvaldo Novais de Oliveira Junior pela colaboração nos estudos com monocamada de Langmuir.

Á Dra. Thatyane Marimoto Nobre Pavinatto pela presente colaboração nos estudos com monocamada de Langmuir.

À CAPES pela bolsa concedida.

À FAPESP, CNPq e CAPES pelo apoio técnico e financeiro ao laboratório.

Enfim, à todos vocês

\section{Muito obrigada.}




\section{“Em tudo dai graça"}

| Tessalonissenses 5:18 


\section{"Todo homem define os limites do mundo de acordo com os limites do seu próprio campo de visão" \\ Arthur Schopenhauer}




\section{Sumário}

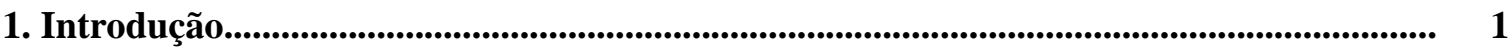

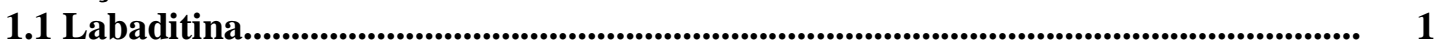

1.2 Interação peptídeo-membrana........................................................................... 2

2. Objetivos gerais...................................................................................................................................... 7

2.1 Os objetivos específicos....................................................................................... 7

3. Materiais e Métodos............................................................................................................................ 8

3.1 Síntese dos peptídeos............................................................................................................. 8

3.2 Clivagem dos peptídeos............................................................................................................... 8

3.3 Ciclização do peptídeo............................................................................................... $\quad 10$

3.4 Purificação dos peptídeos.................................................................................................... $\quad 10$

3.5 Espectrometria de Massas................................................................................................................ 11

3.6 Determinação da concentração dos peptídeos................................................................. 12

3.7 Preparação de lipossomos....................................................................................................... 12

3.8 Determinação do diâmetro dos Lipossomos................................................................ 13

3.9 Ensaios de Fluorescência de Triptofano.................................................................... 13

3.10 Supressão de Fluorescência...................................................................................... 14

3.11 Dicroísmo Circular............................................................................................................................ 15

3.12 Simulação por Dinâmica Molecular........................................................................... 16

3.13 Calorimetria diferencial de varredura...................................................................... 19

3.14 Monocamada de Langmuir..................................................................................................... 19

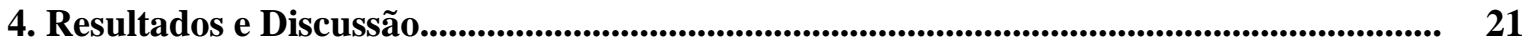

4.1 Obtenção e purificação dos peptídeos................................................................................. 21

4.1.1 Síntese de peptídeos......................................................................................... 21

4.1.2 Clivagem........................................................................................................................................ 23

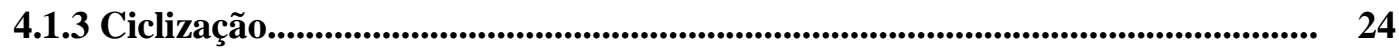

4.1.4 Purificação................................................................................................ 24

4.1.5 Espectrometria de Massas.................................................................................. 26

4.2 Estudo de interação do peptídeo com interface lipídica e em solução...................... 28

4.2.1 Monocamada de Langmuir.............................................................................. 29

4.2.2 Micelas............................................................................................................. 42

4.2.2.1 Espectrometria de Fluorescência em micelas.......................................... 43

4.2.2.2 Supressão da Fluorescência em micelas........................................................ 46

4.2.2.3 Dicroísmo Circular do peptídeo em micelas............................................. 49

4.2.2.4 Simulação por Dinâmica Molecular (DM): interação do peptídeo 53 com micelas.

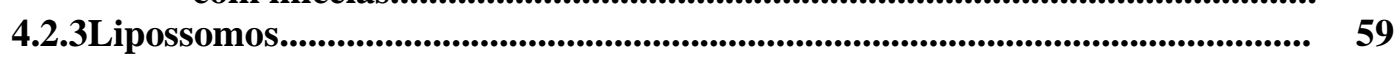

4.2.3.1 Efeito da concentração do peptídeo no diâmetro do lipossomo....... 59

4.2.3.2 Espectrometria de Fluorescência em lipossomos.................................... 64

4.2.3.3 Supressão da Fluorescência em lipossomos............................................. 66

4.2.3.4 Dicroísmo Circular em lipossomos....................................................... 70

4.2.3.5 Calorimetria diferencial de varredura (DSC).................................... 75

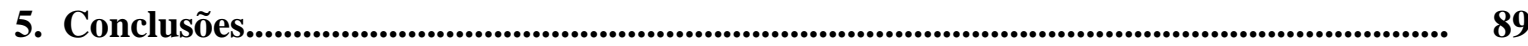

6. Referência Bibliográfica.................................................................................................................. 94 


\section{Índice de Abreviaturas}

$\lambda$ máx Comprimento de onda de máxima emissão

$\varepsilon \quad$ Coeficiente de Extinção Molar

$\Theta \quad$ Elipticidade

$\Delta \mathbf{H} \quad$ Variação da Entropia

ACN Acetonitrila

AcOEt Acetato de Etila

Boc $t$-Butiloxicarbonila

Bzl Benzil

CD Dicroísmo Circular

CG Coarse grained

Chol Colesterol

CLAE Cromatografia Líquida de Alta Eficiência

Cp Capacidade calorífica à pressão constante

CSC Calorimetry Sciences Corporation

DCM Diclorometano

Dic $\quad N, N^{\prime}$-Diisopropilcarbodiimida

DIEA $N$-Etildiisopropilamina

DLS Espalhamento dinâmico de luz

DM Dinâmica Molecular

DMF $\quad N, N^{\prime}-$ Dimetilformamida

DPPC Dipalmitoilfosfatidilcolina

DPPS Dipalmitoilfosfatidilserina

DSC Calorimetria Diferencial de Varredura

EDT 1, 2-Etanoditiol

Fmoc 9-Fluorenilmetiloxcarbonil

Fo/F Intensidade de fluorescência inicial/ intensidade atual

GROMACS GROnigen MAChine for Simulation

GUV Vesículas Multilamelares grandes

HBTU Hexafluorofosfato de 2-(1H-Benzotriazol-1-il)-1,1,3,3-tetrametilurônio

HOBt $N$-Hidroxibenzotriazol

IP Índice de Polidispersão

Ksv Constante de Sterm-Volmer 


\begin{tabular}{ll} 
L/P & Lipídio/Peptídeo \\
$\mathbf{L}_{1}$ & Peptídeo análogo-linear \\
LC & Fase líquido-condensado \\
LE & Fase líquido-expandido \\
Lo & Peptídeo Labaditina \\
LPC & Lisofosfatidilcolina \\
LPS & Lipopolissacarídeo \\
LUV & Vesículas unilamelares grandes \\
ODS & Octadecilsilano \\
PC & Peptídeo cíclico \\
RMSD & Desvio médio da raiz quadrada \\
SDS & Dodecil Sulfato de Sódio \\
SUV & Vesículas unilamelares pequenas \\
tBu & $t$-Butil \\
TFA & Ácido Trifluoroacético \\
Tm & Temperatura de transição principal \\
TRIS & Tris(hidroximetil)-aminometano \\
$\boldsymbol{\pi}$ & Pressão superficial \\
\hline
\end{tabular}

\section{ABREVIATURAS DOS AMINOÁCIDOS PRESENTES NA \\ LABADITINA E ANÁLOGO LINEAR}

$\begin{array}{ll}\text { A } & \text { Alanina } \\ \text { G } & \text { Glicina } \\ \text { I } & \text { Isoleucina } \\ \text { L } & \text { Leucina } \\ \text { T } & \text { Treonina } \\ \text { V } & \text { Valina } \\ \text { W ou Trp } & \text { Triptofano }\end{array}$




\section{RESUMO}

Labaditina é um decapeptídeo cíclico, hidrofóbico, extraído da Jatropha Multifida, uma planta da família Euphorbiaceae. É mais resistente à degradação proteolítica que seus respectivos isômeros lineares; e forma pontes de hidrogênio internamente, facilitando sua inserção em membrana biológica. Estudos tem mostrado que a restrição conformacional dos peptídeos cíclicos aumenta sua afinidade e especificidade à membrana. Devido à essas características físicas e às atividades biológicas apresentadas, tais como inibição da via clássica do sistema complemento humano in vitro e atividade antibacteriana para Streptococcus mutans, este peptídeo tem ganhado interesse biológico e farmacológico. Sobretudo, ainda não é conhecido seu mecanismo de ação. Devido à isso, os peptídeos Labaditina (Lo) e o análogo linear $\left(\mathrm{L}_{1}\right)$, estruturalmente diferentes, foram estudados com o objetivo de obter informações quanto ao mecanismo de ação, interação e possíveis alterações estruturais frente a membranas biológicas. O comportamento do Lo e $\mathrm{L}_{1}$ foi avaliado na presença de diferentes composições de lipídios (DPPC, DPPC:Chol (9:1), DPPC:DPPS (8:2)) e de detergentes (SDS e LPC), utilizando sistemas miméticos de membrana: monocamada, micela e lipossomo. Em monocamada, sistema planar, foi observado um aumento da pressão superficial, provavelmente causado pela presença de peptídeo. Nos sistemas compostos por DPPC:Chol e DPPC:DPPS o efeito foi maior na presença do $\mathrm{L}_{1}$, sugerindo interação eletrostática entre o peptídeo e as monocamadas. Já o peptídeo Lo, por não possuir carga, apresentou maior interação com a monocamada de DPPC, por ser zwitteriônica. Resultados similares foram obtidos através do estudo com lipossomos constituídos por DPPC, DPPC:Chol (9:1) e DPPC:DPPS (8:2). Em todos os meios, através da espectrofotometria de fluorescência, foi observado um blue-shift, ou seja, migração do triptofano para um ambiente mais apolar. Para o Lo, isso foi maior na presença de DPPC; para o $\mathrm{L}_{1}$, na presença de DPPC:Chol e DPPC:DPPS. Através do DSC foi observado um aumento da entalpia e diminuição da cooperatividade $\left(\Delta \mathrm{t}_{1 / 2}\right)$, causado pela presença de peptídeo na bicamada. Em DPPC:Chol (9:1) e DPPC:DPPS esse efeito foi maior na presença do $\mathrm{L}_{1}$; e em DPPC, na presença do Lo, confirmando os resultados anteriores. Essas interações peptídeo-mimético de membrana foram acompanhadas por mudanças conformacionais, observadas através do $\mathrm{CD}$. $\mathrm{O}$ peptídeo Lo, tanto em meio aquoso, quanto na presença dos diferentes lipossomos está nãoordenado, entretanto, possui diferenças conformacionais em cada meio. O peptídeo $\mathrm{L}_{1}$ em meio aquoso apresenta estrutura ao acaso com interação entre os triptofanos, porém em DPPC e em DPPC:Chol (9:1) sofre alteração conformacional, distanciando os triptofanos; em DPPC:DPPS (8:2) sofreu alteração para $\beta$-folha. Isso demonstra que a composição lipídica induz diferentes conformações nos peptídeos e pode afetar seu mecanismo de ação. No estudo com micelas também foi observado interação de ambos os peptídeos com SDS, e também com LPC. Em SDS os estudos sugerem que o $\mathrm{L}_{1}$ está mais inserido no meio apolar que o Lo; já em LPC, o Lo. Esses peptídeos também apresentaram alteração conformacional na presença das micelas. O peptídeo Lo, tanto em SDS, quanto em LPC, apresentou conformação não-ordenada, porém diferentes. Já o peptídeo $\mathrm{L}_{1}$ apresentou conformação $\beta$-folha na presença de SDS e LPC, porém também com diferenças. Os resultados demonstram que o peptídeo com estrutura linear $\left(\mathrm{L}_{1}\right)$ possui maior liberdade conformacional. Portanto, alguns fatores dirigem o processo de interação destes peptídeos: conformação e hidrofobicidade. Devido à diferença estrutural (cíclica e linear), esses peptídeos conferem diferentes hidrofobicidades, e isso interfere na conformação da molécula, além do meio lipídico. E finalizando o estudo, foi identificado através da DM que o resíduo de triptofano da posição 2 é o aminoácido mais inserido no meio apolar das micelas, após interação. Assim, um possível mecanismo de interação do peptídeo Lo é baseado, inicialmente, na adsorção do peptídeo na superfície lipídica. Em seguida ocorre a interação hidrofóbica membrana-peptídeo, acompanhada pela inserção do triptofano da posição 2 na região mais profunda da membrana, induzindo alterações conformacionais na molécula mediante a interação, dos outros resíduos, com a membrana.

Palavras-chave: Peptídeo, membrana, mecanismo de ação, Labaditina. 


\begin{abstract}
Labaditin is a cyclic decapeptide with high hydrophobic character, extracted from Jatropha Multifida, a plant from Euphorbiaceae family. It is more resistant to proteolytic degradation than its corresponding linear isomers. Studies have been showed that conformational restriction of cyclic peptide increases its affinity and specificity to the membrane. Due to these physical characteristics and to the biological activities shown, such as inhibition of the classical pathway of human complement system in vitro and antibacterial activity for Streptococcus mutans, this peptide has attracted biological and pharmacological interest. However, neither the target nor the action mechanism are known yet. For this reason, the Labaditin (Lo) and the linear analogue $\left(\mathrm{L}_{1}\right)$ peptides, different structures, were studied in an attempt to get information regarding the mechanism of action, interaction and possible conformational changes due to the interaction with biological membranes. The behavior of Lo and $\mathrm{L}_{1}$ was studied in the presence of different lipid compositions (DPPC, DPPC:Chol (9:1), DPPC:DPPS $(8: 2)$ ) and of detergents (SDS and LPC), using membrane mimetic systems: monolayer, micelle and liposome. In monolayer, planar system, it was observed an increase of surface pressure, probably caused by the presence of peptide. In the systems composed by DPPC:Chol and DPPC:DPPS the effect was greater in the presence of $\mathrm{L}_{1}$, implying electrostatic interaction between the peptide and the monolayers. Lo peptide, on the other hand, due to the fact that it does not have charges, presented greater interaction with the DPPC monolayer, a zwitterionic molecule. Similar results were obtained through studies with liposome composed by DPPC, DPPC:Chol (9:1) and DPPC:DPPS (8:2). In all environments, through fluorescence spectroscopy, a blue-shift was observed, which means, migration of the tryptophan to a more non-polar environment. For Lo, it was higher in the presence of DPPC; for $\mathrm{L}_{1}$, in the presence of DPPC:Chol and DPPC:DPPS. Using the DSC technique an increase of enthalpy and a decrease of cooperativity was observed $\left(\Delta \mathrm{t}_{1 / 2}\right)$, due to the presence of peptide in the bilayers. In DPPC:Chol (9:1) and DPPC:DPPS this effect was greater in the presence of $\mathrm{L}_{1}$; while in DPPC, in the presence of Lo, confirming the previous results. These peptide-membrane mimetic interaction was followed by conformational changes, observed through the CD. The Lo peptide has a unordered conformation in aqueous environment, and in the presence of liposomes also is unordered, although with differences. $\mathrm{L}_{1}$ peptide in aqueous environment presents random coil structure with interaction between tryptophan, but in DPPC and in DPPC:Chol (9:1) it suffers conformational changes, distancing tryptophan; in DPPC:DPPS (8:2) it changes to $\beta$-sheet. This demonstrates that the lipidic composition induces conformational changes in peptides and it may affect their mechanism of action. In the study with micelles it was also observed interaction between peptides-SDS, and also with peptides-LPC. In SDS, the studies suggest that $\mathrm{L}_{1}$ is more inserted in the non-polar environment than Lo; in LPC, Lo is more inserted. These peptides also presented conformational changes in the presence of micelles. Lo peptide, both in SDS, and in LPC, presented unordered conformation, but differently. $\mathrm{L}_{1}$ peptide presented $\beta$-sheet conformation in the presence of SDS and LPC, but also with differences. The results show that the peptide with linear structure $\left(L_{1}\right)$ has greater conformational liberty. Therefore, some factors are responsible to the interaction process of these peptides: conformation and hydrophobicity. Due to the structural difference (cyclic and linear), these peptides present different hydrophobicity, and it interferes in the conformation of the molecule, as well as the lipidic environment. On the last study it was identified through DM that the tryptophan residue from position 2 is the amino acid most inserted in the micelles, after interaction. Thus, a possible Lo peptide interaction mechanism is based, initially, on the adsorption of the peptide on the lipidic surface. Next, there is a hydrophobic interaction peptide-membrane followed by the tryptophan insertion of the position 2 in the deepest region of the membrane, inducing conformational changes in the molecule, through the interaction of the other residues with the membrane.
\end{abstract}

Keywords: Peptide, Membrane, Mechanism of Action, Labaditin. 


\section{Introdução}

\subsection{Labaditina}

Peptídeos cíclicos (CPs) são moléculas mais resistentes à degradação proteolítica (KWON e KODADEK, 2007; XIAO e PEI, 2007; QIAN et al., 2013) e que frequentemente formam pontes de hidrogênio internamente, facilitando sua inserção em membranas (KITAMURA et al., 1999; QIAN et al., 2013). Além disso, a restrição conformacional dos CPs aumenta sua afinidade e especificidade aos receptores (REZAI e BOCK, 2006; BOCKUS et al., 2013; QIAN et al., 2013).

Uma nova classe de CPs, pertencente ao grupo Caryophyllaceae, apresenta de 7-10 aminoácidos (TAN e ZHOU, 2006; ZHANG et al., 2009; PICCHI et al., 2009; BARBER et al., 2013). A Bioboleína (9 resíduos) e a Labaditina (10 resíduos), ambos isolados da Jatropha Multifida, foram os primeiros CPs deste grupo a serem descritos na literatura (KOSASI et al., 1989; TAN e ZHOU, 2006; BARBOSA et al., 2011). Recente revisão apresentou 19 outros PCs isolados das espécies Jatropha (SABANDAR et al., 2013), com várias atividades biológicas, como antiproliferativa, imunomodulatória, antifúngica, antimalárica.

Em particular, a Labaditina (VWTVWGTIAG) é um peptídeo hidrofóbico, tem atividade antimicrobiana, anticolinesterase e inibe a ativação da via clássica do sistema complemento humano in vitro (BARBOSA et al., 2011; SABANDAR et al., 2013; KOSASI et al., 1989). Neste contexto, é importante compreender as contribuições das interações hidrofóbicas e eletrostáticas no processo de inserção do peptídeo na membrana biológica. $\mathrm{O}$ meio hidrofóbico certamente tem importante função na partição do peptídeo (BERMEJO et al., 2013; GIERASCH et al., 1982; ROWE et al., 1998), especialmente os resíduos aromáticos. 
Além disso, o conhecimento acerca da relação estrutura-atividade é um fator importante para desvendar a forma mais comum que a molécula assume enquanto exerce sua atividade (AUVIN-GUETTE et al., 1999). Baseado nisso, estudo tem sido realizado avaliando o efeito do $\mathrm{pH}$, temperatura e agentes desnaturantes na estrutura secundária da Labaditina (Lo) e do seu análogo linear $\left(\mathrm{L}_{1}\right)$. Foi verificado que a variação desses parâmetros não afeta significativamente a conformação desses peptídeos. Também foi avaliada a interação peptídeo-lipossomo constituído por DPPC. O Lo demonstrou estar mais inserido na bicamada do que o $\mathrm{L}_{1}$. Através da análise da estrutura secundária desses peptídeos foi observado que o $\mathrm{L}_{1}$ em meio aquoso apresenta conformação ao acaso, e na presença dos mesmos lipossomos, $\beta$-estrutura. O peptídeo Lo apresenta estrutura não-ordenada tanto em meio aquoso, quanto na presença de DPPC-lipossomo, embora com diferenças conformacionais (BARBOSA et al., 2011).

Assim, o atual trabalho apresenta estudos complementares, buscando compreender os princípios que governam a partição dessas moléculas apolar e anfipática na membrana, obtendo maiores informações quanto ao mecanismo de ação da Labaditina.

\subsection{Interação peptídeo-membrana}

Estudos tem mostrado que os peptídeos se inserem nas membranas por diferentes mecanismos. Os peptídeos antimicrobianos formam poros, causam a desestabilização da membrana e, consequentemente, a morte celular (SATO e FEIX, 2006). Essa classe de peptídeo interage primeiro com a superfície externa da membrana bacteriana, os lipopolissacarídeos (LPS), em gram-negativas, e os peptídeoglicanos, em gram-positivas. Essas membranas de bactérias são compostas preferencialmente por fosfolipídios aniônicos, enquanto que as de células de mamíferos por fosfolipídios zwitteriônicos. Assim, a atividade seletiva de um peptídeo depende da sua composição, e também da célula-alvo. 
A composição fosfolipídica da membrana, fluidez, tamanho, carga e curvatura podem influenciar na orientação e profundidade de inserção do peptídeo na membrana (MATSUZAKI e MURASE, 1994). Devido à espessura das membranas, ao redor de $30 \AA$, é esperado que o peptídeo tenha um determinado comprimento mínimo. Muitas vezes as moléculas, principalmente antimicrobianas, tem mostrado tamanho inferior (entre 10 e 15 resíduos). Estudos tem mostrado que elas apresentam diferentes mecanismos, baseado na sua auto-organização, para superar o fato de serem curtos (CHEN et al., 2011).

Com intuído de esclarecer esses diferentes mecanismos de ação das diferentes moléculas encontradas, algumas técnicas têm sido empregadas avaliando a interação peptídeo-membrana, tal como dicroísmo circular, ressonância paramagnética eletrônica, espectrometria de fluorescência, monocamada de Langmuir e outras (BOKVIST at al., 2004; GALDIERO et al., 2013; JELINEK e SHEYNIS, 2010).

As membranas plasmáticas são barreiras que isolam o meio intra do extracelular. Agem como transportadores de íons e macromoléculas, como receptores, além de outras funções. Muitas dessas funções são reflexos do seu conteúdo lipídico (ALBERTS et al., 2002).

Os lipídios mais abundantes nas membranas são os fosfolipídios. A principal função deles, sobretudo, é estrutural. Neste trabalho foi utilizado sistemas miméticos de membrana (Figura 1) compostos por fosfolipídios (lipossomos e monocamada de Langmuir) e também detergentes (micelas). Esses compostos permitem estudar e caracterizar a superfície da membrana, avaliando a curvatura, o grau de hidratação e a compactação.

Os fosfolipídios se organizam em diferentes formas, tais como lipossomo, bicamada e outros. Já os surfactantes, análogo aos lipídios, por apresentar uma única cadeia de hidrocarboneto possui forma cônica, o que favorece a formação de micelas. Além disso, as 
micelas são estruturas circulares compostas por grupos lipofílicos orientados para o interior da estrutura e os grupos hidrofílicos para o exterior.

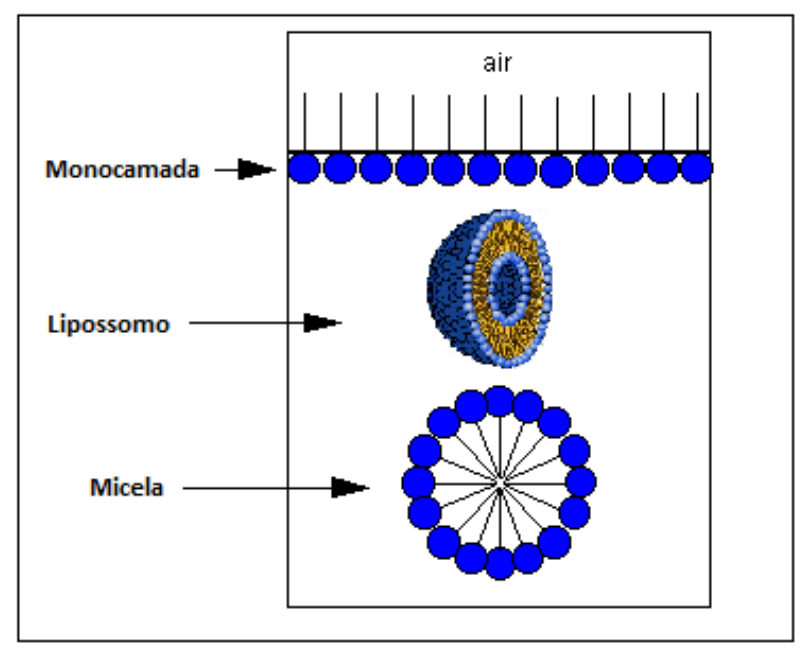

Figura 1. Modelos de membranas.

(http://employees.csbsju.edu/hjakubowski/classes/ch125/IB1_IMF_Lipid_Aggregates.html)

Por serem anfifílicos, os surfactantes, podem promover a solubilização de materiais insolúveis e também reduzir a tensão superficial da solução (GRIFFITHS e CHEUNG, 2002; SHIPOVSKOV et al., 2005).

Os lipossomos são estruturas esféricas formadas por uma ou mais bicamada de lipídio, em formato esférico, com interior aquoso. Tais estruturas são muito semelhantes a membranas naturais, porém simplificado, pois é composta apenas por lipídios.

Os lipossomos podem ser classificados conforme seu tamanho: vesículas multilamelares (MLV): formadas por bicamadas fosfolipídicas intercaladas por compartimentos aquosos, diâmetro entre 100-1000 nm; vesículas unilamelares pequenas (SUV): constituídas por apenas uma bicamada fosfolipídica, diâmetro <100 nm; vesículas unilamelares grandes (LUV): constituídas por apenas uma bicamada fosfolipídica, diâmetro 
entre 100-500 nm, vesículas multilamelares grandes (GUV): diâmetro $\geq 1 \mu \mathrm{m}$ (SANTOS e CASTANHO, 2002; SCARPA et al.,1998).

Já a monocamada lipídica é um sistema simplificado de modelo de membrana cujas moléculas de lipídio são adsorvidas na interface ar-água com as cabeças polares em contato com a água e as caudas hidrofóbicas estendidas no meio gasoso (BACIA e SCHWEIZER, 2005; FERREIRA et al., 2005). As monocamadas são adequadas para o estudo das interações entre lipídios e entre lipídio-peptídeo. Isso é feito em uma cuba, um recipiente geralmente retangular feito de material hidrofóbico cuja compressão do filme é realizada através de barreiras móveis, diminuindo a área superficial ocupada pelo filme (Figura 2). Essa pressão é medida através de um sensor de tensão superficial, geralmente uma placa de Wilhelmy em uma eletrobalança. A mínima pressão medida é zero e a máxima é de 72,8 mN/m $\left(25^{\circ} \mathrm{C}\right)$, correspondente à água pura (SHAW, 1992). No estágio inicial da compressão a área superficial entre as moléculas é extensa, elas encontram-se na fase gasosa; ao comprimir as moléculas começam a interagir, fase líquido-expandida. Com a redução da área as moléculas começam a apresentar um arranjo regular, fase líquido-condensada. Com o aumento da compactação surge a fase sólida ou também conhecida como condensada, fase cuja área é o limite da dispersão molecular. Se a monocamada continuar sendo comprimida, máxima compactação, as moléculas se agrupam desordenadamente formando multicamadas (Figura 3), efeito denominado colapso (FERREIRA et al., 2005).

A pressão de superfície $(\pi)$ é definida como a diferença da tensão superficial entre uma subfase sem lipídio $\left(\gamma_{0}\right)$ e uma subfase com o filme lipídico $(\gamma)$, ou seja, $\pi=\gamma_{0}-\gamma$. 


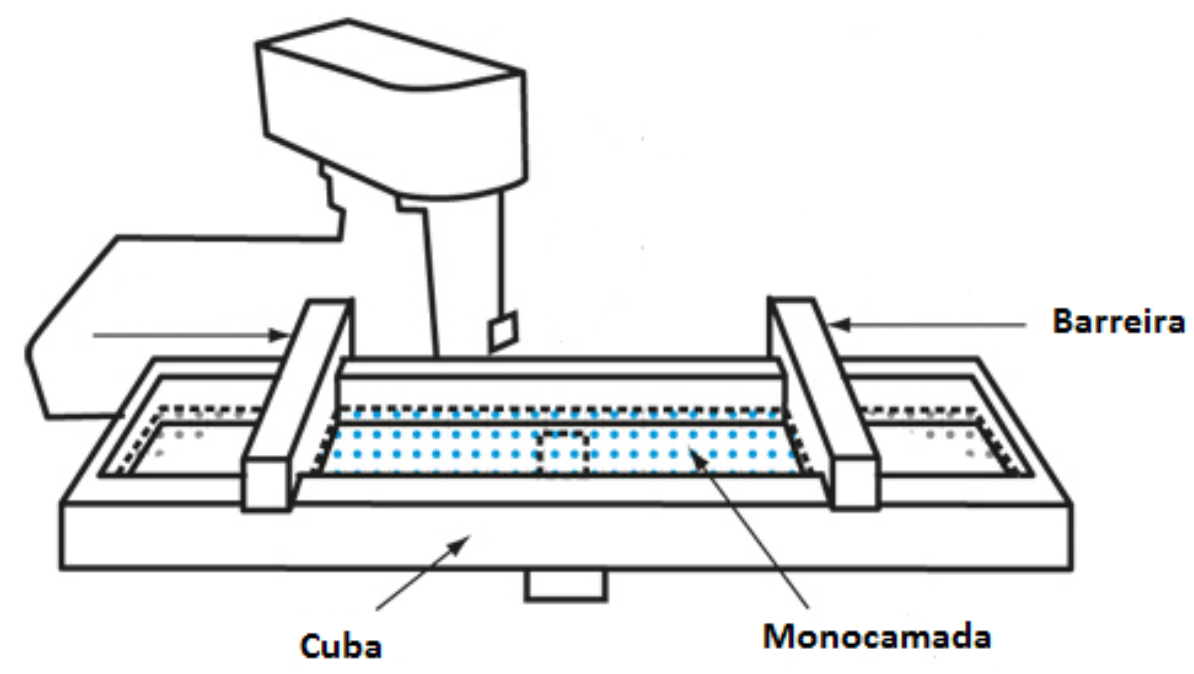

Figura 2. Esquema da cuba de Langmuir (Retirado de http://sunmil.epfl.ch/page-68954en.html).

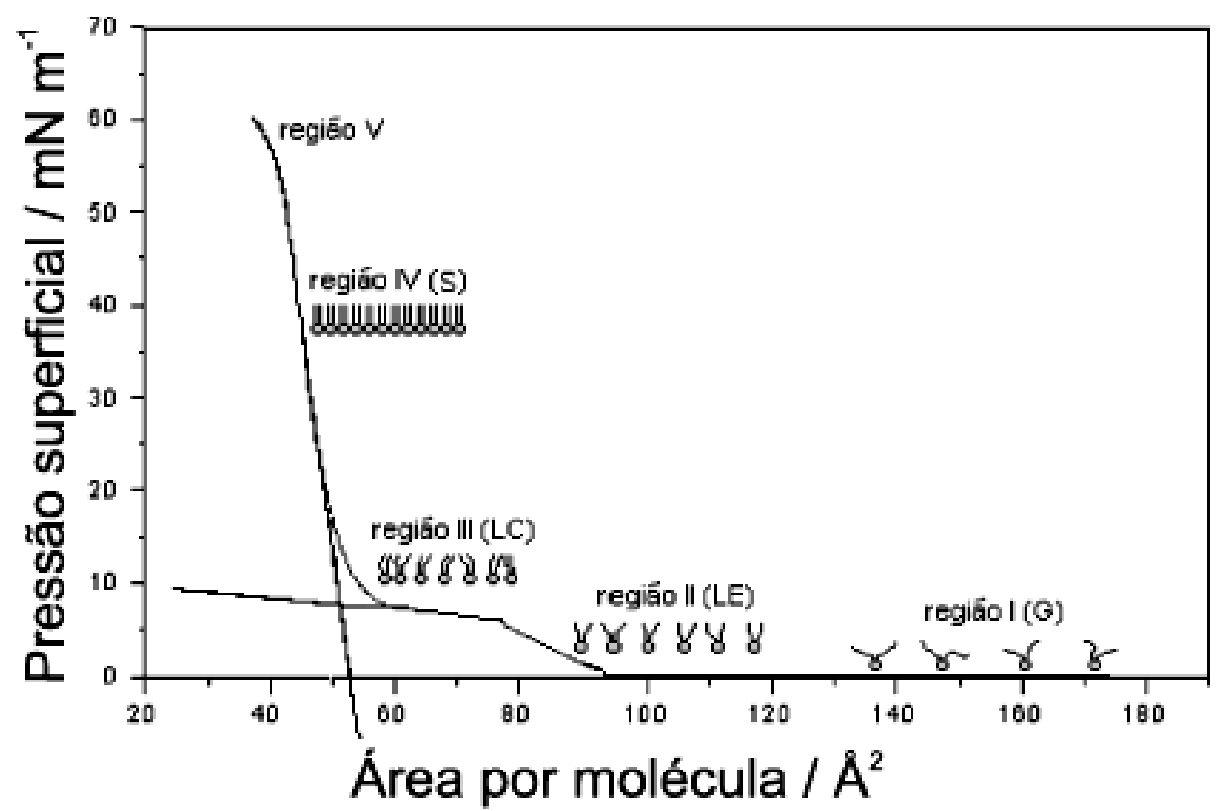

Figura 3. Isoterma de pressão de superfície do DPPC puro (FERREIRA et al., 2005). Região I: fase gasosa; região II: fase líquido-expandida (LE); região III: fase líquidocondensada (LC); região IV: fase condensada ou sólida (S) e região V: colapso. 


\section{Objetivos Gerais}

Estudos anteriores revelaram que o peptídeo cíclico Labaditina (Lo) possui maior interação com lipossomo constituído por DPPC, que seu análogo linear $\left(\mathrm{L}_{1}\right)$. Além disso, Lo apresentou atividade antimicrobiana (S. C. Barbosa et al., 2011). Baseado nisso, esse trabalho tem como objetivo estudar o comportamento da Labaditina e seu análogo linear em diferentes sistemas de membrana (micelas, monocamadas e lipossomos), de diferentes composições (zwitteriônica, aniônica, variando a compactação) empregando-se diferentes técnicas (Espectrometria de fluorescência, dicroísmo circular, monocamada de Langmuir, DLS e DSC).

\subsection{Objetivos Específicos}

1. Sintetizar e purificar os peptídeos Labaditina (Lo) e análogo linear $\left(\mathrm{L}_{1}\right)$.

2. Avaliar a importância da conformação cíclica na busca de moléculas mais bioativas, frente a estudos comparativos com molécula análoga linear.

3. Avaliar a interação peptídeo-mimético de membrana, utilizando diferentes composições (SDS, LPC, DPPC, DPPC:Chol (9:1) e DPPC:DPPS (8:2)).

4. Analisar as alterações conformacionais ocorridas nas biomoléculas, ocasionadas pela interação com as diferentes composições lipídicas.

5. Avaliar a interação dos peptídeos com miméticos de membrana de diferentes curvaturas. 


\section{Materiais e Métodos}

\subsection{Síntese dos peptídeos}

A estratégia utilizada para a síntese da Labaditina (Lo) e seu análogo $L_{1}$ foi a Fmoc/tBu (S. C. Barbosa et al., 2011). A síntese foi realizada em resina do tipo Wang, $371 \mathrm{mg}$, com grau de substituição de $0,55 \mathrm{mmol} / \mathrm{g}$, escala $0,2 \mathrm{mmol}$, cujo primeiro aminoácido (glicina) já estava acoplado. Os peptídeos Lo e $\mathrm{L}_{1}$ foram feitos juntos e separados apenas após a clivagem, pois diferem apenas na estrutura (cíclica e linear). Todos os aminoácidos, exceto glicina, foram acoplados usando 3 vezes de excesso (3 equivalentes).

O protocolo Fmoc/tBu (Figura 4) consiste de passos cíclicos de acoplamento e desproteção de aminoácidos. A desproteção da cadeia peptídica, retirada do grupo Fmoc base-lábil, foi efetivada através da lavagem em solução $20 \%$ piperidina/DMF durante 20 minutos. Após cada acoplamento e desproteção foram efetuadas lavagens com os solventes orgânicos DMF e DCM, respectivamente, e o teste de ninidrina. Antes de cada acoplamento a resina foi solvatada ("inchada") com DCM.

\subsection{Clivagem dos peptídeos}

A clivagem do peptidil-resina $(695 \mathrm{mg}$ ) foi realizada pela reação com uma solução contendo 5\% água ultra pura (Millipore ${ }^{\circledR}$ Direct Q), 2,5\% fenol, 2,5\% EDT, 5\% tioanisol e $82,5 \%$ TFA, chamado de reagente $\mathrm{K}$, durante duas horas, na proporção de $10 \mathrm{~mL} / \mathrm{g}$ de peptidil-resina, conforme Barbosa et al. (2011). Após esse tempo, os peptídeos foram precipitados com éter etílico a $4^{\circ} \mathrm{C}$, filtrados em uma placa porosa e separados da resina através da extração com uma solução $50 \%$ solvente A / 50\% solvente B (Solvente A: 0,045\% TFA/ $\mathrm{H}_{2} \mathrm{O}$ e Solvente B: 0,036\% TFA/acetonitrila). Essa solução, 50\% solvente A / $50 \%$ solvente B mais o peptídeo, foi concentrada à baixa pressão e liofilizada. Obteve-se um pó branco, posteriormente identificado e caracterizado por CLAE. 
INíCIO

$2 \times$ DMF

$1 \times 20 \%$ piperidina em DMF

$1 \times 20 \%$ piperidina em DMF por $20 \mathrm{~min}$.

$2 \times$ DMF

$2 \times$ DMF

$2 \times \mathrm{DCM}$

0,6 Eq. de Fmoc-aa + DIClHoBt

em DCM / DMF (1:1, v/v)

ACOPLAMENTO

[duração 1 a 2 horas]

$2 \times$ DMF

$2 \times \mathrm{DCM}$

PRÓXIMO CICLO

Teste de Ninidrina

Negativo

\section{Positivo}

Figura 4. Representação em fluxograma do protocolo de síntese empregando-se a metodologia Fmoc/tBu. 


\subsection{Ciclização do peptídeo}

Após a clivagem e caracterização o peptídeo $\mathrm{L}_{1}$ foi ciclizado, para a obtenção do Lo, conforme Barbosa et al. (2011). Para isso 150,1 mg do peptídeo linear $\left(\mathrm{L}_{1}\right)$ foi solubilizado em DMF (137 mL). A reação foi ativada com HBTU (10 equivalentes) e a base trietilamina (5 equivalentes), por 2 horas. Após esse período foi extraído com acetato de etila (AcOEt) e água, através de um funil de separação. $\mathrm{O}$ volume obtido nessa extração foi concentrado à baixa pressão, liofilizado e analisado em CLAE (BARAGUEY et al., 1998).

\subsection{Purificação dos peptídeos}

A purificação de cada um dos peptídeos brutos foi realizada em CLAE System Gold BECKMAN (preparativo) com coluna $10 \mathrm{~cm}$ x $250 \mathrm{~mm}$; partícula de $5 \mu \mathrm{m}$; C18, Kromasil. A determinação das frações puras foi realizada, analiticamente, em CLAE Shimadzu LC10A/C-47A (analítico) com coluna $250 \mathrm{~mm}$ x 4,6 cm; partícula de $5 \mu \mathrm{m}$; ODS - kromasil.

As condições cromatográficas (Tabela 1) foram previamente padronizadas por Barbosa et al. (2011).

TABELA 1: Condições cromatográficas (modo preparativo e analítico) utilizadas na purificação dos peptídeos sintetizados.

\section{Modo Preparativo}

\begin{tabular}{cc}
\hline Solventes & A: $0,045 \%$ TFA/ $\mathrm{H}_{2} \mathrm{O}$ \\
\cline { 2 - 2 } & B: 0,036\% TFA $/ A C N$ \\
\hline Gradiente $(\mathbf{L o})$ & $20 \%-50 \%$ de solvente B em $90 \mathrm{~min}$ \\
Gradiente $\left(\mathbf{L}_{\mathbf{1}}\right)$ & $15 \%-45 \%$ de solvente B em $90 \mathrm{~min}$. \\
Fluxo & $5 \mathrm{~mL} / \mathrm{min}$ \\
Comprimento de onda de deteç̧ão & $220 \mathrm{~nm}$. \\
\hline
\end{tabular}




\begin{tabular}{cc}
\hline \multicolumn{3}{c}{ Modo Analítico } \\
\hline Solventes & A: $0,045 \%$ TFA $/ \mathrm{H}_{2} \mathrm{O}$ \\
\cline { 2 - 2 } Gradiente $\left(\mathbf{L}_{\mathbf{0}}\right):$ & B: $0,036 \% \mathrm{TFA} / \mathrm{ACN}$ \\
Gradiente $\left(\mathbf{L}_{\mathbf{1}}\right):$ & isocrático $34 \%$ de solvente B \\
Fluxo & isocrático $40 \%$ de solvente B \\
Comprimento de onda de detecção: & $1,0 \mathrm{~mL} / \mathrm{min}$ \\
\hline
\end{tabular}

\subsection{Espectrometria de Massas}

A massa molar de cada peptídeo foi determinada utilizando um espectrômetro de massas ultrOTOF ${ }_{Q}$ - ESI-TOF (Bruker Daltonics, Billerica, MA, EUA). As amostras foram introduzidas diretamente na fonte de ionização, via bomba de infusão, com um fluxo de 10 $\mu \mathrm{L} / \mathrm{min}$. A voltagem do capilar foi mantida a $3 \mathrm{kV}$ e a temperatura do gás de desolvatação a $250^{\circ} \mathrm{C}$. Os experimentos foram realizados utilizando o modo positivo, sendo o nitrogênio o gás de colisão.

\subsection{Determinação da concentração dos peptídeos}

A concentração das soluções peptídicas foi determinada, espectrofotometricamente, considerando o coeficiente de extinção molar $(\varepsilon)$ do triptofano igual a $5600 \mathrm{M}^{-1} \cdot \mathrm{cm}^{-1}(\mathrm{~S}$. C. Barbosa et al., 2011). O coeficiente de extinção molar dos peptídeos foi determinado em função da quantidade de resíduos triptofano presentes na molécula, conforme a equação abaixo:

$$
\boldsymbol{E} \text { peptídeo }=\left(\mathrm{N}^{\mathrm{o}} \text { de } \operatorname{Trp}\right) . \boldsymbol{E}(\operatorname{trp})
$$




\begin{tabular}{cc}
\hline Peptídeo & $\begin{array}{c}\text { Coeficiente de extinção molar do } \\
\text { peptídeo }(\varepsilon) \mathrm{M}^{-1} \cdot \mathrm{cm}^{-1}\end{array}$ \\
\hline Lo & 11200 \\
$\mathrm{~L}_{1}$ & 11200 \\
\hline
\end{tabular}

A determinação da concentração dos peptídeos segue a lei de Beer-Lambert, conforme:

\section{$\operatorname{Absorbância~}_{(280 \mathrm{~nm})}=\boldsymbol{E}$ peptídeo $\cdot \mathbf{b}(\mathrm{cm}) \cdot \mathbf{C}(\mathrm{mol} / \mathrm{L})$}

\subsection{Preparação de lipossomos}

Lipossomos constituídos por DPPC, DPPC/DPPS (8:2), DPPC/Chol (9:1) (Figura 5) foram preparados pelo método de extrusão, dissolvendo o lipídio em clorofórmio. A remoção do solvente orgânico foi realizada através da passagem de um fluxo de gás $\mathrm{N}_{2}$ pela solução (evaporação) e da secagem à vácuo (dessecador) por 5 horas. O filme formado foi ressuspenso em tampão TRIS.HCl $50 \mathrm{mM}$, pH 7, aquecido em banho seco $\left(60^{\circ} \mathrm{C}\right)$ e agitado de 10 em 10 minutos, durante 1 hora. Essa emulsão lipídica de sistemas multilamelares foi, através de um aparelho extrusor (Liposofast, da Avestin, Ottawa, Canadá), fracionada (rompida) pela passagem por uma membrana de policarbonato com diâmetro de poro de 100 nm, 21 vezes, resultando em sistemas unilamelares (lipossomos).

É importante destacar que para os estudos de calorimetria foram preparados lipossomos com concentração de lipídio de $5 \mathrm{mg} / \mathrm{mL}$, enquanto que $1 \mathrm{mg} / \mathrm{mL}$ foram utilizados nos demais experimentos. 
Dipalmitoilfosfatidilserina (DPPS)

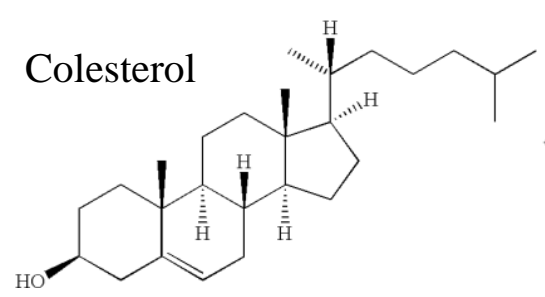

$(16: 0)$
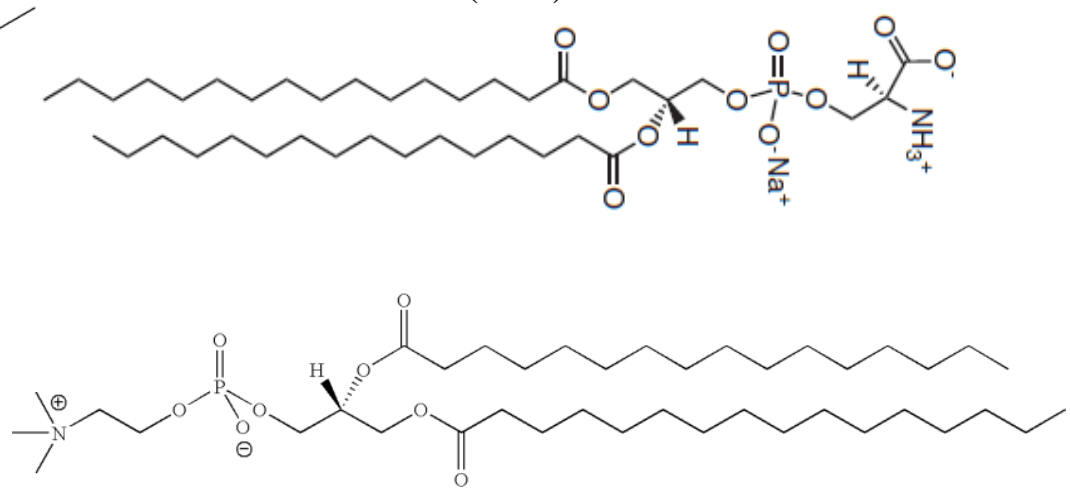

Dipalmitoilfosfatidilcolina (DPPC)

$(16: 0)$

Figura 5: Estruturas moleculares dos lipídios utilizados na preparação dos lipossomos.

\subsection{Determinação do diâmetro dos Lipossomos}

A estabilidade dos lipossomos foi avaliada medindo-se a distribuição de tamanho das partículas por espalhamento de luz dinâmico (DLS) (equipamento Beckman Coulter, modelo N5). Com o objetivo de obter um adequado ajuste da intensidade, as amostras de lipossomo foram previamente diluídas. A estabilidade dessas estruturas também foi acompanhada na presença de diferentes razões molares lipídio/peptídeo (L/P), de 20 a 60, pH 7,0, após 2 horas de incubação à temperatura ambiente. Essa distribuição de tamanho das partículas presentes na solução foi avaliada também através do índice de polidispersão (IP).

\subsection{Ensaios de Fluorescência de Triptofano}

Os experimentos de fluorescência foram realizados utilizando lipossomos e micelas, separadamente.

Lipossomo: foi realizado em um espectrofluorímetro Hitachi F-4500, com fendas de excitação e emissão fixadas em 5,0 nm de largura. As soluções de peptídeo (Lo e $\left.\mathrm{L}_{1}\right)$, pH 
7,0, foram analisadas na ausência $(51 \mu \mathrm{M})$ e presença de lipossomos constituídos por DPPC, DPPC/DPPS (8:2), DPPC/Chol (9:1). Os estudos foram realizados variando a razão molar lipídio/peptídeo (L/P) de 20 a 60.

Micela: foi realizado em um espectrofluorímetro modelo Spectronic SLM 8100. As soluções de peptídeo $\left(\right.$ Lo e $\left.\mathrm{L}_{1}\right), 10 \mu \mathrm{M}$, foram analisada com diferentes concentrações de detergente SDS (0 a $50 \mathrm{mM})$ e LPC (0 a $10 \mu \mathrm{M})$, variando a razão molar detergente/peptídeo (D/P) de 0 a $5 \times 10^{3}$ e 0 a 1 , respectivamente.

O comprimento de onda de excitação dos triptofanos presentes nos peptídeos foi 280 nm, e a emissão de fluorescência foi na faixa de 300 a $450 \mathrm{~nm}$. Em cada espectro foi obtida a intensidade de máxima fluorescência (F) e o comprimento de onda de máxima emissão $(\lambda \max )$

\subsection{Supressão da Fluorescência}

A supressão da fluorescência do triptofano foi realizada na ausência e na presença de mimético de membrana.

Lipossomo: foram adicionadas alíquotas de $0,4 \mu \mathrm{L}$ de uma solução estoque de acrilamida (6 M) em uma cubeta contendo uma solução fixa de peptídeo $(51 \mu \mathrm{M})$ e em outra com DPPC, DPPC/DPPS (8:2), DPPC/Chol (9:1), contendo a razão molar L/P = 20.

Micela: foram adicionadas alíquotas de $0,2 \mu \mathrm{L}$ de uma solução estoque de acrilamida (6 M) em uma cubeta contendo uma solução fixa de peptídeo $(10 \mu \mathrm{M})$ e em outra com SDS e LPC, contendo a razão molar detergente/peptídeo de $5 \times 10^{3}$ e 1, respectivamente.

A supressão da fluorescência do triptofano foi calculada conforme a equação de Stern-Volmer:

$$
\mathrm{Fo} / \mathrm{F}=1+\mathrm{Ksv} \cdot[\mathrm{Q}],
$$


onde Fo e F são intensidade de fluorescência na presença e ausência de supressor, respectivamente; [Q] é a concentração do supressor; Ksv é a constante de Stern-Volmer.

\subsection{Dicroísmo Circular}

Os espectros de dicroísmo circular (CD) foram obtidos utilizando um espectropolarímetro JASCO modelo J-810, na região UV-distante (190 a $250 \mathrm{~nm}$ ). As medidas foram realizadas à temperatura ambiente, com cubeta de quartzo, caminho óptico de $1 \mathrm{~mm}$.

Os espectros com lipossomo foram obtidos variando a razão molar L/P de 20 a 60 , utilizando os lipídios DPPC, DPPC/DPPS (8:2) e DPPC/Chol (9:1), separadamente.

Já com micelas foram utilizadas soluções de $100 \mu \mathrm{M}$ de $\mathrm{Lo}_{\mathrm{e}} \mathrm{L}_{1}, \mathrm{pH}$ 7,0, variando a concentração de SDS (0 a $50 \mathrm{mM})$ e LPC (0 a $10 \mu \mathrm{M})$, separadamente.

Cada amostra foi incubada por $2 \mathrm{~h}$ e analisada conforme os parâmetros abaixo (Tabela 2).

TABELA 2: Parâmetros de análise por dicroísmo circular.

\begin{tabular}{ccc}
\hline Parâmetros & Lipossomo & Micelas \\
\hline Resolução & $0,1 \mathrm{~nm}$ & $0,1 \mathrm{~nm}$ \\
Velocidade de Varredura & $100 \mathrm{~nm} / \mathrm{min}$ & $100 \mathrm{~nm} / \mathrm{min}$ \\
Tempo de Resposta & $1 \mathrm{~s}$ & $2 \mathrm{~s}$ \\
Largura de Banda & $1 \mathrm{~nm}$ & $1 \mathrm{~nm}$ \\
Acumulações & 50 & 50 \\
\hline
\end{tabular}




\subsection{Simulação por Dinâmica Molecular}

Os estudos de dinâmica molecular (DM) foram realizados com SDS e LPC, seguindo o esquema representado na Figura 6. Para a obtenção dos complexos peptídeo-micela, os sistemas foram simulados por DM, usando o modelo de representação de moléculas CoarseGrained (CG) e campo de força Martini (MARRINK et al., 2007; MONTICELLI et al., 2008). Em seguida, as estruturas atômicas dos complexos peptídeo-micela foram reconstituídas a partir de suas correspondentes representações CG, usando o algoritmo desenvolvido por Rzepiela et al. (2010). Finalmente, os sistemas resultantes foram submetidos à simulação DM com o campo de força GROMOS96 53a6 (OOSTENBRINK et al., 2004), para a análise dos dados. Todas as simulações foram realizadas com o pacote de simulação GROMACS 4.0.5 (HESS et al., 2008).

Realizamos estudos de DM com os peptídeos cíclico (Lo) e linear $\left(\mathrm{L}_{1}\right)$, usando as micelas SDS e LPC. Assim, sistemas CG contendo as micelas em caixas cúbicas foram preparadas e equilibradas durante 500 ns. Um sistema foi construído com 60 moléculas de SDS, 60 íons $\mathrm{Na}^{+}$e 18.244 moléculas de água; outro sistema foi construído com 100 moléculas de LPC e 24.740 moléculas de água. Os parâmetros de campo de força para o modelo CG de SDS foram os mesmos que os descritos por Jalili e Akhavan (2011), enquanto que os de LPC foram derivados do campo de força do DPPC (MARRINK et al., 2007). Assim, quatro sistemas foram construídos a partir destes, cada um contendo o peptídeo cíclico ou linear perto de uma micela, SDS ou LPC, com suas moléculas de água e íons. As moléculas de água e os íons sobrepostos com átomos de peptídeos foram removidos e os íons foram adicionados em novas posições. Para os sistemas contendo o peptídeo linear, um íon de $\mathrm{Na}^{+}$e de $\mathrm{Cl}^{-}$foram inseridos em posições eletrostaticamente favoráveis para neutralizar as cargas dos peptídeos. As simulações destes sistemas começaram com minimização de energia, utilizando um algoritmo steepest-descent, para eliminar maus 
contatos e forças indesejáveis. As simulações de DM foram realizadas durante 5 ns, com passos de 10 fs de tempo de integração; restrições de posição foram aplicados para as coordenadas atômicas dos peptídeos. Finalmente, todas as restrições foram removidas e as simulações foram realizadas para $1 \mu$ s com passo de 30 fs de tempo, a $300 \mathrm{~K}$. Os parâmetros utilizados nestas simulações são os mesmos do campo de força descrito por Martini (MONTICELLI et al., 2008) e estão disponíveis em http://md.chem.rug.nl/marrink/coarsegrain.html.

As estruturas atômicas dos complexos peptídeo-micela, incluindo uma camada de 0,5 nm de moléculas de água de hidratação e íons, foram invertidas das configurações finais obtidas nas simulações CG. Estes sistemas foram colocados no centro das caixas dos dodecaedros rômbicos e completados com as moléculas de água e íons. Os maus contatos desses sistemas foram eliminados, por minimização de energia, utilizando um algoritmo steepest-descent. Em seguida, as simulações foram realizadas para 200 ps, com restrição de posições para os complexos peptídeo-micela.

As simulações foram então realizadas durante 20 e 40 ns para os sistemas contendo as micelas SDS e LPC, respectivamente, em um intervalo de tempo de 2 fs. Os parâmetros de campo de força para as moléculas de SDS foram os mesmos que os utilizados no trabalho de Tummala Striolo (2008) e os parâmetros das moléculas de LPC foram derivados da molécula de DPPC (KUKOL, 2009). O modelo SPC (BERENDSEN et al., 1987) foi usado para as moléculas de água. As ligações covalentes dos detergentes e peptídeos foram restringidas pelo algoritmo LINCS (HESS et al., 1997), enquanto o algoritmo SETTLE (MIYAMOTO e KOLLMAN, 1992) foi usado para manter rígidas as moléculas de água do SPC. A temperatura de cada componente do sistema foi regulada separadamente pelo algoritmo do Berendsen (BERENDSEN et al., 1984), utilizando um tempo de correlação de 0,1 ps. A pressão (1 bar) foi controlada também pelo algoritmo de pressão do Berendsen 
(tempo de correlação de 0,5 ps). Um “cutoff” no van der Waals foi aplicado a 1,0 nm, e as interações eletrostáticas foram avaliadas pelo método de soma das malhas de partículas de Ewald (particle mesh Ewald summation method) (DARDEN et al.,1993). As equações de movimento da DM foram integradas pelo algoritmo de "leap-frog" (HOCKNEY et al., 1974).
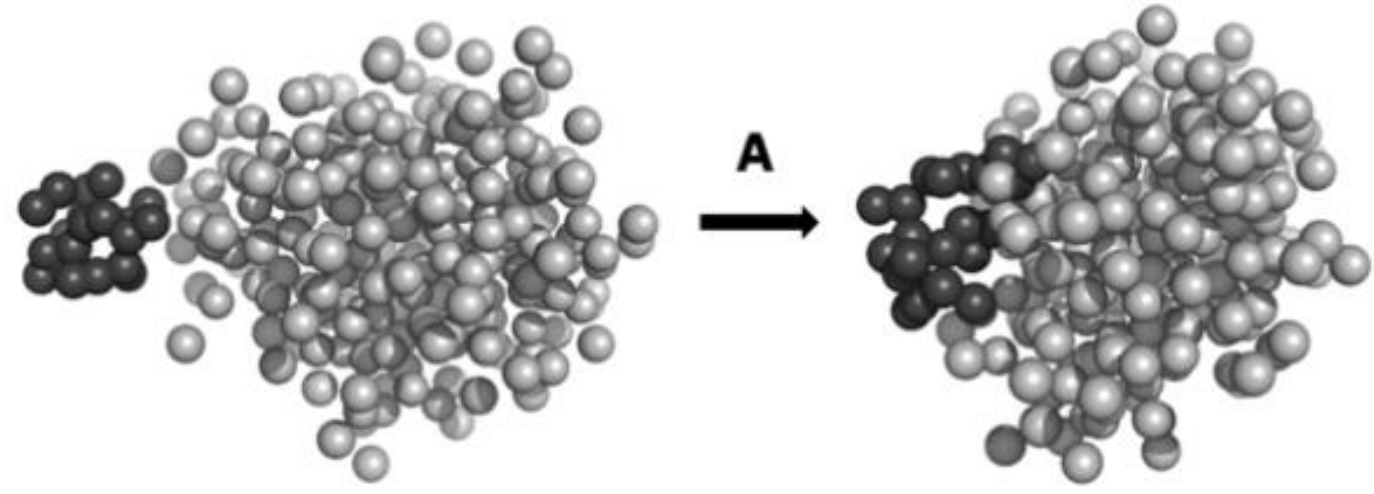

B
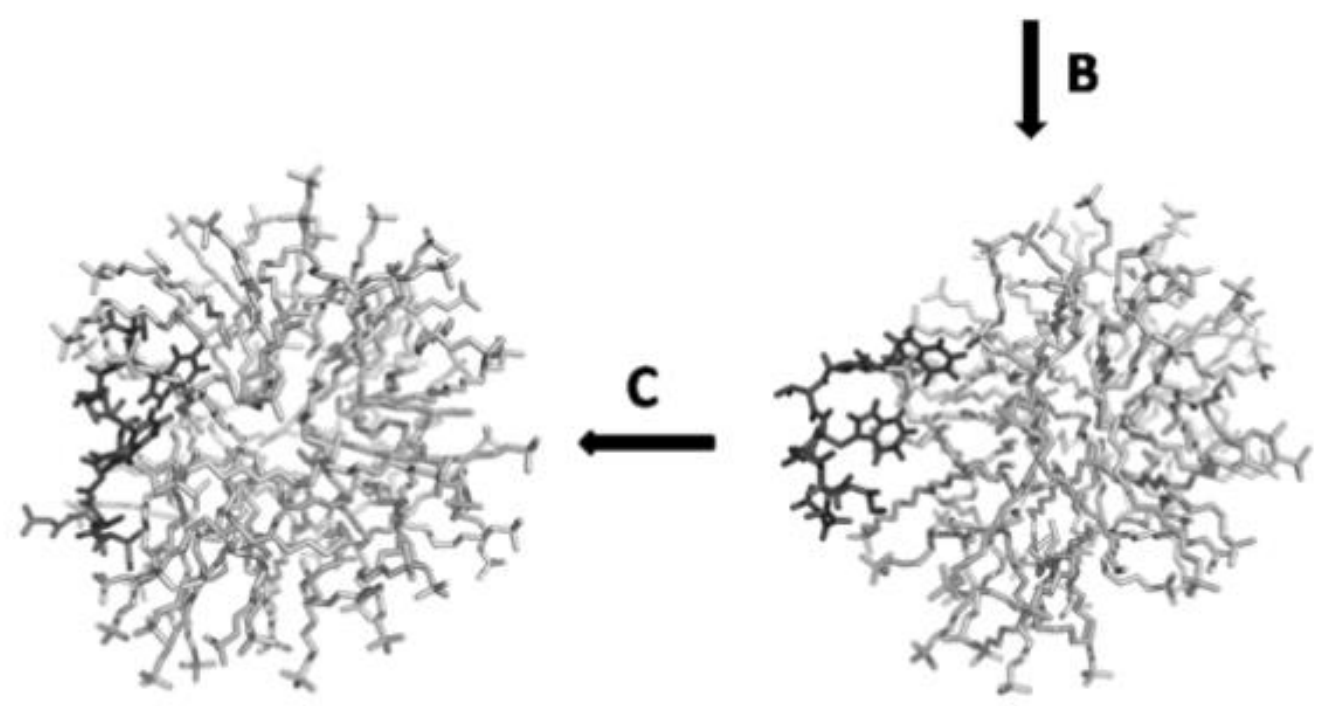

Figura 6. Esquema da Simulação, considerando o sistema contendo o peptídeo linear e micela SDS. As moléculas de água e íons foram removidas para melhor visualização. (A) 
formação do complexo peptídeo-micela por simulação CG; (B) reconstrução dos detalhes atômicos do complexo peptídeo-micela; (C) simulação do complexo com detalhes atômicos.

\subsection{Calorimetria diferencial de varredura}

Os estudos de calorimetria foram realizados utilizando um aparelho N-DSC II: Differential Scanning Calorimeter da empresa Calorimetry Sciences Corporation (CSC). Os lipossomo (5mg/mL), constituídas por DPPC, DPPC/DPPS (8:2), DPPC/Chol (9:1), foram analisados na ausência e presença dos peptídeos Lo e $\mathrm{L}_{1}$, separadamente, variando a razão molar L/P (20 a 60), pH 7,0.

Cada amostra e a referência (lipossomo) foi inicialmente desaeradas, antes de ser aplicada no compartimento do calorímetro $(300 \mu \mathrm{L})$. Foi realizada uma varredura de temperatura, variando de 20 a $60^{\circ} \mathrm{C}$, com velocidade de aquecimento de $0,25^{\circ} \mathrm{C} / \mathrm{min}$.

\subsection{Monocamada de Langmuir}

As medidas da pressão superficial foram realizadas em uma mini-KSV Langmuir. As isotermas $\pi$-A foram coletadas usando uma cuba $\left(\operatorname{Vol}_{\text {máx }}=250 \mathrm{~mL}\right)$ e barreiras móveis, ambas de Teflon. Foi utilizada subfase aquosa cuja tensão superficial é de $72.4 \pm 1 \mathrm{mN} / \mathrm{m}$. Assim, foi espalhado $37 \mu \mathrm{L}(1 \mathrm{mg} / \mathrm{mL})$ de lipídio DPPC, DPPC/Chol (9:1) ou DPPC/DPPS (8:2), separadamente, sobre a superfície aquosa (235 mL). Após a aplicação, esperou-se 15 min para a completa evaporação do solvente.

As isotermas $\pi$-A foram obtidas após a cinética de adsorção do peptídeo na monocamada ter atingido o equilíbrio. Para tal, após formado o filme lipídico na superfície injetou-se diferentes concentrações de peptídeo, separadamente, na subfase. A cinética de adsorção do peptídeo na subfase foi obtida acompanhando a variação $\pi(\mathrm{N} / \mathrm{m})$ em função do tempo (s), sem compressão das barreiras. Após a adsorção do peptídeo ter atingido o equilíbrio foram obtidas as isotermas comprimindo as barreiras a uma velocidade constante 
de $10 \mathrm{~mm} / \mathrm{min}$ (NOBRE et al., 2010). Todos os experimentos foram realizados a $25^{\circ} \mathrm{C}$. As isotermas $\pi$-A foram obtidas usando diferentes concentrações de peptídeo (Lo e $\mathrm{L}_{1}$ ), variando de 0,0235 a $0,0704 \mu \mathrm{M}$. 


\section{Resultados e Discussão}

\subsection{Obtenção e purificação dos peptídeos}

\subsubsection{Síntese de peptídeos}

Uma vez que a Labaditina é um peptídeo cíclico constituído por 10 aminoácidos, a síntese poderia ter sido iniciada por qualquer um dos resíduos, no entanto, iniciou-se estrategicamente por uma glicina, porque é o único aminoácido que não apresenta quiralidade, ou seja, não forma enantiômeros tanto na primeira etapa da síntese quanto na ciclização (BARAGUEY al., 1998). Como a Labaditina apresenta duas glicinas (uma na posição 1 e outra na 5, Tabela 3) escolhemos fazer a síntese do peptídeo $\mathrm{L}_{1}$ iniciando-se pela glicina da posição 1. Assim, o Lo foi obtido pela ciclização do $\mathrm{L}_{1}$ previamente sintetizado. Esta estratégia já foi padronizada anteriormente no mestrado (BARBOSA et al., 2011).

TABELA 3. Sequência de aminoácidos dos peptídeos estudados. Lo é a Labaditina (peptídeo cíclico) e $\mathrm{L}_{1}$ seu análogo na forma linear. Estão representados do $\mathrm{N}$-terminal para o C-terminal.

\begin{tabular}{ccccccccccc}
\hline Peptídeo & $\mathbf{1}$ & $\mathbf{2}$ & $\mathbf{3}$ & $\mathbf{4}$ & $\mathbf{5}$ & $\mathbf{6}$ & $\mathbf{7}$ & $\mathbf{8}$ & $\mathbf{9}$ & $\mathbf{1 0}$ \\
\hline Lo e $\mathrm{L}_{1}$ & $\mathrm{~V}$ & $\mathrm{~W}$ & $\mathrm{~T}$ & $\mathrm{~V}$ & $\mathrm{~W}$ & $\mathrm{G}$ & $\mathrm{T}$ & $\mathrm{I}$ & $\mathrm{A}$ & $\mathrm{G}$ \\
\hline
\end{tabular}

Assim, a síntese do peptídeo linear foi realizada em resina do tipo Wang já com o primeiro aminoácido acoplado à resina (Glicina) através de uma ligação éster, ou seja, ligação do nucleófilo $-\mathrm{OH}$ da resina ao grupo C-terminal (WORDEN et al., 2004). O segundo aminoácido foi acoplado ao grupo N-terminal do primeiro aminoácido ligado à resina através da formação de uma ligação amida, e assim por diante. No final da síntese o peptídeo foi clivado da resina obtendo-se a extremidade C-terminal na forma livre (ácido 
carboxílico).

Foi utilizado o protocolo Fmoc/tBu, conforme materiais e métodos. O Fmoc tem a vantagem de ser base-lábil, ou seja, a desproteção do amino-grupo, retirada do grupo Fmoc do Fmoc-peptidil-resina, é feita através da adição de uma solução básica (WADE et al., 1999).

Os solventes utilizados durante a síntese foram diclorometano (DCM) e dimetilformamida (DMF). O DMF solubilizou melhor o aminoácido protegido e o DCM "inchou" (aumentou o volume) a resina, favorecendo o acoplamento do aminoácido. Essa observação inicial é fundamental para o sucesso da síntese, pois a utilização de um bom solvente aumenta a exposição dos grupos reativos, viabilizando a realização da reação sintética em menor tempo e gasto (SANTINI et al., 1998).

O acoplamento dos aminoácidos foi possibilitado ativando o grupo carboxila, por duas horas, com DIC/HOBt, formando ligação amida (JIA et al., 2005).

Após cada acoplamento e desproteção foi realizado o teste de ninidrina (STEWART e YOUNG, 1984) para verificar a eficiência dessas etapas. A massa de peptidil-resina está apresentada na Tabela 4:

TABELA 4: Sumário dos rendimentos obtidos para os diferentes peptídeos sintetizados. O rendimento de síntese foi calculado considerando-se a escala de síntese e a massa molar (MM) teórica do respectivo peptídeo, determinadas a partir da sequência de aminoácidos do peptídeo, utilizando o site http://www.innovagen.se.

\begin{tabular}{lcccccc}
\hline Peptídeo & $\begin{array}{c}\text { Peptídeo } \\
\text { teórico } \\
\text { com } \\
\text { protetor } \\
(\mathrm{mg})\end{array}$ & $\begin{array}{c}\text { Peptidil-resina } \\
(\mathrm{mg})\end{array}$ & $\begin{array}{c}\text { Peptídeo } \\
(\mathrm{mg})\end{array}$ & $\begin{array}{c}\text { Escala } \\
\text { Síntese } \\
(\mathrm{mmol})\end{array}$ & $\begin{array}{c}\text { MM } \\
\text { Teórico } \\
(\mathrm{g} / \mathrm{mol})\end{array}$ & $\begin{array}{c}\text { Rendimento } \\
(\%)\end{array}$ \\
\hline $\mathrm{L}_{1}$ & 1573,14 & 695 & 300,1 & 0,2 & 1089,3 & $90,5 \%$ \\
Lo & - & - & - & - & 1071,3 & - \\
\hline
\end{tabular}




\subsubsection{Clivagem}

A clivagem dos peptídeos foi realizada em meio ácido, conforme descrito em Materiais e Métodos, usando o reagente K (KING et al., 1990). Os peptídeos clivados foram precipitados com éter etílico a $4^{\circ} \mathrm{C}$, que além da precipitação possibilitou concentrar a amostra a baixa pressão (em rotavaporador), otimizando o procedimento (RUCHALA et al., 2004).

A massa total de peptídeo $\mathrm{L}_{1}$ bruto, obtida após a clivagem de $695 \mathrm{mg}$ de peptidilresina, foi de 300,1 $\mathrm{mg}$. Uma vez que a escala de síntese planejada foi de 0,2 mmol e sabendo-se que a massa molecular teórica do peptídeo com protetor é de 1573,14 mg, foi possível calcular o rendimento de síntese, 90,5\% (BARAGUEY et al., 1998; BARBOSA et al., 2011).

A solução obtida após a clivagem foi concentrada, por rotavaporação, liofilizada e analisada por CLAE (BERTHELOT et al., 2006). O cromatograma obtido apresentou apenas um pico proeminente com tempo de retenção de 15,74 min (Figura 7).

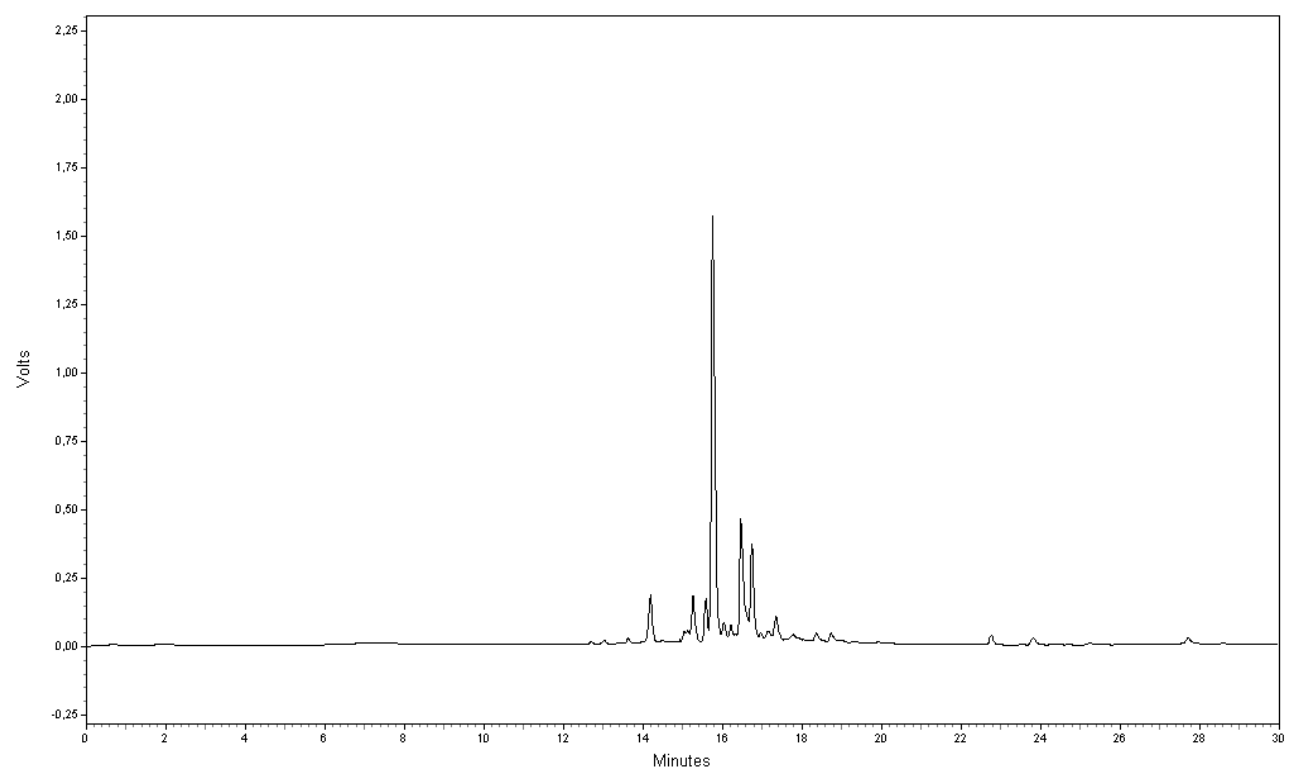

Figura 7: Cromatograma do peptídeo sintético $L_{1}$ bruto $\left(t_{r}=15,74 \min \right)$ sintetizado conforme descrito em Materiais e Métodos. A CLAE foi realizada em gradiente 5-95\% de solvente B $(0,036 \% \mathrm{TFA} / \mathrm{ACN})$, durante $30 \mathrm{~min}$. 


\subsubsection{Ciclização}

O método de ciclização do peptídeo $\mathrm{L}_{1}$, para a obtenção do peptídeo Lo, foi eficiente. Ao comparar o cromatograma do peptídeo ciclizado com o do peptídeo linear $\left(\mathrm{L}_{1}\right)$, ambos obtido por CLAE (Figuras 7 e 8), foi observado um deslocamento do tempo de retenção do peptídeo cíclico (de 15,74 para 20,76 minutos), conforme esperado. Isso ocorreu devido ao aumento da hidrofobicidade da molécula após a ciclização. Essa reação resulta na perda de uma molécula de água e também das cargas dos C e N-terminais.

O peptídeo foi extraído da solução de DMF utilizando acetato de etila (AcOEt). Isso foi possível porque o peptídeo Lo é mais solúvel em AcOEt do que em DMF. Além disso, esses solventes são imiscíveis, permitindo a extração. Após, o acetato de etila foi evaporado à baixa temperatura, evitando a degradação do peptídeo.

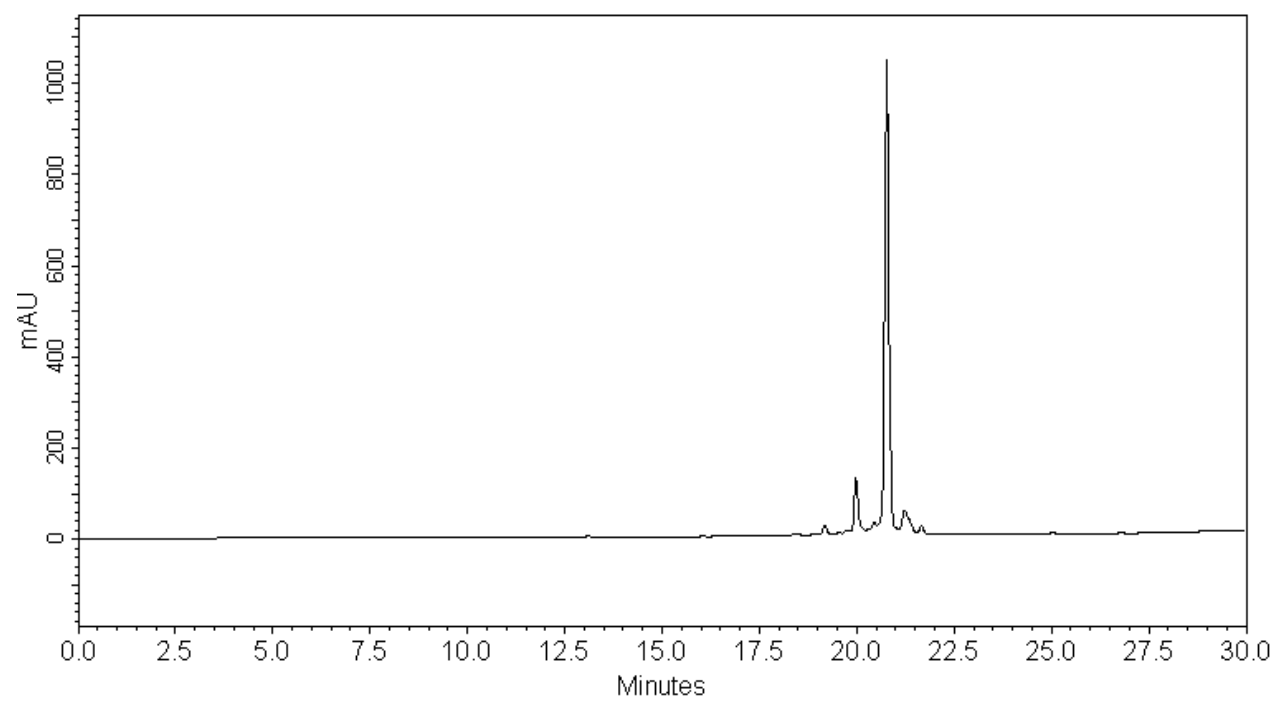

Figura 8: Cromatograma do peptídeo ciclizado Lo $\left(t_{\mathrm{r}}=20,76 \mathrm{~min}\right)$ a partir do peptídeo linear $\mathrm{L}_{1}$ bruto, conforme descrito em Materiais e Métodos. A CLAE foi realizada em gradiente $5-95 \%$ de solvente $\mathrm{B}(0,036 \% \mathrm{TFA} / \mathrm{ACN})$, durante $30 \mathrm{~min}$.

\subsubsection{Purificação}

A purificação dos peptídeos foi realizada utilizando a técnica CLAE, conforme descrito em Materiais e Métodos. Assim, 124,6 mg do peptídeo Lo foi solubilizado em 25\% 
de solvente $\mathrm{B} /$ solvente $\mathrm{A}$ e aplicado na coluna cromatográfica (escala preparativa). $\mathrm{O}$ material eluído da coluna foi coletado em frações de 2,5 mL e analisado, separadamente, em CLAE modo isocrático (escala analítica) a $34 \%$ de solvente $\mathrm{B}$, para a determinação das frações com peptídeo puro. Essas frações selecionadas foram reunidas e liofilizadas, conforme descrito em Materiais e Métodos. O peptídeo puro (Figura 9) apresentou grau de pureza de 97\% (Tabela 5).

O mesmo procedimento foi realizado com o peptídeo $\mathrm{L}_{1}$ (Figura 10), conforme descrito em Materiais e Métodos, e obtendo-se o material com grau de pureza acima de 95\% (Tabela 5).

TABELA 5: Sumário da purificação dos peptídeos Lo e $\mathrm{L}_{1}$.

\begin{tabular}{ccc}
\hline & Massa bruta & Grau de pureza \\
Peptídeo & $(\mathrm{mg})$ & $(\%)$ \\
\hline Lo & 128,31 & 97 \\
$\mathrm{~L}_{1}$ & 140,60 & 95 \\
\hline
\end{tabular}

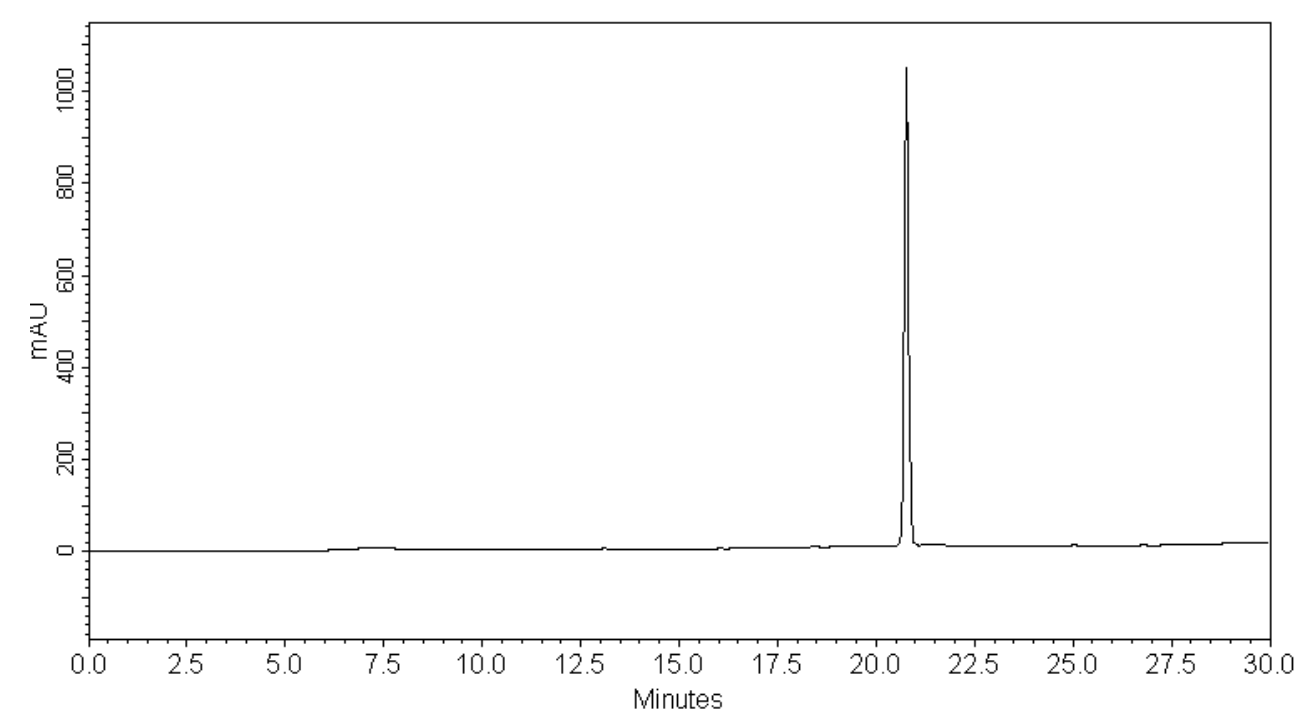

Figura 9: Cromatograma do peptídeo sintético Lo purificado conforme descrito em Materiais e Métodos. A CLAE foi realizada em gradiente 5-95\% de solvente B (0,036\% TFA/ACN), durante 30min, fluxo $1 \mathrm{~mL} / \mathrm{min}$, detecção em $220 \mathrm{~nm}$. 


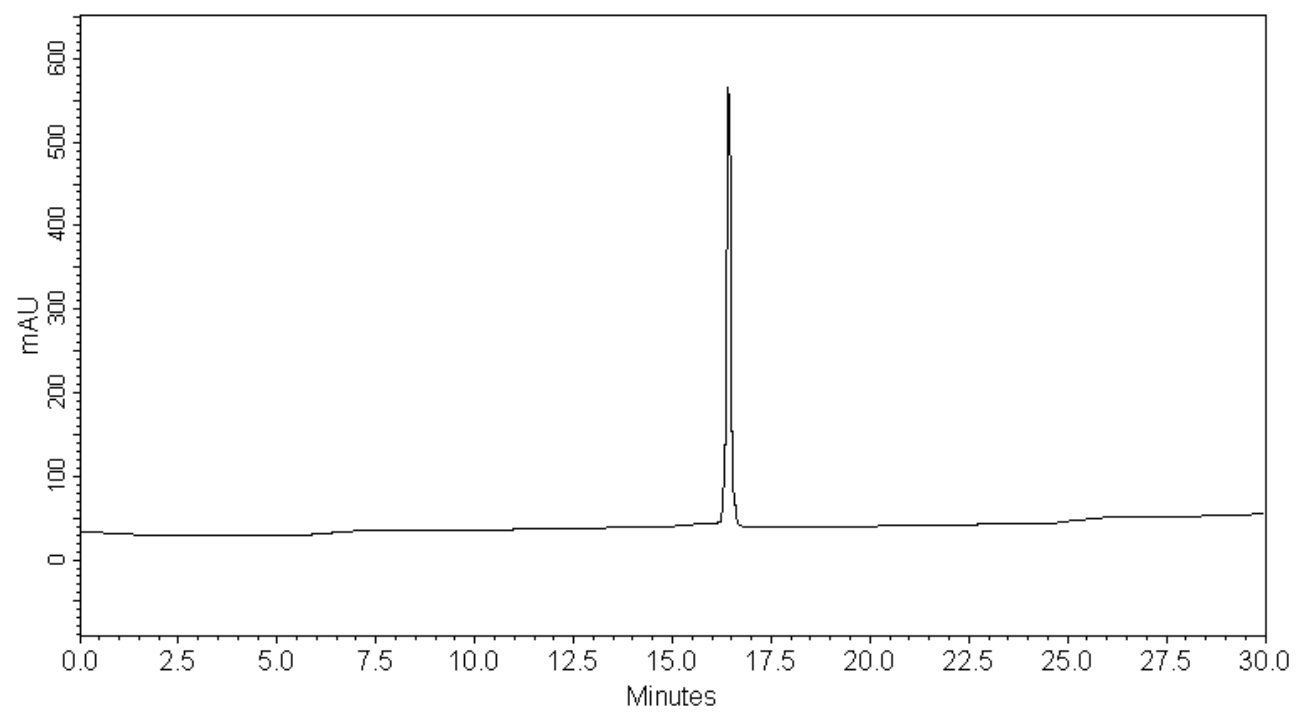

Figura 10: Cromatograma do peptídeo sintético $\mathrm{L}_{1}$ purificado conforme descrito em Materiais e Métodos. A CLAE foi realizada em gradiente 5-95\% de solvente B $(0,036 \%$ TFA/ACN), durante 30min, fluxo $1 \mathrm{~mL} / \mathrm{min}$, detecção em 220nm.

\subsubsection{Espectrometria de Massas}

Os peptídeos, sintetizados através da técnica síntese em fase sólida, foram caracterizados por espectrometria de massas (Figuras 11 e 12) cujos espectros comprovam a obtenção do material desejado, uma vez que os valores obtidos condizem com os valores teóricos, calculados através do software da Innovagen (http://www.innovagen.se). Como pode ser observado na Tabela 6, as massas teóricas e as obtidas por espectrometria de massas confirmam a obtenção dos peptídeos planejados, conforme Barbosa et al. (2011).

TABELA 6: Massas molares dos peptídeos Lo e $\mathrm{L}_{1}$. Foram obtidas por espectrometria de massas (massa real) e pelo software da Innovagen (http://www.innovagen.se), através da sequência de aminoácidos do peptídeo (massa teórica).

\begin{tabular}{ccc}
\hline \multirow{2}{*}{ Peptídeo } & \multicolumn{2}{c}{ Massa molecular $(\mathrm{g} / \mathrm{mol})$} \\
\cline { 2 - 3 } & Teórica & Espectrometria de massas \\
\hline Lo & 1071,3 & 1071,5486 \\
$\mathrm{~L}_{1}$ & 1089,3 & 1089,5631 \\
\hline
\end{tabular}




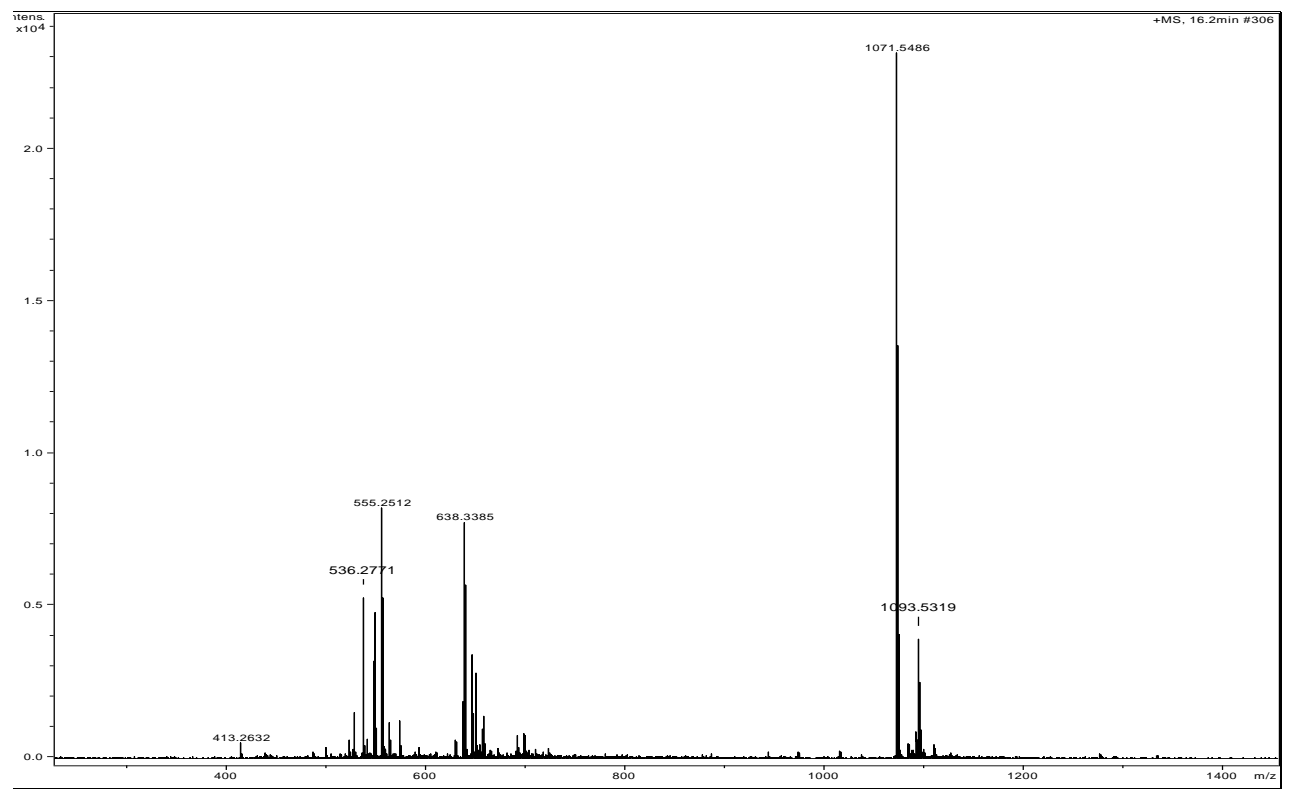

Figura 11: Espectro de Massas do peptídeo Lo determinado utilizando um espectrômetro de

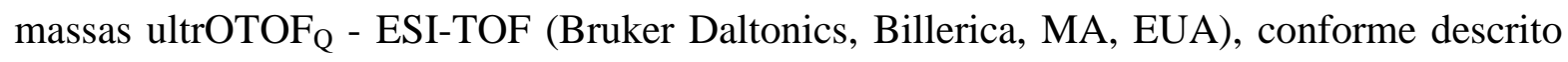
em Materiais e Métodos.

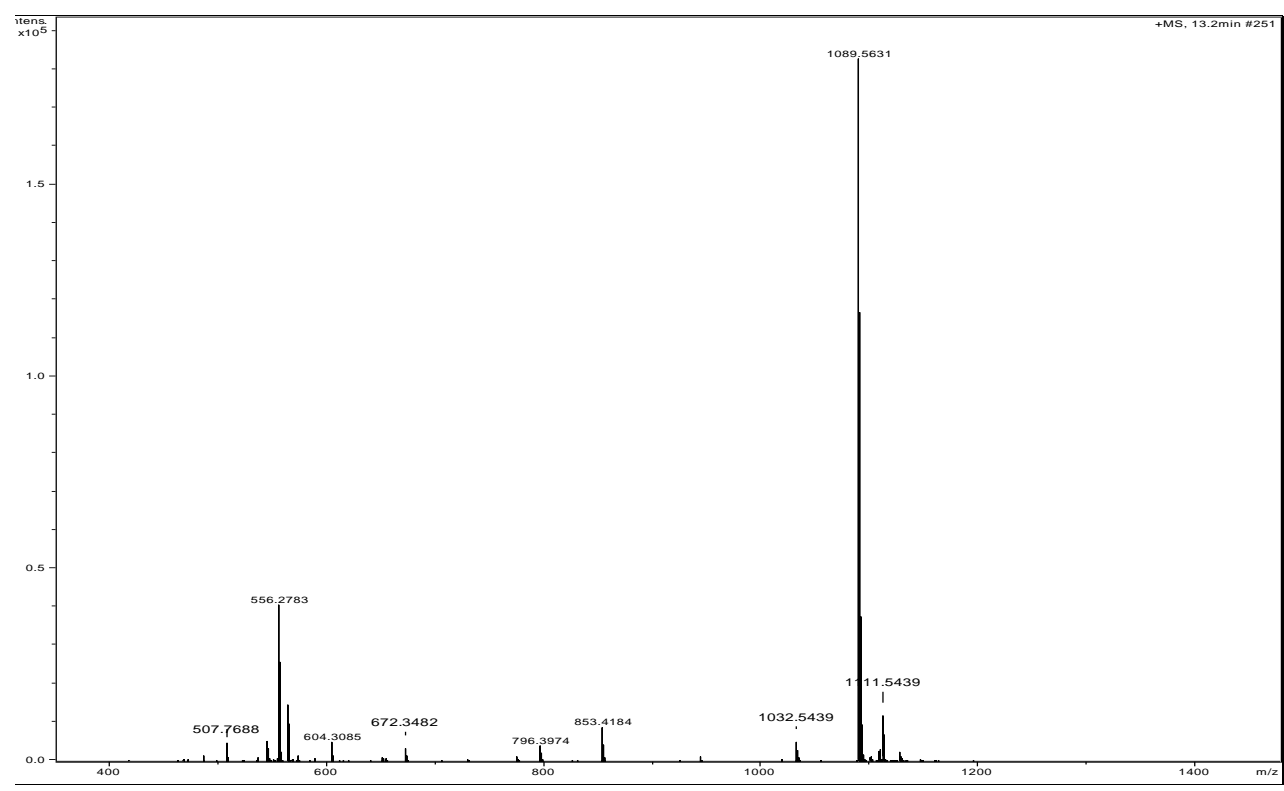

Figura 12: Espectro de Massas do peptídeo $L_{1}$ determinado utilizando um espectrômetro de massas ultrOTOF ${ }_{Q}$ - ESI-TOF (Bruker Daltonics, Billerica, MA, EUA), conforme descrito em Materiais e Métodos. 


\subsection{Estudo de interação do peptídeo com interface lipídica e em solução}

Com base na estrutura cíclica e caráter hidrofóbico da Labaditina, é importante o conhecimento detalhado acerca do mecanismo de interação e possíveis alterações estruturais frente a membranas biológicas. Assim, o comportamento do Lo e $\mathrm{L}_{1}$ foi estudado na presença de diferentes lipídios (DPPC, DPPC:Chol (9:1), DPPC:DPPS (8:2)) e detergentes (SDS e LPC), empregando-os em monocamada, lipossomo e micela.

Os PCs (fosfatidilcolinas) são os lipídios mais abundantes nos diferentes tipos de membranas biológicas (NELSON e COX, 2011; ATTWOOD et al., 2013). O DPPS é um lipídio eletrostaticamente negativo, com carga líquida -1 (URUSHIBARA e HICKS, 2013). A cabeça polar, comparada ao DPPC, é pequena, composta por um aniônico grupo fosfato e um zwitteriônico aminoácido serina.

O colesterol é um esterol muito presente nas biomembranas celulares de animais (RÓG e PASENKIEWICZ-GIERULA, 2001; TIERNEY et al., 2005). Suas principais funções biológicas são: manutenção da fluidez e redução da permeabilidade passiva da membrana (RÓG e PASENKIEWICZ-GIERULA, 2001). É composto por 4 anéis fundidos e um grupo hidroxila. Estudos mostram que ele se insere na membrana com o grupo hidroxila voltado para a cabeça polar PC e os anéis em contato com as cadeias apolares dos lipídios (LOURA e ALMEIDA, 2004) (Figura 13).

Já o SDS é um detergente aniônico cuja única cadeia hidrofóbica é composta por 12 carbonos e o grupo cabeça por sulfato. O LPC (16:0) é um detergente análogo ao DPPC, difere por apresentar uma única cadeia hidrofóbica.

Em um trabalho anterior foi determinado o limite de solubilidade de ambos os peptídeos em meio aquoso, ao redor de $270 \mu \mathrm{M}$ (BARBOSA et al., 2011). Baseado nessa informação todos os experimentos foram realizados dentro desse limite de solubilidade, em uma concentração de peptídeo apropriada para que o sinal obtido nas diferentes técnicas 
utilizadas esteja numa ordem de grandeza bem superior aos ruídos da linha de base dos diferentes equipamentos empregados.

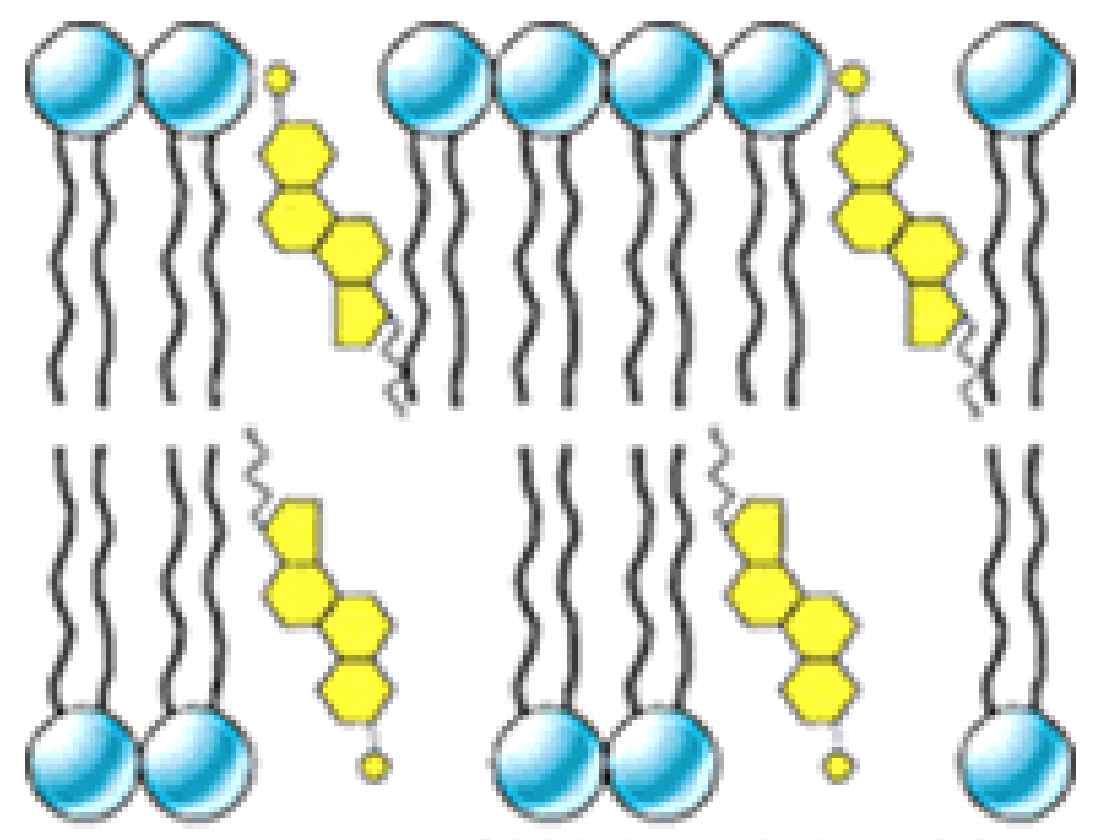

Figura 13: Esquema de inserção do colesterol na membrana (http://www.hipertrofia.org/forum/topic/90111-nutrition-101/page-4).

\subsubsection{Monocamada de Langmuir}

Os filmes de Langmuir são formados por uma única camada, sem curvatura (MAGGIO et al., 2005; WIECEK et al., 2008). Utilizamos os lipídios DPPC, DPPC:Chol (9:1), DPPC:DPPS (8:2) para comporem as monocamadas. A forma da isoterma obtida a partir da monocamada depende da temperatura e das características do lipídio, como tamanho e presença de insaturações na cadeia carbônica. Os lipídios utilizados (DPPC e DPPS) apresentam cadeia lipídica com o mesmo tamanho, sem insaturações, diferindo apenas na cabeça polar (Figura 5). 
Assim, através da compressão da monocamada de DPPC puro foi obtida a isoterma $\pi$-A para este lipídio (Figura 14). A extrapolação de uma reta traçada paralelamente ao eixo da fase mais condensada até o eixo das abcissas permitiu determinar a área superficial mínima por molécula, $47 \AA^{2} /$ molec. para a monocamada de DPPC, valor muito próximo ao relatado na literatura, $46 \AA^{2} /$ molec. à $24^{\circ} \mathrm{C}$ (SHAW, 1992; MA e ALLEN, 2006; OHE et al., 2007). Essa pequena diferença pode ser atribuída à temperatura em que as análises foram realizadas. Nesta mesma curva também foi observado um patamar, ao redor de $6 \mathrm{mN} / \mathrm{m}$, referente à coexistência das fases líquido-expandida (LE) e líquido-condensada (LC).

O primeiro indício da interação peptídeo-lipídio foi fornecido por medidas de cinética de adsorção dos peptídeos Lo e $\mathrm{L}_{1}$, separadamente, na presença do filme de DPPC na interface líquido-ar. Entretanto, primeiramente foram realizadas as cinéticas de adsorção para o peptídeo na interface líquido-ar. $\mathrm{Na}$ ausência de lipídio, a adição dos peptídeos $(0,071 \mu \mathrm{M})$ na subfase aquosa não provocou variação na pressão superficial até $2 \mathrm{~h}$. Entretanto, após a compressão da interface com as barreiras da cuba de Langmuir verificouse variação da pressão superficial (Figura 15), que atingiu valores de 18 e $25 \mathrm{mN} / \mathrm{m}$ para o peptídeo Lo e $\mathrm{L}_{1}$, respectivamente. Isso sugere que apesar da cinética de adsorção não ter alterado significativamente, ambos os peptídeos se dirigem para a interface água-ar conforme o aumento da compressão.

Na presença da monocamada de DPPC concentrações crescentes dos peptídeos Lo e $\mathrm{L}_{1}$ (Figuras 16 e 17) foram adicionadas, separadamente, e as curvas de cinética de adsorção obtidas. Observou-se para Lo (Figura 16) um aumento da pressão superficial $(\pi)$, chegando a $4 \mathrm{mN} / \mathrm{m}$ em $0,071 \mu \mathrm{M}$ de peptídeo. Este resultado sugere que Lo apresenta atividade superficial induzida pela presença do fosfolipídio. Já o peptídeo $\mathrm{L}_{1}$ não promoveu variação na pressão superficial (Figura 17). Portanto, os resultados sugerem que o peptídeo Lo tem maior atividade superficial induzida do que o peptídeo $\mathrm{L}_{1}$ para monocamadas de DPPC à 
baixo empacotamento. Isso ocorre, provavelmente, devido à ausência de cargas terminais e elevado caráter hidrofóbico do Lo, já que o DPPC apresenta carga líquida zero (Figura 16) e isso favorece a interação hidrofóbica.

Após o sistema ter atingido o equilíbrio de adsorção, ao redor de 1000 s, para ambos os peptídeos, foram obtidas as isotermas $\pi$-A de DPPC na presença dos peptídeos (Figuras 14 e 19). Com Lo (Figura 14), à baixa pressão de superfície foi constatada grande expansão das curvas até a concentração de $0,059 \mu \mathrm{M}$. Já na fase LC, na presença de Lo, as curvas não apresentaram grandes variações entre si, principalmente acima de $30 \mathrm{mN} / \mathrm{m}$. A concentração 0,059 $\mu \mathrm{M}$ é denominada concentração de saturação do efeito de expansão pelo Lo. Essa saturação pode ser melhor observada através da Figura 18, que representa as variações de área por molécula a uma pressão fixa $(25 \mathrm{mN} / \mathrm{m})$. Este valor de pressão de superfície é relevante por estar próximo ao empacotamento lipídico em uma membrana celular (MARSH, 1996). No final da compressão, próximo ao colapso, todas as monocamadas do Lo atingiram elevados valores de pressão superficial, quando comparado a monocamada de DPPC puro, passando a apresentar praticamente o mesmo formato, nos mesmos valores de área por molécula e pressão de superfície. Também foi possível observar um deslocamento da área mínima por molécula para maiores valores (51 $\mathrm{A}^{2} /$ molec.), indicando um espaçamento das moléculas de lipídio devido á inserção do peptídeo na monocamada (Tabela 7) (SHAW, 1992).

$\mathrm{Na}$ presença de $\mathrm{L}_{1}$ (Figura 19), a monocamada de DPPC à baixa pressão de superfície também apresentou crescente expansão das curvas conforme o aumento da concentração do peptídeo (entre 0,035 e 0,071 $\mu \mathrm{M}$ ), porém menos acentuada que a observada para peptídeo Lo. Entretanto, para pressão superficial acima de $10 \mathrm{mN} / \mathrm{m}$, o deslocamento para maiores áreas por molécula é mais pronunciado do que o observado para o peptídeo Lo (área por molécula chegou a $54 \mathrm{~A}^{2} /$ molec. em $0,071 \mu \mathrm{M}$ ). Isso sugere que o 
peptídeo Lo tem maior afinidade com lipídio DPPC à baixa pressão superficial, porém, essa afinidade decresce conforme o aumento da pressão, expulsando moléculas do peptídeo da interface. Já $\mathrm{L}_{1}$ permaneceu incorporado ao filme mesmo que sob elevada condição de empacotamento lipídico, sugerindo que sua interação com essa monocamada é mais eficiente que a do peptídeo Lo. Este resultado deve estar relacionado com a diferente estrutura dos peptídeos, cíclica e linear. O peptídeo linear, possivelmente, ocupa menor área, e, por tal motivo, é capaz de permanecer incorporado ao filme mesmo ao longo da compressão. Já a estrutura cíclica pode ter sido expulsa por ocupar maior valor de área. Portanto, $\mathrm{L}_{1}$, por ser linear, empacota melhor que o Lo.

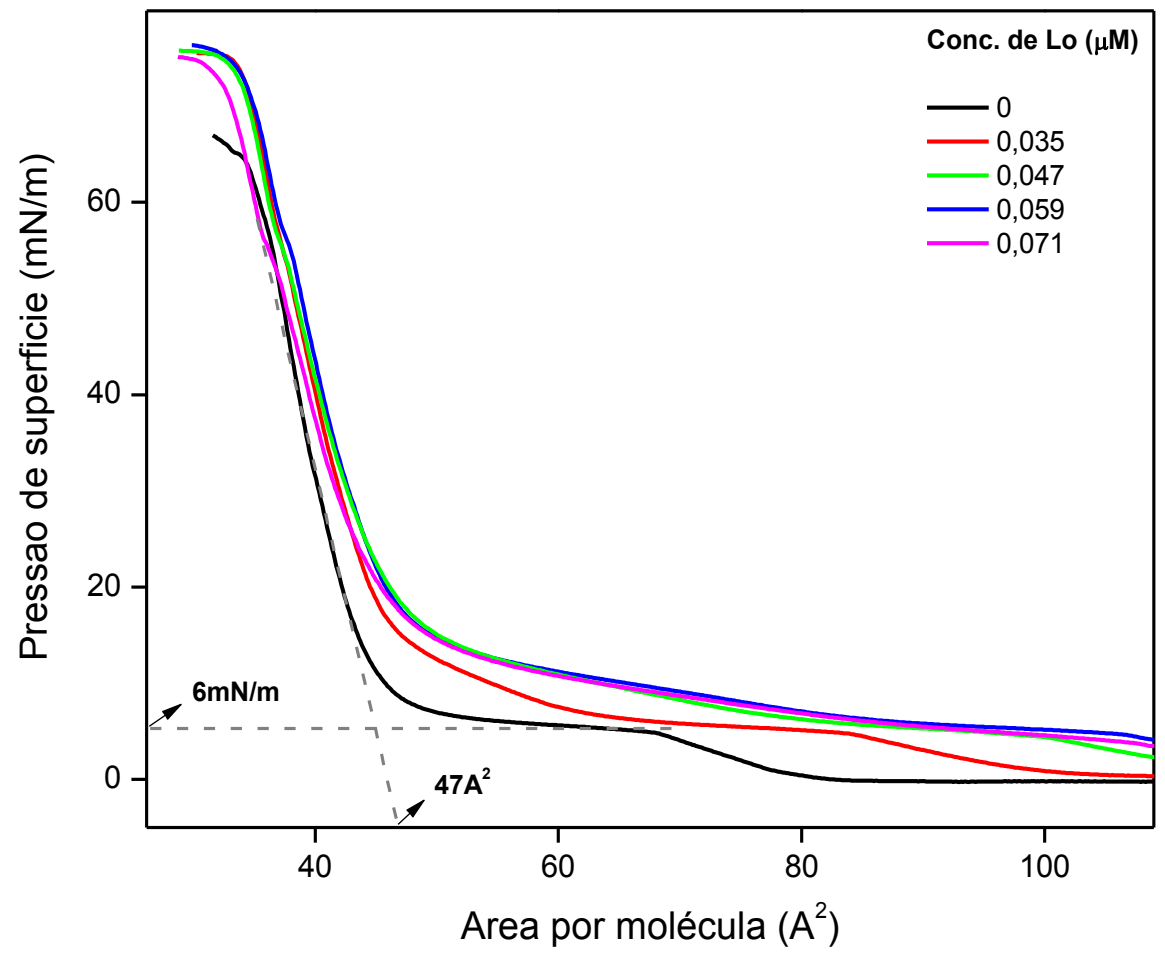

Figura 14: Isotermas $\pi$-A de monocamadas de DPPC, na ausência e presença de diferentes concentrações do peptídeo Lo, preparadas sobre a superfície da subfase aquosa, a $25^{\circ} \mathrm{C} \pm$ $1^{\circ} \mathrm{C}$. 


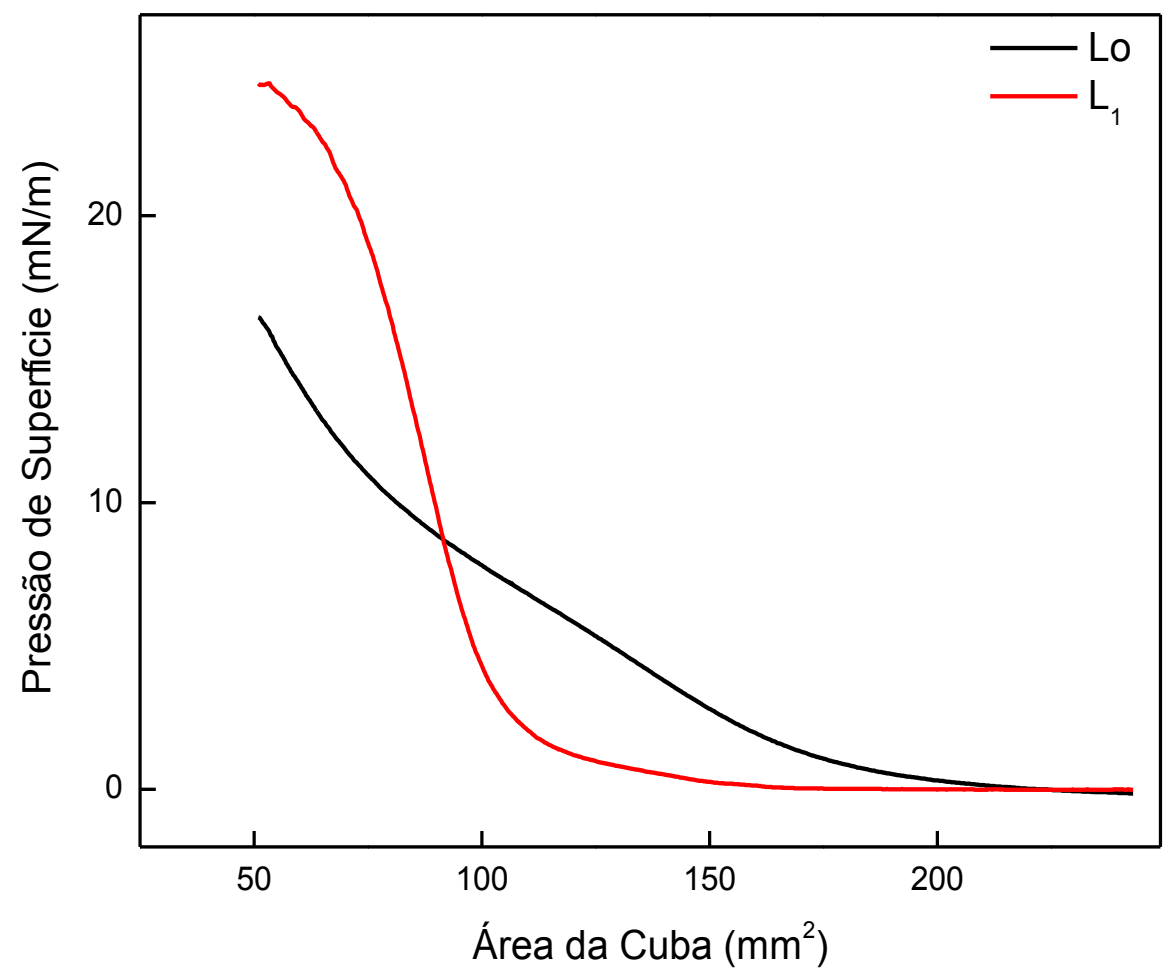

Figura 15: Isotermas de Gibbs dos peptídeos Lo e $\mathrm{L}_{1}$ em subfase aquosa, a $25^{\circ} \mathrm{C} \pm 1^{\circ} \mathrm{C}$.

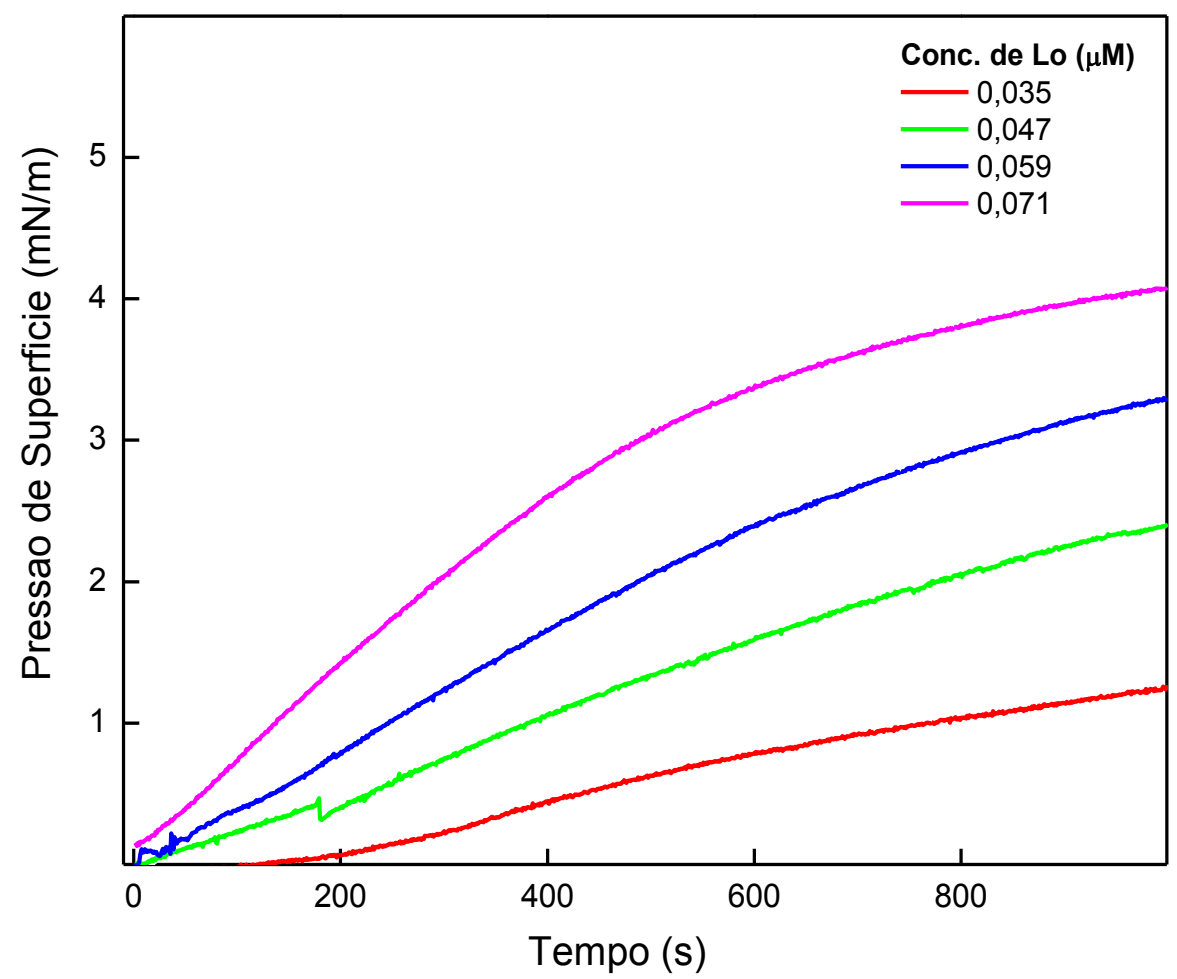

Figura 16: Cinéticas de adsorção de diferentes concentrações do peptídeo Lo em monocamada expandida de DPPC, com subfase aquosa, a $25^{\circ} \mathrm{C} \pm 1^{\circ} \mathrm{C}$. 


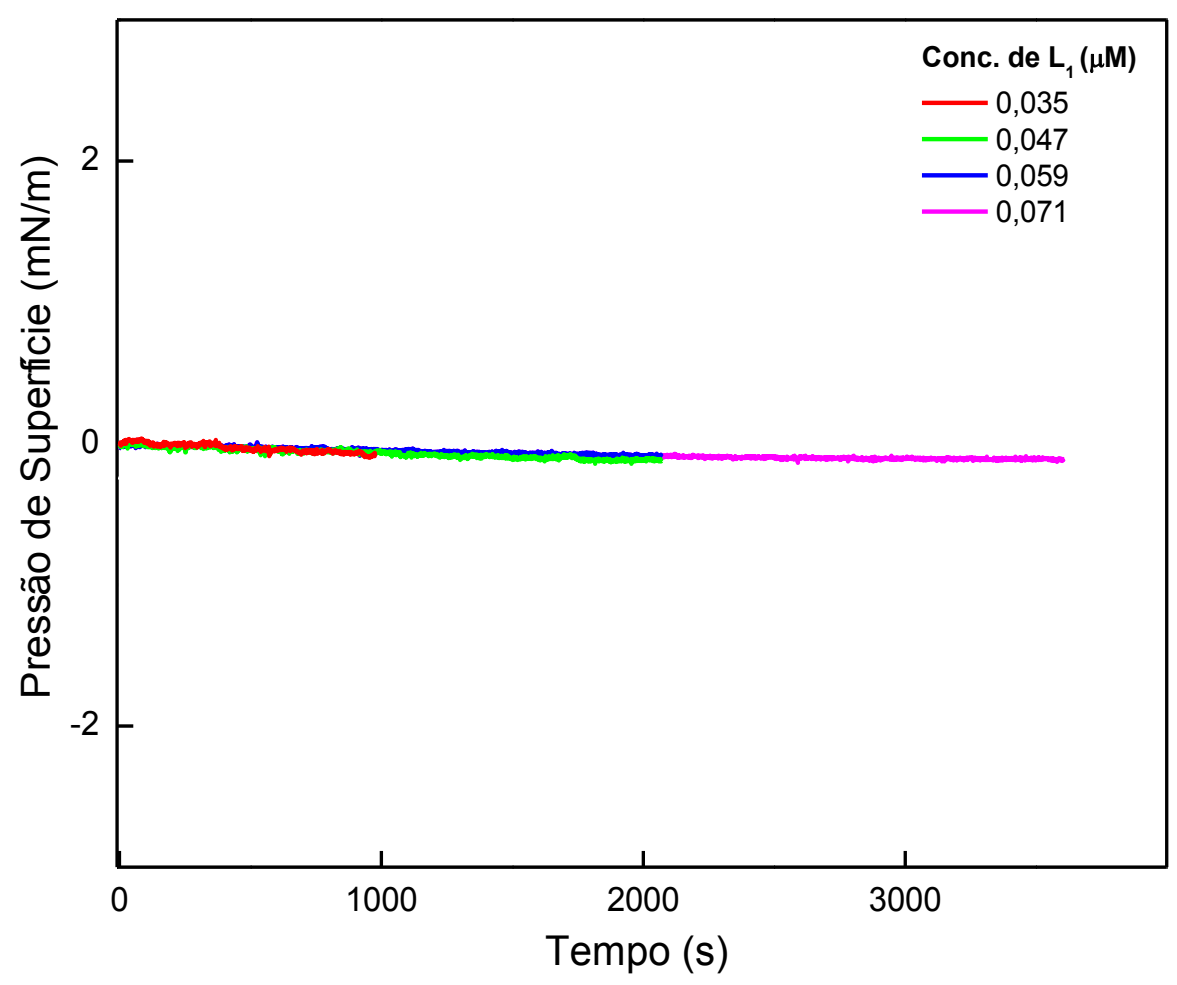

Figura 17: Cinéticas de adsorção de diferentes concentrações do peptídeo $\mathrm{L}_{1}$ em monocamada expandida de DPPC, com subfase aquosa, a $25^{\circ} \mathrm{C} \pm 1^{\circ} \mathrm{C}$.

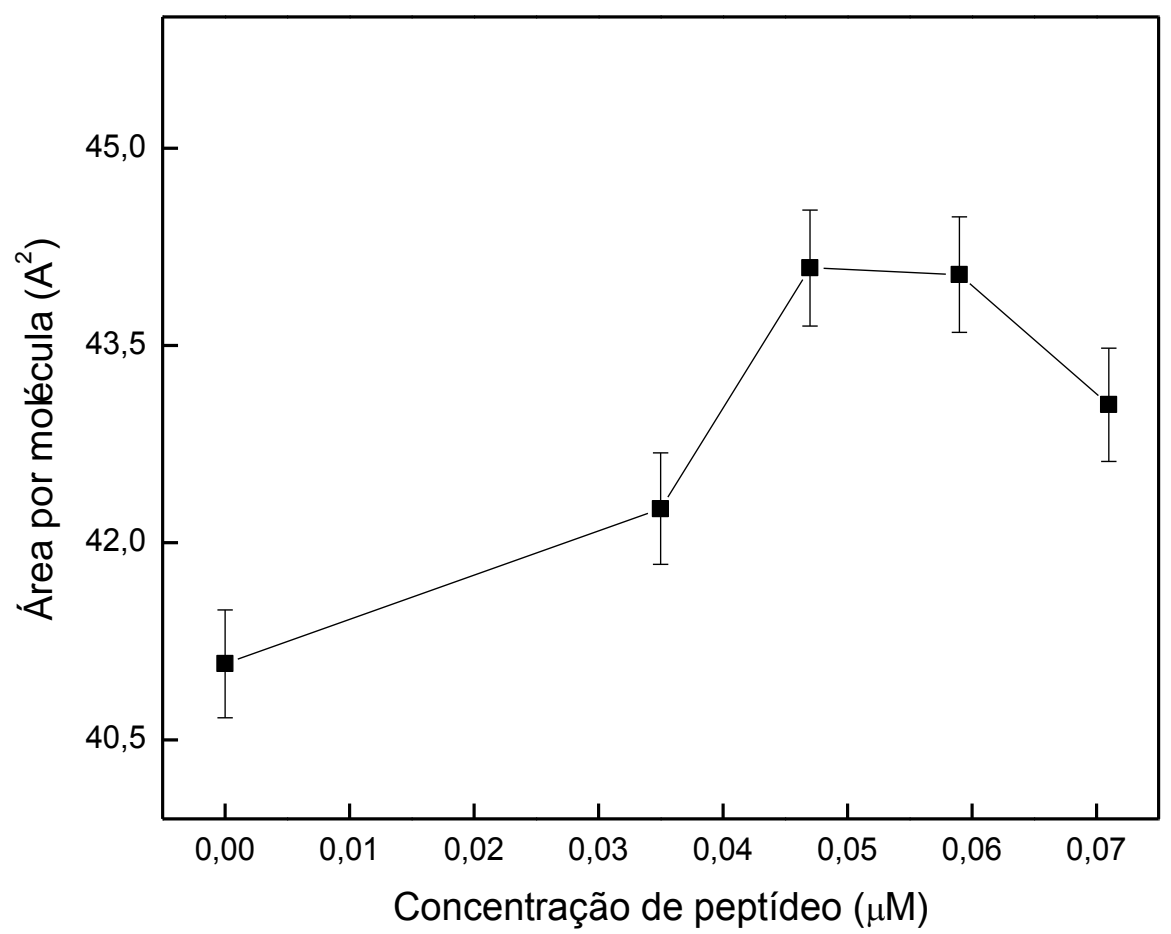

Figura 18: Variação da área por molécula à uma pressão constante de $25 \mathrm{mN} / \mathrm{m}$ em função da concentração de peptídeo Lo, em uma monocamada de DPPC. 


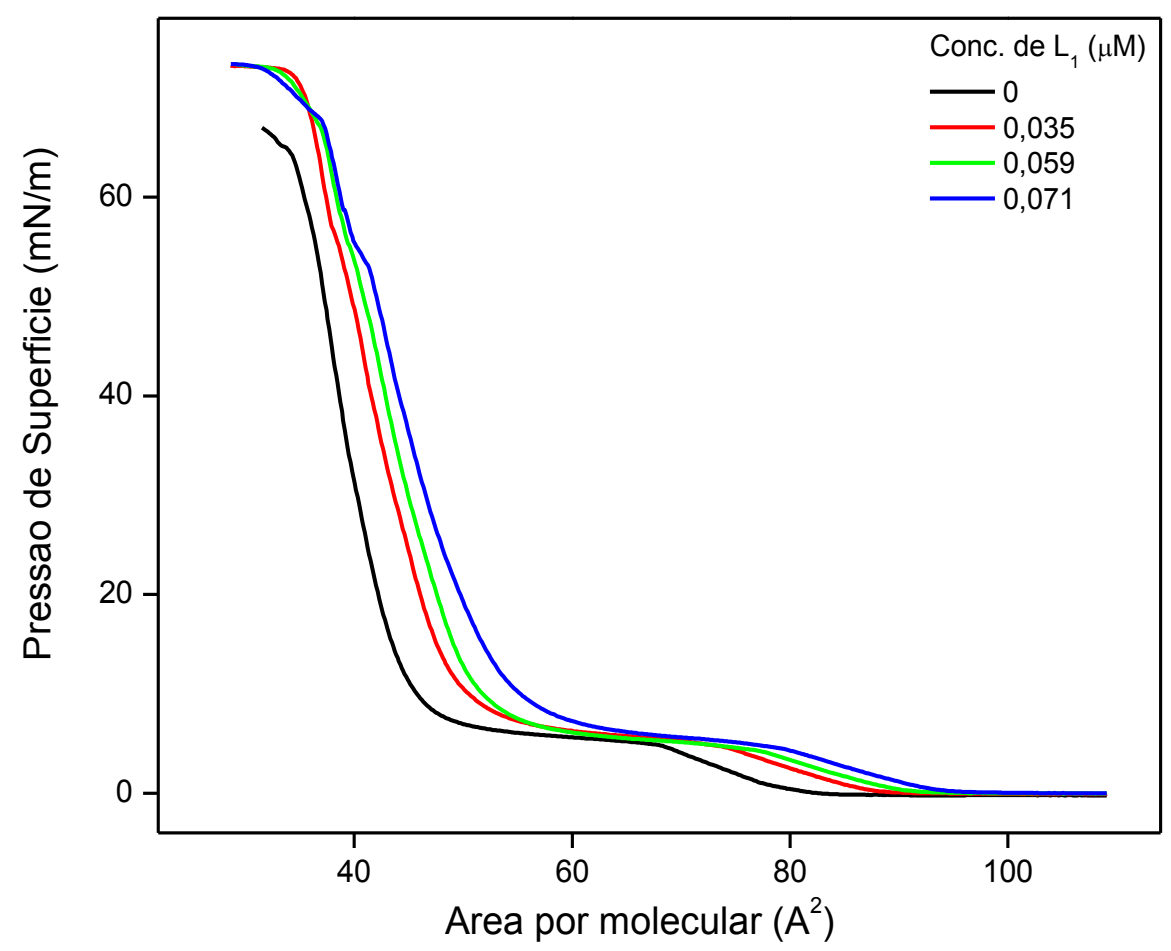

Figura 19: Isotermas $\pi$-A de monocamadas de DPPC, na ausência e presença de diferentes concentrações do peptídeo $\mathrm{L}_{1}$, preparadas sobre a superfície da subfase aquosa, a $25^{\circ} \mathrm{C} \pm$ $1^{\circ} \mathrm{C}$.

A isoterma de DPPC:Chol (9:1) (Figuras 20 e 21), comparado ao DPPC puro, sofreu redução da área mínima por molecular (46 A²/molec.) (Tabela 7) devido à incorporação do colesterol, que causou a condensação da monocamada (RÓG e PASENKIEWICZGIERULA, 2001; OHE et al., 2007).

Nessas condições, ao avaliar através da cinética de adsorção a interação do peptídeo Lo (Figura 22) com essa monocamada não foi observada expressiva variação na pressão superficial. Na presença do $\mathrm{L}_{1}$ (Figura 23) também não houve variação na pressão superficial até a concentração de $0,047 \mu \mathrm{M}$; no entanto, em $0,059 \mu \mathrm{M}$ houve um lento aumento da pressão superficial conforme o tempo, chegando próximo à $1,5 \mathrm{mN} / \mathrm{m}$ em $5,5 \mathrm{~h}$; e em 0,071 $\mu \mathrm{M}$ essa adsorção chegou a $2 \mathrm{mN} / \mathrm{m}$ em 2,5 h.

Esses resultados sugerem menor adsorção dos peptídeos no filme lipídico, provavelmente, devido à presença do colesterol, que provoca aumento na ordem dos 
carbonos e da densidade superficial da membrana (RÓG e PASENKIEWICZ-GIERULA, 2001; OHE et al., 2007), tornando a monocamada menos fluida.

Após a adsorção dos peptídeos na monocamada ter atingido o equilíbrio, foram obtidas as isotermas $\pi$-A do DPPC:Chol (9:1). Na presença de ambos os peptídeos, Lo e $\mathrm{L}_{1}$ (Figuras 20 e 21), houve expansão da monocamada de DPPC:Chol (9:1). A adsorção e/ou inserção dos peptídeos na interface também foi identificada através da variação nos valores de área mínima, Lo apresentou $50 \mathrm{~A}^{2} /$ moléc. e $\mathrm{L}_{1} 52 \mathrm{~A}^{2} /$ moléc., demonstrando que $\mathrm{L}_{1}$ tem maior afinidade com esta monocamada do que o Lo, porém essa diferença não é grande. Os dados estão sumarizados na Tabela 7.

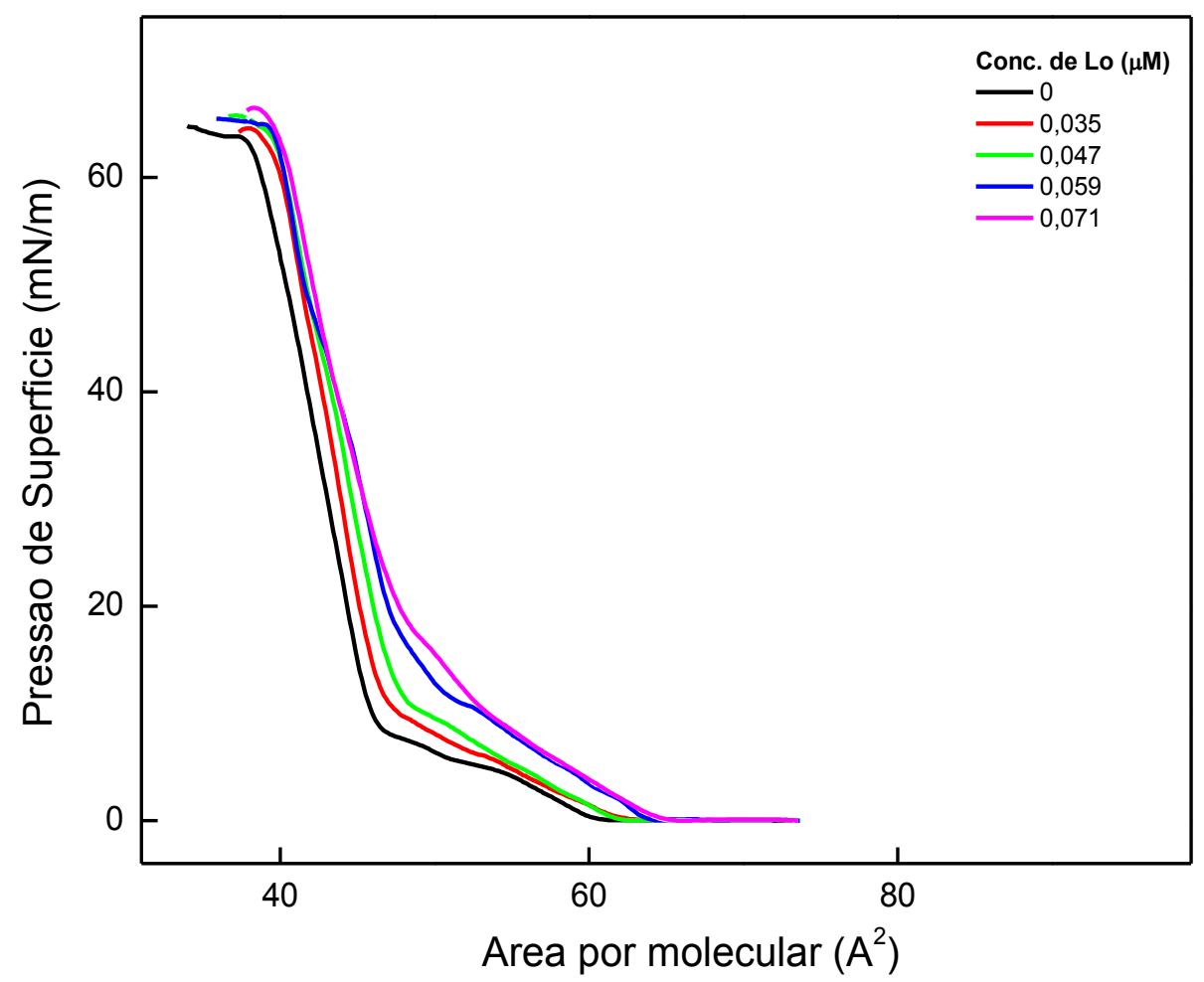

Figura 20: Isotermas $\pi$-A de monocamadas de DPPC:Chol (9:1), na ausência e presença de diferentes concentrações do peptídeo Lo, preparadas sobre a superfície da subfase aquosa, a $25^{\circ} \mathrm{C} \pm 1^{\circ} \mathrm{C}$. 


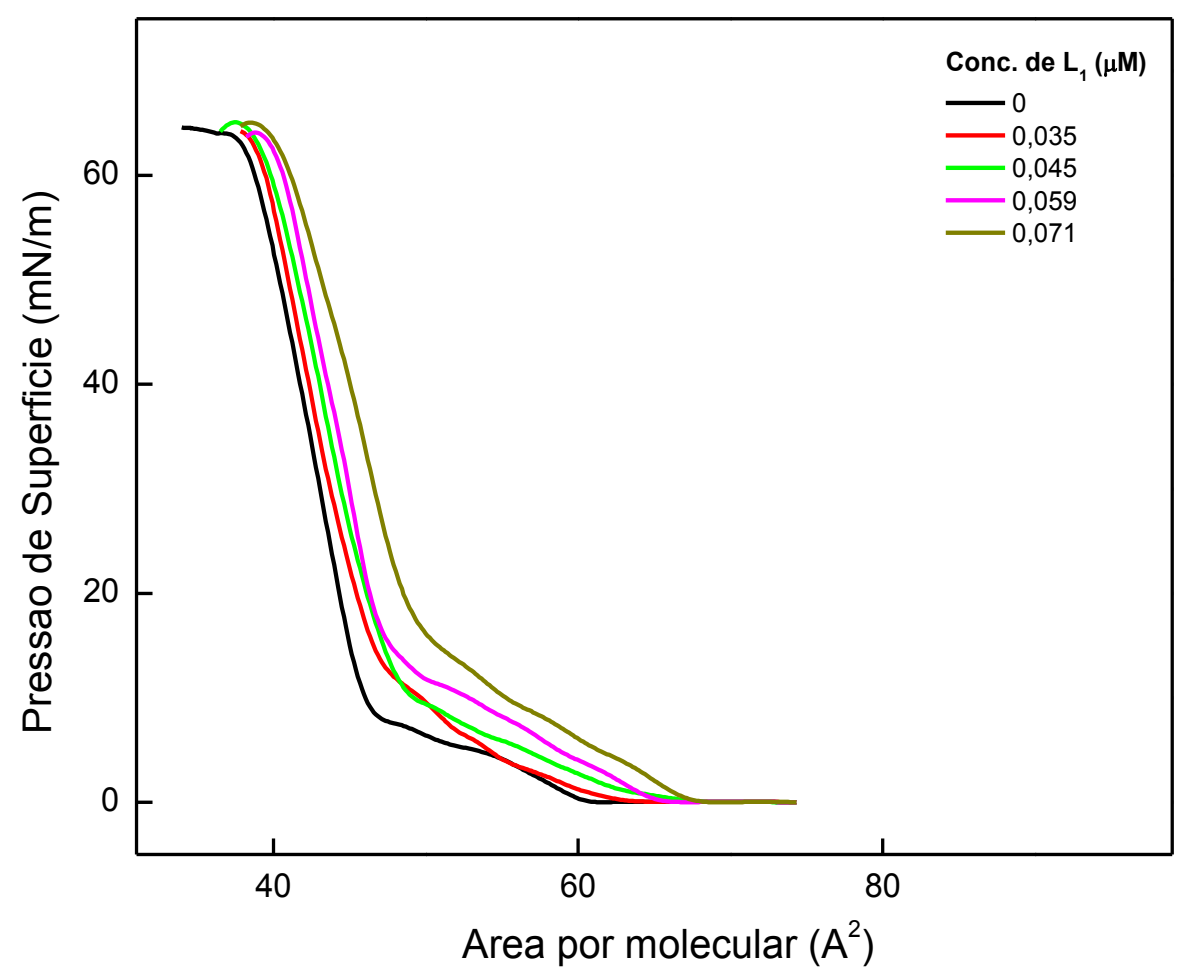

Figura 21: Isotermas $\pi$-A de monocamadas de DPPC:Chol (9:1), na ausência e presença de diferentes concentrações do peptídeo $\mathrm{L}_{1}$, preparadas sobre a superfície da subfase aquosa, a $25^{\circ} \mathrm{C} \pm 1^{\circ} \mathrm{C}$.

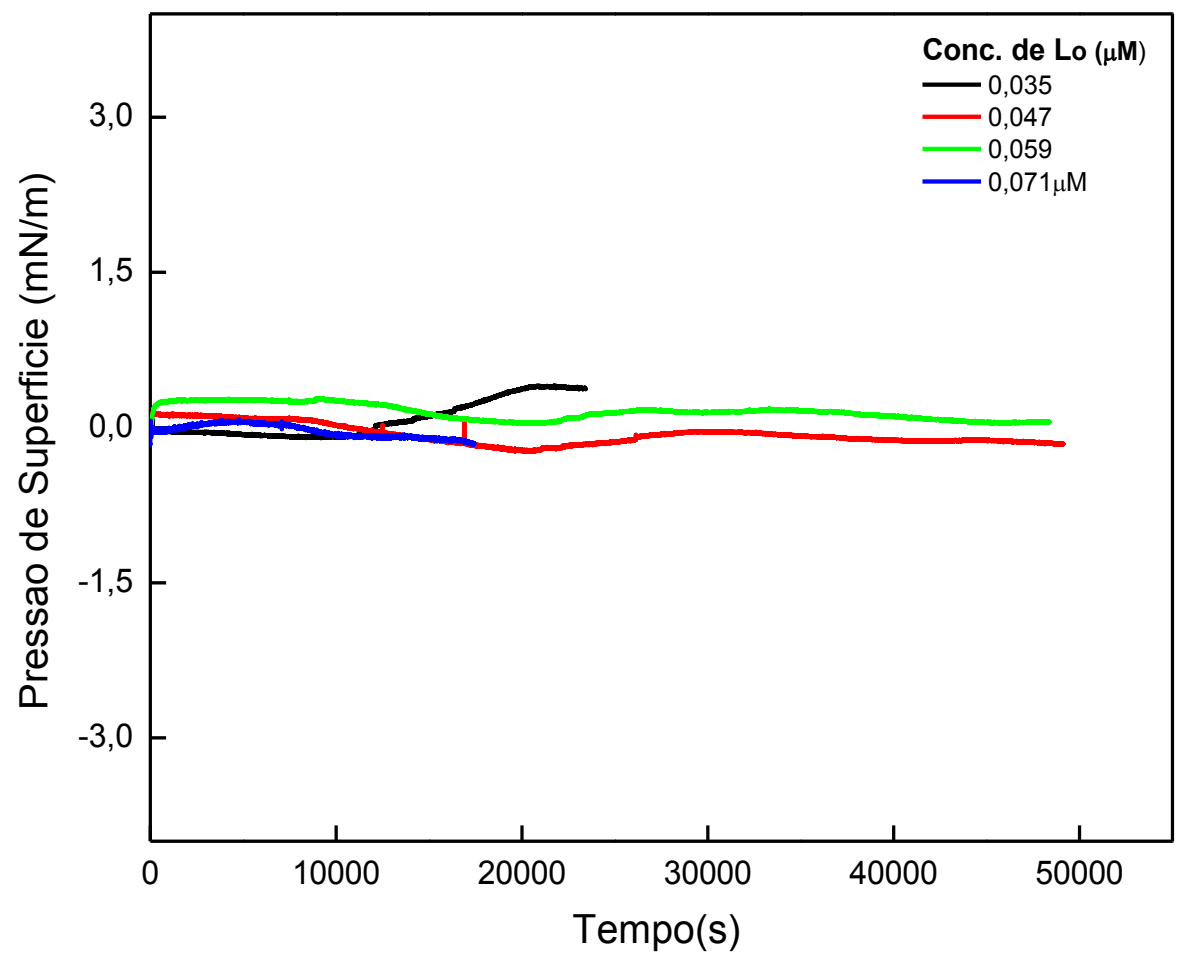

Figura 22: Cinéticas de adsorção de diferentes concentrações do peptídeo Lo em monocamada de DPPC:Chol (9:1), com subfase aquosa, a $25^{\circ} \mathrm{C} \pm 1^{\circ} \mathrm{C}$. 


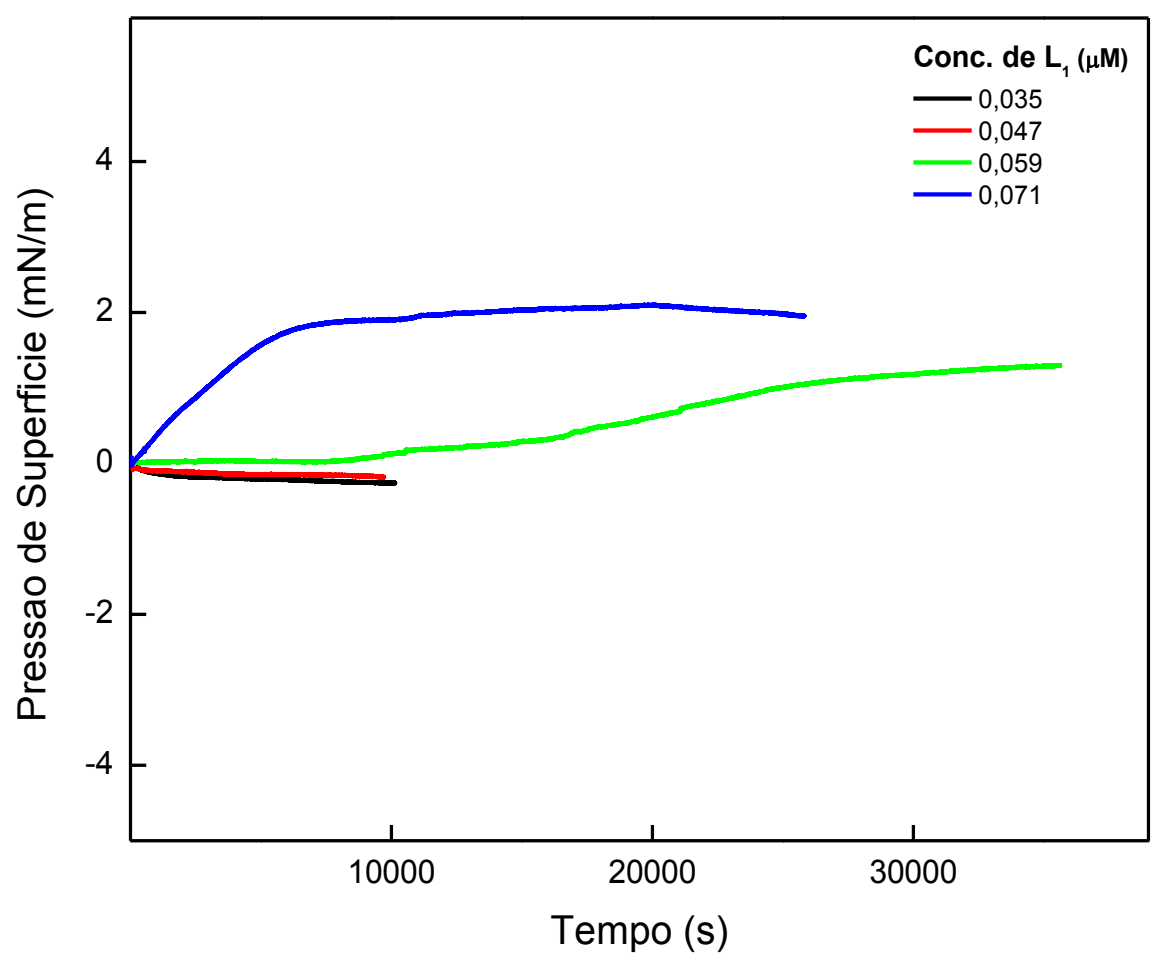

Figura 23: Cinéticas de adsorção de diferentes concentrações do peptídeo $\mathrm{L}_{1}$ em monocamada de DPPC:Chol (9:1), com subfase aquosa, a $25^{\circ} \mathrm{C} \pm 1^{\circ} \mathrm{C}$.

A isoterma de DPPS puro é altamente condensada, característica de lipídios com fortes interações de van der Waals, devido à pequena cabeça polar lipídica. A monocamada é estabilizada por interações eletrostáticas e ligações de hidrogênio com a subfase (STEINKOPT et al., 2012). Conforme já mencionado, o DPPS tem o mesmo número de átomos de carbono na cadeia hidrofóbica que o DPPC, no entanto, difere devido a presença do grupo fosfatidilserina, que ocupa menor área por molécula que o grupo fosfatidilcolina do DPPC (STEINKOPT et al., 2012). Por isso, a isoterma de DPPC:DPPS (8:2) sofre redução na área mínima por molécula ( $45 \mathrm{~A}^{2} /$ molec.), ou seja, a monocamada é levemente mais compactada (Figuras 24 e 25; Tabela 7). Essa isoterma de DPPC:DPPS (8:2) puro tem formato semelhante aos encontrados na literatura (ROSS at al., 2001).

Assim, através da cinética de adsorção foi avaliada a interação de ambos os peptídeos com o filme lipídico composto por DPPC:DPPS (8:2). Na presença de Lo (Figura 26), somente acima de $0,059 \mu \mathrm{M}$ houve aumento da pressão superficial $(\pi)$. Essa variação da 
pressão superficial foi maior conforme o aumento da concentração de peptídeo, chegando a $2 \mathrm{mN} / \mathrm{m}$, com redução no tempo de adsorção, chegando a 42 min na presença de $0,071 \mu \mathrm{M}$. Já na presença do peptídeo $\mathrm{L}_{1}$ (Figura 27) esse aumento da pressão superficial ocorreu à partir da concentração $0,047 \mu \mathrm{M}$. Além disso, foi observada uma redução no tempo de adsorção conforme o aumento da concentração de peptídeo na subfase, chegando a adsorver logo após sua inserção na subfase, na concentração de $0,071 \mu \mathrm{M}$.

A adsorção e incorporação do peptídeo linear, $\mathrm{L}_{1}$, na monocamada de DPPC:DPPS (8:2) foi mais rápida devido, provavelmente, à interação eletrostática entre a monocamada lipídica aniônica e as cargas terminais do peptídeo linear. Já o peptídeo cíclico, por ser hidrofóbico, apresentou adsorção mais lenta devido à presença do lipídio aniônico DPPS.

Após estabilizada a adsorção dos peptídeos no filme lipídico, foram obtidas as isotermas $\pi$-A do DPPC:DPPS (8:2). Na presença de Lo (Figuras 24) houve expansão da monocamada em todas as fases, sendo um pouco maior na região entre 18 e $30 \mathrm{mN} / \mathrm{m}$. Entretanto, essa expansão foi menor que na presença do $L_{1}$. De acordo com a Tabela 7, o peptídeo Lo (49 A²/molec.) apresentou menor variação da área mínima por molécula, comparado ao $\mathrm{L}_{1}\left(60 \mathrm{~A}^{2} /\right.$ molec.). Isso demonstra que a incorporação do $\mathrm{L}_{1}$ resultou em maior deslocamento da isoterma, provocado pela maior quantidade de moléculas na interface ou pela configuração destas moléculas na interface. $\mathrm{O}$ aumento da ordem nas cadeias hidrofóbica, densidade da membrana (condensação) e, principalmente, o caráter aniônico aparenta dificultar a interação do peptídeo Lo (Tabela 7). 


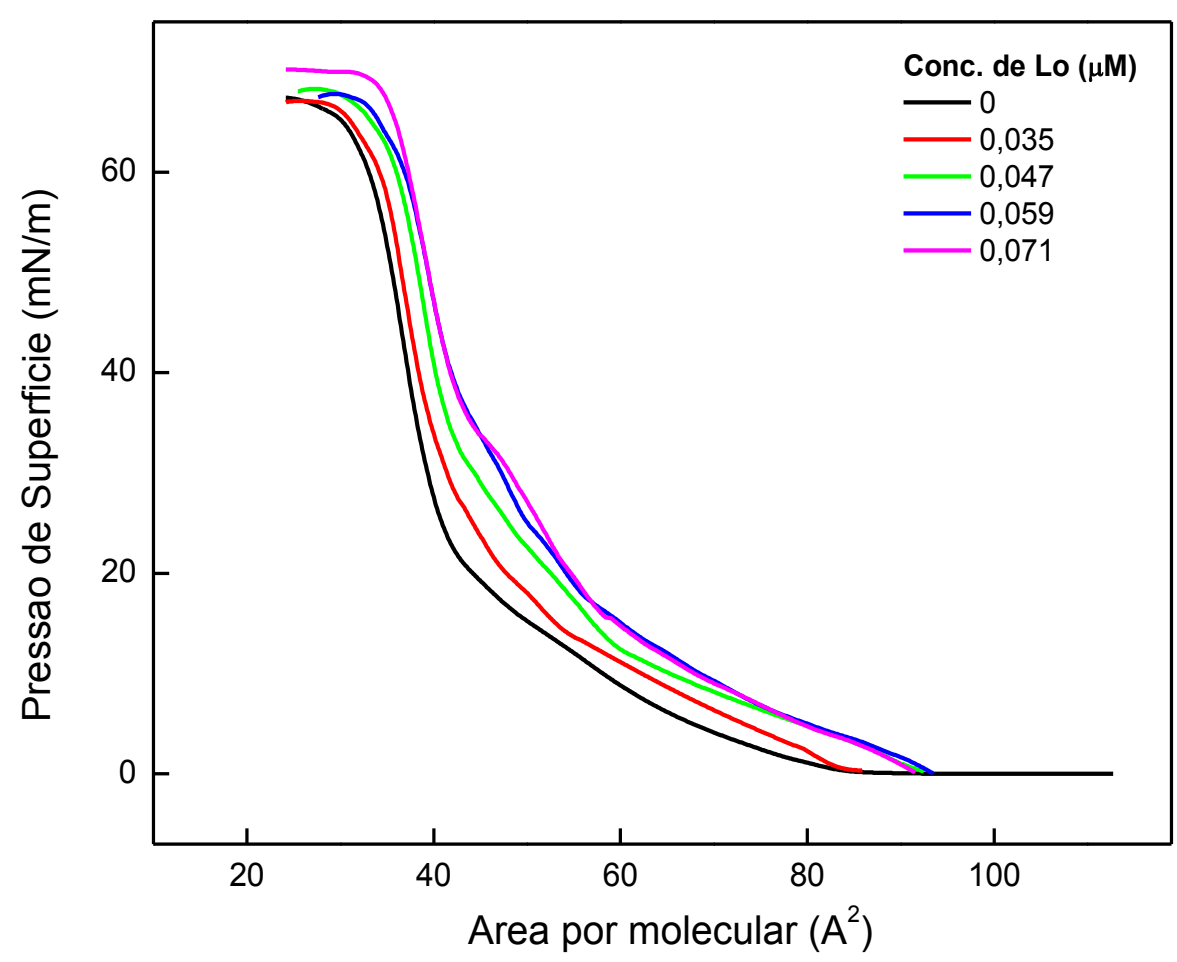

Figura 24: Isotermas $\pi$-A de monocamadas de DPPC:DPPS (8:2), na ausência e presença de diferentes concentrações do peptídeo Lo, preparadas sobre a superfície da subfase aquosa, a $25^{\circ} \mathrm{C} \pm 1^{\circ} \mathrm{C}$.

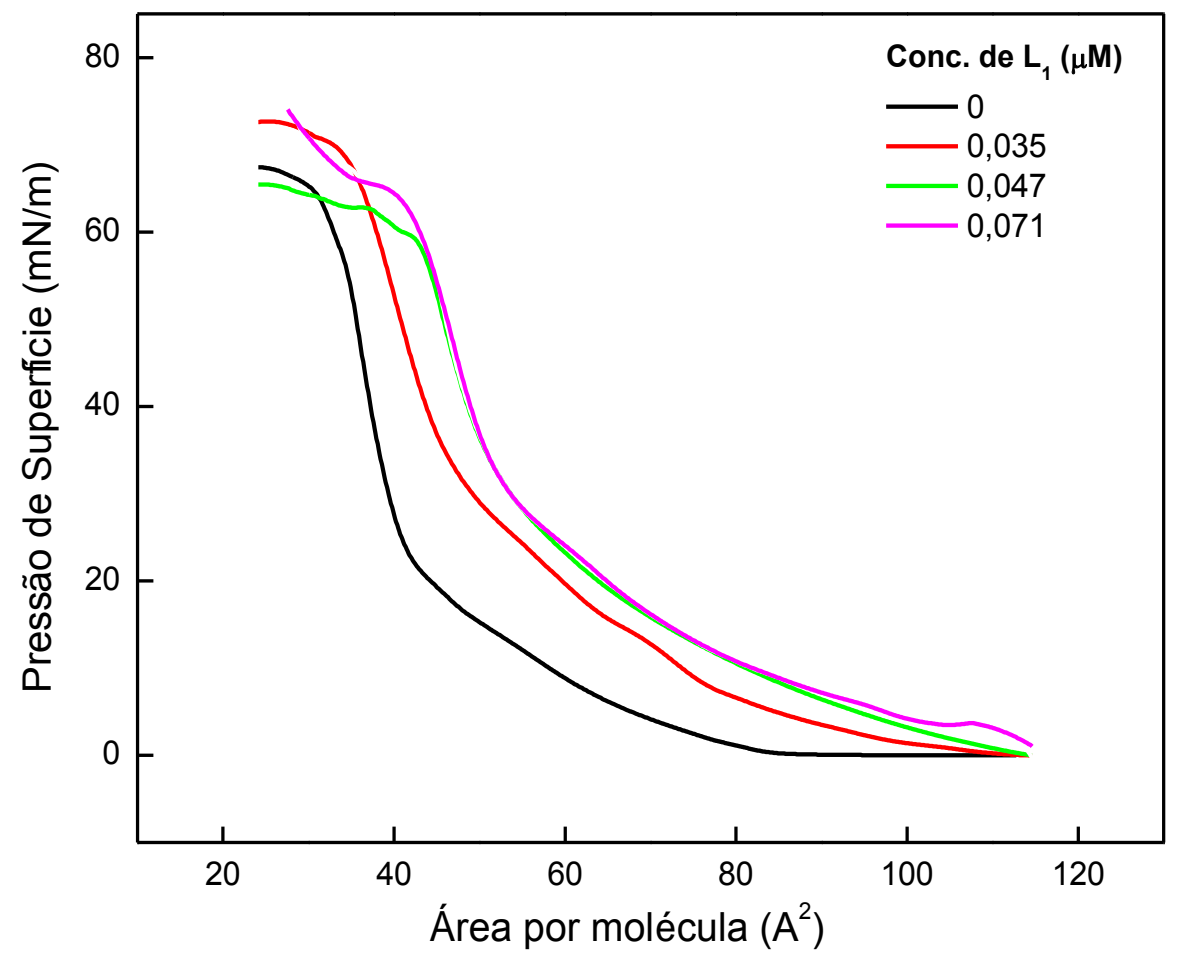

Figura 25: Isotermas $\pi$-A de monocamadas de DPPC:DPPS (8:2), na ausência e presença de diferentes concentrações do peptídeo $\mathrm{L}_{1}$, preparadas sobre a superfície da subfase aquosa, a $25^{\circ} \mathrm{C} \pm 1^{\circ} \mathrm{C}$. 


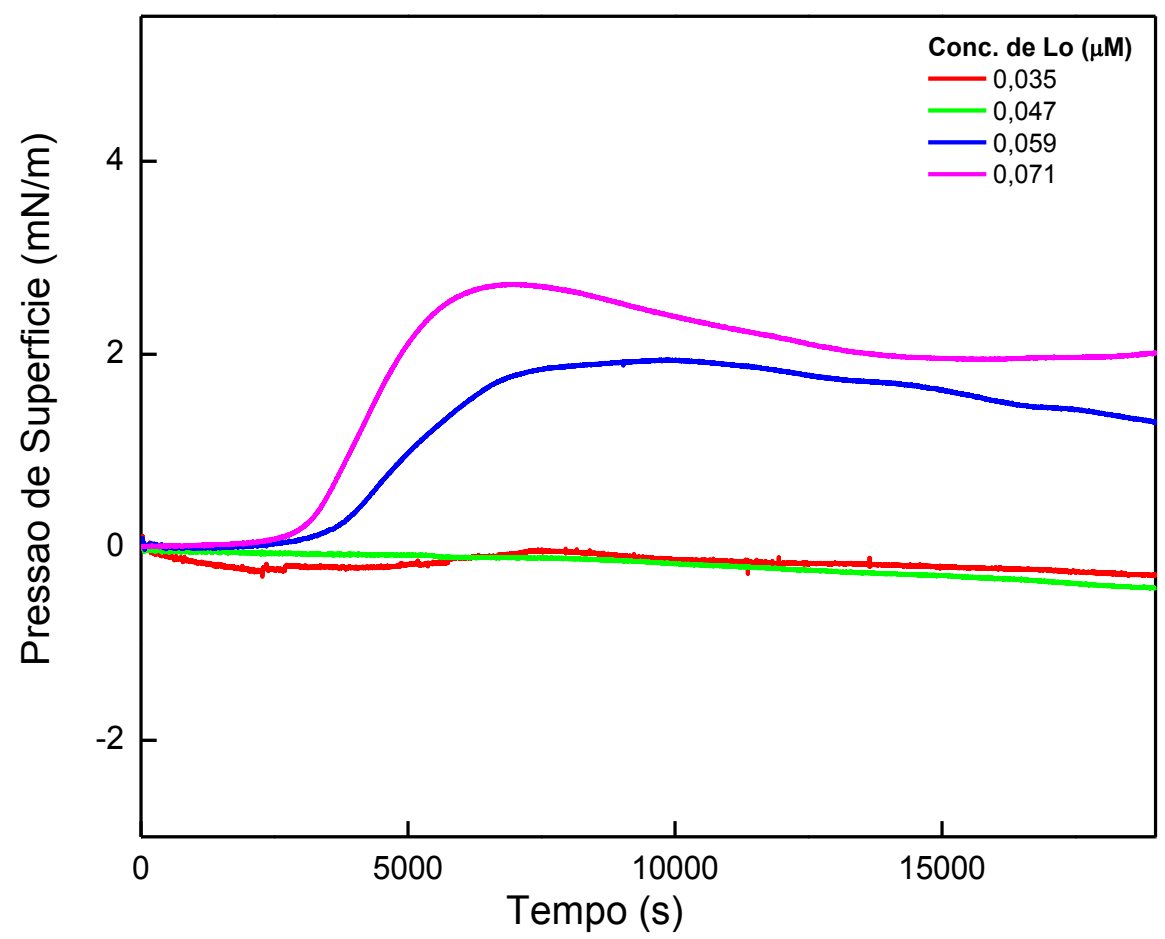

Figura 26: Cinéticas de adsorção de diferentes concentrações do peptídeo Lo em monocamada de DPPC:DPPS (8:2), com subfase aquosa, a $25^{\circ} \mathrm{C} \pm 1^{\circ} \mathrm{C}$.

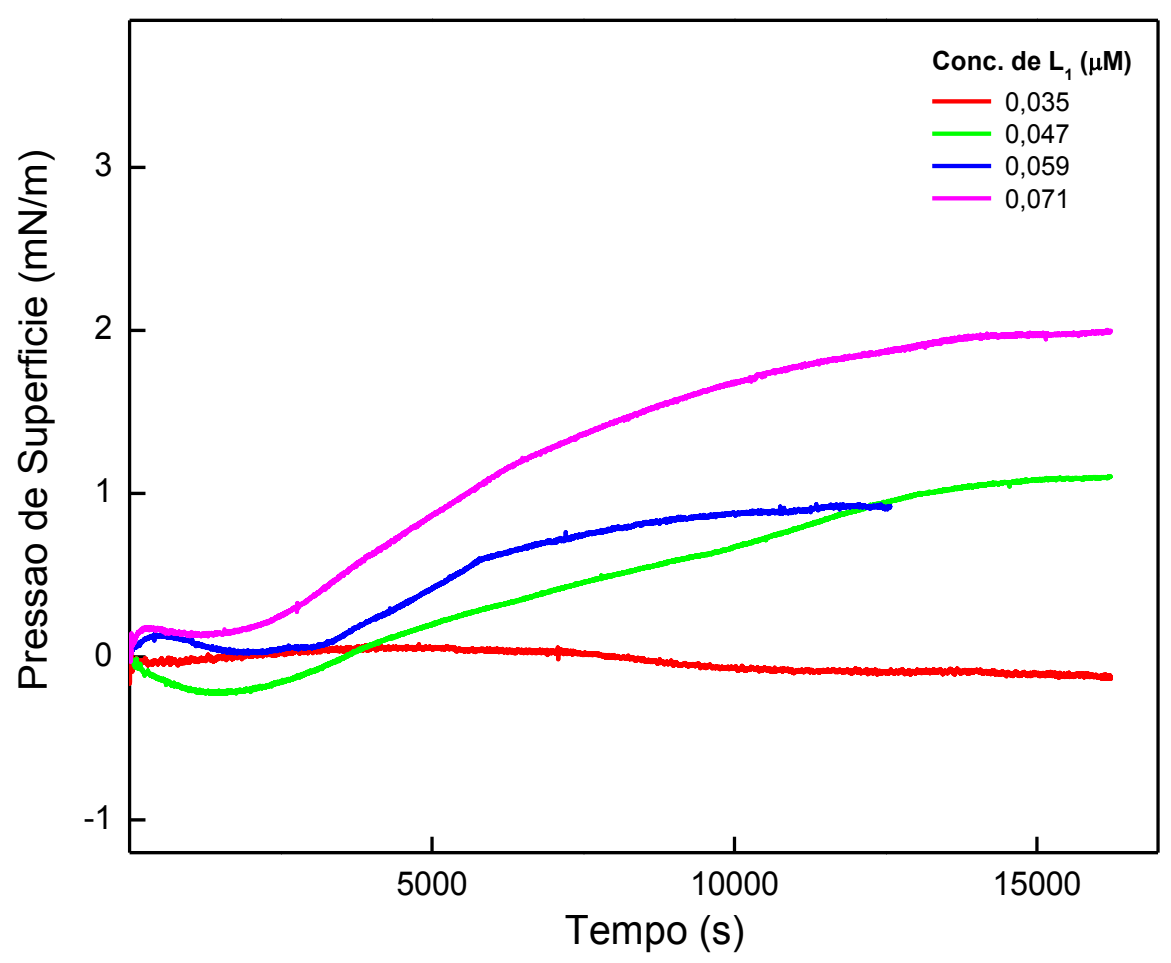

Figura 27: Cinéticas de adsorção de diferentes concentrações do peptídeo $\mathrm{L}_{1}$ em monocamada de DPPC:DPPS (8:2), com subfase aquosa, a $25^{\circ} \mathrm{C} \pm 1^{\circ} \mathrm{C}$. 
TABELA 7: Relação das áreas mínimas por molécula dos diferentes meios na presença e ausência de peptídeo.

\begin{tabular}{cccc}
\hline & \multicolumn{3}{c}{ Área mínima por molécula $\left(\mathrm{A}^{2}\right)$} \\
\cline { 2 - 4 } Peptídeo & DPPC & DPPC:Chol (9:1) & DPPC:DPPS (8:2) \\
$(0,071 \mu \mathrm{M})$ & & 46 & 45 \\
\hline 0 & 47 & 50 & 49 \\
Lo & 51 & 52 & 60 \\
$\mathrm{~L}_{1}$ & 54 & & \\
\hline
\end{tabular}

Portanto, os resultados sugerem que o peptídeo linear, $\mathrm{L}_{1}$, tem maior afinidade por monocamadas de DPPC:DPPS e DPPC:Chol, provavelmente por apresentar cargas terminais, propiciando interação eletrostática com o DPPS e a hidroxila do colesterol, respectivamente. Já o peptídeo cíclico, Lo, por não apresentar cargas, é mais hidrofóbico que o $\mathrm{L}_{1}$, favorecendo sua maior inserção em monocamada zwitteriônica, DPPC.

Alguns fatores dirigem esse processo de adsorção: conformação e hidrofobicidade. A diferença estrutural dos peptídeos Lo e $\mathrm{L}_{1}$, cíclica e linear, respectivamente, confere diferentes hidrofobicidades, e consequentemente também contribui para a conformação (NAKANISHI et al., 2001).

\subsubsection{Micelas}

Micelas são agregados formados por moléculas anfifílicas que se associam espontaneamente em solução aquosa, conforme sua concentração micelas crítica (CMC). Abaixo da CMC o detergente está em sua maioria na forma de monômeros, porém acima da CMC associam-se em forma de micelas, com diâmetro entre 2-6 nm. A CMC depende do tamanho da cadeia do hidrocarboneto, temperatura, força iônica (MANIASSO et al., 2001). Esse sistema é simples, parecido com lipossomos, porém difere por ter maior curvatura e hidratação. 


\subsubsection{Espectrometria de Fluorescência em micelas}

Afim de desvendar o mecanismo de interação dos peptídeos Lo e $\mathrm{L}_{1}$ com micelas de SDS e de LPC, foi realizado o estudo de fluorescência dos aminoácidos triptofano (Trp), presentes na estrutura de ambos os peptídeos ( $2^{\circ}$ e $5^{\circ}$ resíduo) (LADOKHIN et al., 2000; ZHANG et al., 2013).

As mudanças conformacionais dos peptídeos podem provocar maior ou menor aproximação das cadeias laterais e/ou grupos ionizáveis em relação ao triptofano (VAN DER WEL et al., 2007), agindo como supressores, afetando assim a intensidade de fluorescência. A migração desse mesmo aminoácido de um ambiente para outro, variando a polaridade, pode causar alteração no comprimento de onda máxima emissão ( $\lambda$ max) (PARK et al., 1995; LADOKHIN et al., 2000; BARBOSA et al., 2011).

Em um estudo anterior, realizado por Barbosa et al. (2011), foi avaliada a interação de ambos os peptídeos com lipossomos constituídos por DPPC. Foi observado um decaimento na intensidade de fluorescência conforme o aumento da concentração de peptídeo $\left(\right.$ Lo e $\left.L_{1}\right)$. Esta redução na intensidade de fluorescência é atribuída às mudanças conformacionais sofridas pelo peptídeo, ou seja, maior aproximação das cadeias laterais de alguns aminoácidos com relação ao grupo indol do triptofano, agindo portando como supressores e afetando este parâmetro (CHEN e BARKLEY, 1998; LADOKHIN et al., 2000; ZHANG et al., 2013). Além disso, observou-se blue-shift do $\lambda \operatorname{max,~ou~seja,~}$ deslocamento do $\lambda \max$ de emissão de fluorescência dos peptídeos para menores valores de comprimento de onda.

Analogamente, nesse estudo realizado com micelas foi observado (Figuras 28 e 29) um blue-shift dos peptídeos Lo e $\mathrm{L}_{1}$, na presença de SDS e LPC. Assim, a interação dos peptídeos com SDS (Figura 28) é caracterizada por um significante deslocamento do $\lambda$ max da solução aquosa $(\lambda \max =350 \mathrm{~nm})$ para menor comprimento de onda (azul), quando na 
presença de SDS. Isso ocorreu ainda em uma baixa concentração de SDS (perto da CMC, 8 mM) (XU et al., 2013), variando 7 e $8 \mathrm{~nm}$ (Tabela 8) para Lo e $\mathrm{L}_{1}$, respectivamente. Após essa concentração, o valor de $\lambda$ max de emissão permaneceu constante conforme o aumento da concentração de SDS. O blue-shift do $\lambda \max$ ocorreu devido à mudança de ambiente, passando para um meio mais apolar, portanto os resultados sugerem que pelo menos um dos resíduos de triptofano de ambos os peptídeos estão inseridos em um ambiente mais apolar (CHEN e BARKLEY, 1998; CHRISTIAENS et al., 2002; GOPAL et al., 2013; LAKOWICZ, 2006). Esses resultados demonstram também que os resíduos de triptofano do $\mathrm{L}_{1}$ parecem estar ligeiramente mais inseridos na região hidrofóbica das micelas de SDS que os resíduos de triptofano do Lo, pois apresentaram maior blue-shift. Além disso, concomitantemente com o blue-shift do $\lambda \max$ de emissão, houve uma diminuição na intensidade de fluorescência (dados não apresentados), o que indica alteração na conformação dos peptídeos (CHEN e BARKLEY, 1998; JANA et al., 2006) quando na presença de micelas SDS de micelas.

Referente à interação LPC-peptídeo, também foi observado um blue-shift do $\lambda \max$ de emissão de fluorescência de 5 e $2 \mathrm{~nm}$, respectivamente, para os peptídeos Lo e $\mathrm{L}_{1}$ (Tabela 8), até a concentração de $5 \mu \mathrm{M}$ de LPC, sem alterações acima dessa concentração (Figura 29). Convém destacar que a CMC do LPC varia entre 4-8 $\mu \mathrm{M}$. Tais blue-shifts do $\lambda$ max indicam que os resíduos de triptofano do peptídeo Lo estão mais inseridos no meio apolar que os do $\mathrm{L}_{1}$. De modo semelhante aos resultados de SDS, também houve redução na intensidade de fluorescência máxima do Lo e $\mathrm{L}_{1}$ conforme o aumento da concentração de LPC, revelando que, provavelmente, a interação com micela de LPC promove alterações conformacionais nos peptídeos. Outros autores, com diferentes peptídeos, descreveram resultados semelhantes (PERTINHEZ et al., 1997; VIEIRA et al., 2009; CRUSCA et al., 2011). 


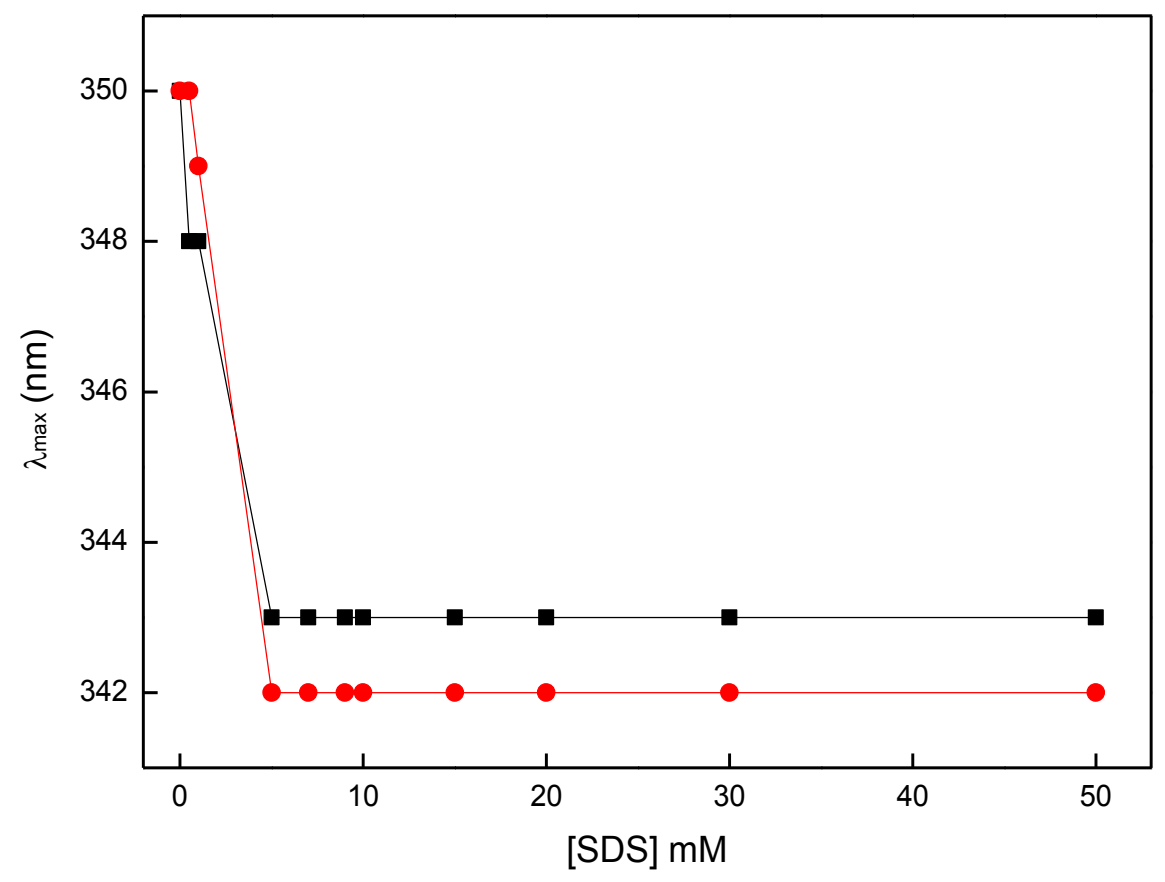

Figura 28: Variação do $\lambda \max$ de emissão da fluorescência dos triptofanos presentes nos dois peptídeos, Lo $(\bullet)$ e $\mathrm{L}_{1}(\bullet)$, estudados na presença de micelas de SDS (0 a $\left.50 \mathrm{mM}\right)$, conforme descrito em Materiais e Métodos.

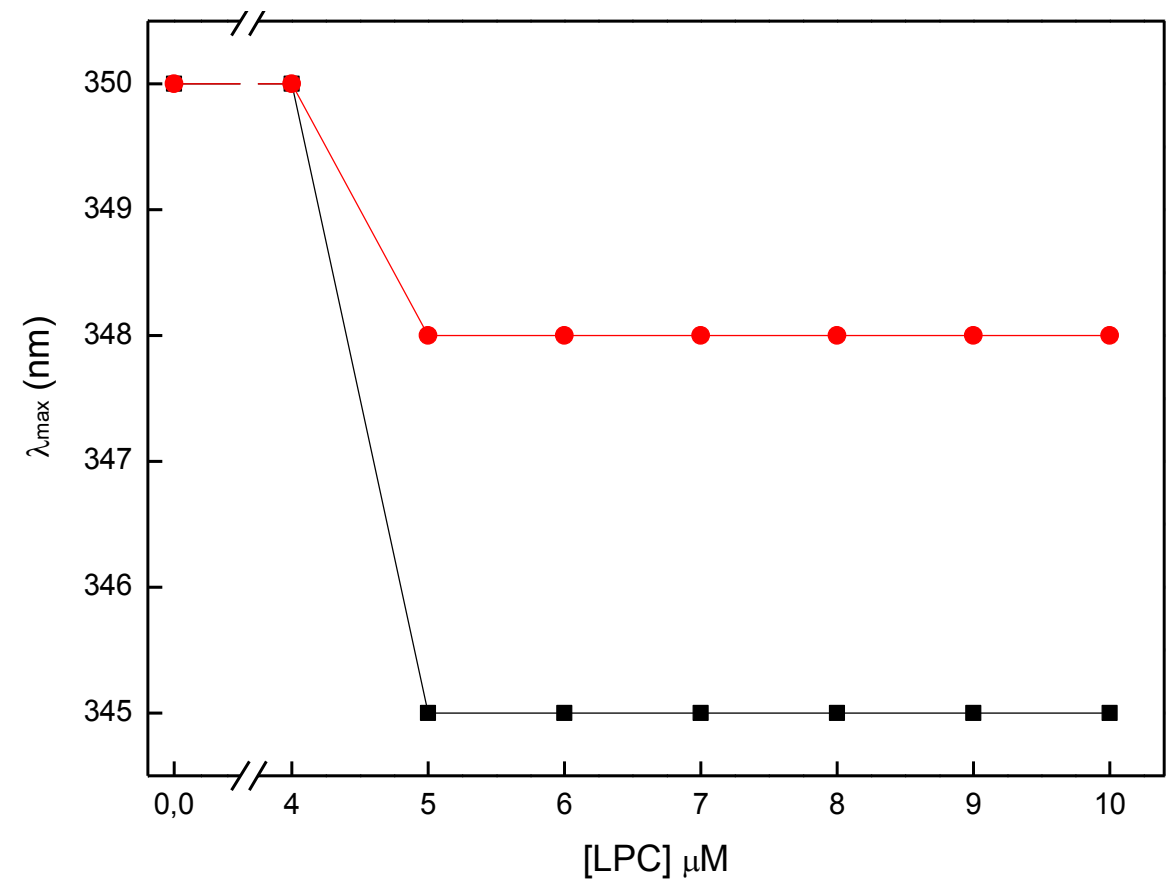

Figura 29: Variação do $\lambda \max$ de emissão da fluorescência dos triptofanos presentes nos dois peptídeos, Lo $(\boldsymbol{\bullet})$ e $\mathrm{L}_{1}(\bullet)$, estudados na presença de micelas de LPC (0 a $\left.10 \mu \mathrm{M}\right)$, conforme descrito em Materiais e Métodos. 


\subsubsection{Supressão da Fluorescência em micelas}

A supressão da fluorescência é um processo no qual observamos a diminuição da intensidade de fluorescência, causada por um agente químico denominado supressor. Neste trabalho usamos a acrilamida, um supressor colisional, que ao colidir com o fluoróforo triptofano presente nos peptídeos Lo e $\mathrm{L}_{1}$, suprime a fluorescência, indicando a profundidade da inserção do fluoróforo triptofano na micela. Como este composto é hidrossolúvel, um maior grau de inserção do fluoróforo na interface lipídica da micela (região apolar da dupla-camada) é indicado por maior fluorescência, pois ele só consegue agir sobre a região que está exposta, não interagindo com a membrana (EFTINK e GHIRON, 1976; LAKOWICZ, 2006).

Assim, a supressão foi medida a partir da obtenção da constante de Stern-Volmer (Ksv) para cada peptídeo, Lo e $\mathrm{L}_{1}$, tanto num microambiente lipídico, quanto no microambiente aquoso (EFTINK e GHIRON, 1976). O Ksv é um parâmetro obtido a partir da tangente da curva de supressão, dada pelo valor inicial da intensidade de fluorescência em relação aos valores pontuais obtidos $(\mathrm{Fo} / \mathrm{F})$ na presença de concentrações crescentes de acrilamida (DEVA e BEHERE, 1999).

Os valores de Ksv em meio aquoso (Figura 30 e 31; Tabela 8) revelaram que os resíduos de triptofano do Lo $\left(12,1 \mathrm{M}^{-1}\right)$ estão mais expostos que os resíduos de triptofano do $\mathrm{L}_{1}\left(8,8 \mathrm{M}^{-1}\right)$. A adição dos detergentes causou diminuição dos valores de $\mathrm{Ksv}$, revelando que Lo e $\mathrm{L}_{1}$ tornaram-se menos expostos ao supressor. Além disso, o gráfico obtido nessa faixa de concentração de acrilamida usada no presente estudo foi uma reta (Figura 30 e 31), o que indica que ambos os resíduos de triptofano, que estão localizados em posições diferentes da cadeia dos peptídeos $\left(2^{\circ}\right.$ e $\left.5^{\circ}\right)$, estão igualmente acessíveis ao supressor (CHRISTIAENS et al., 2002; EFTINK e GHIRON, 1976; LAKOWICZ, 2006). 
De acordo com os dados Ksv (Tabela 8), $\mathrm{L}_{1}$ está mais acessível ao supressor quando interage com micelas LPC, do que com micelas de SDS (LAKOWICZ, 2006). Esta observação reforça o fato de que os triptofanos do $\mathrm{L}_{1}$ estão em um ambiente mais hidrofóbico em micelas de SDS do que em LPC, conforme observado através do blue-shift do $\lambda$ max. Além disso, Lo é menos acessível para a acrilamida em micelas de LPC (Tabela 8).

Segundo Sani (2012) o LPC, e também o DPPC, possuem carga líquida neutra (zwitteriônico) e por isso, apresentam maior interação com peptídeos hidrofóbicos (interação hidrofóbica) do que com os aniônicos (interações eletrostáticas), justificando o Lo apresentar maior interação com micelas de LPC do que de SDS.

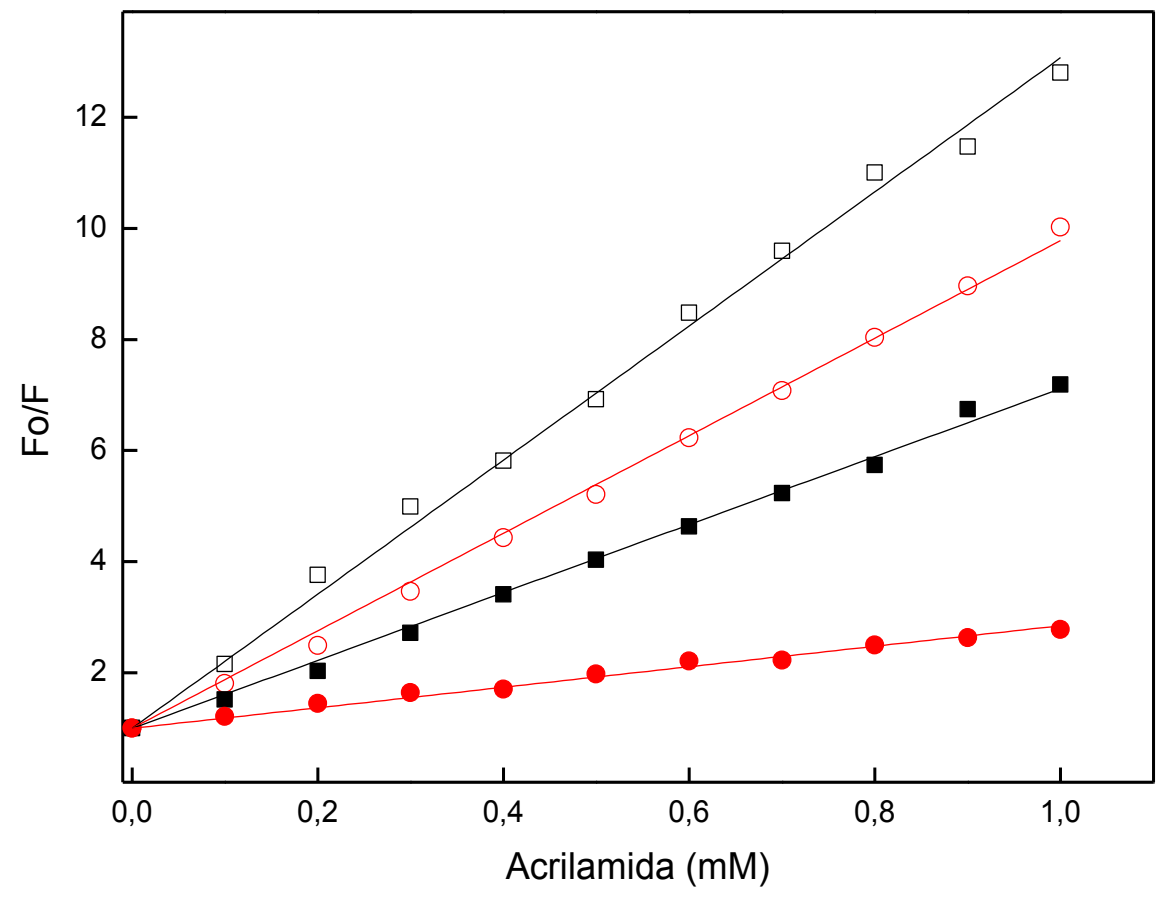

Figura 30: Supressão da fluorescência dos triptofanos presentes nos peptídeos Lo (匹) e $\mathrm{L}_{1}$ $(\bullet$ ), na ausência (símbolos abertos) e presença (símbolos preenchidos) de micelas de SDS, pH 7,0, conforme descrito em Materiais e Métodos. 


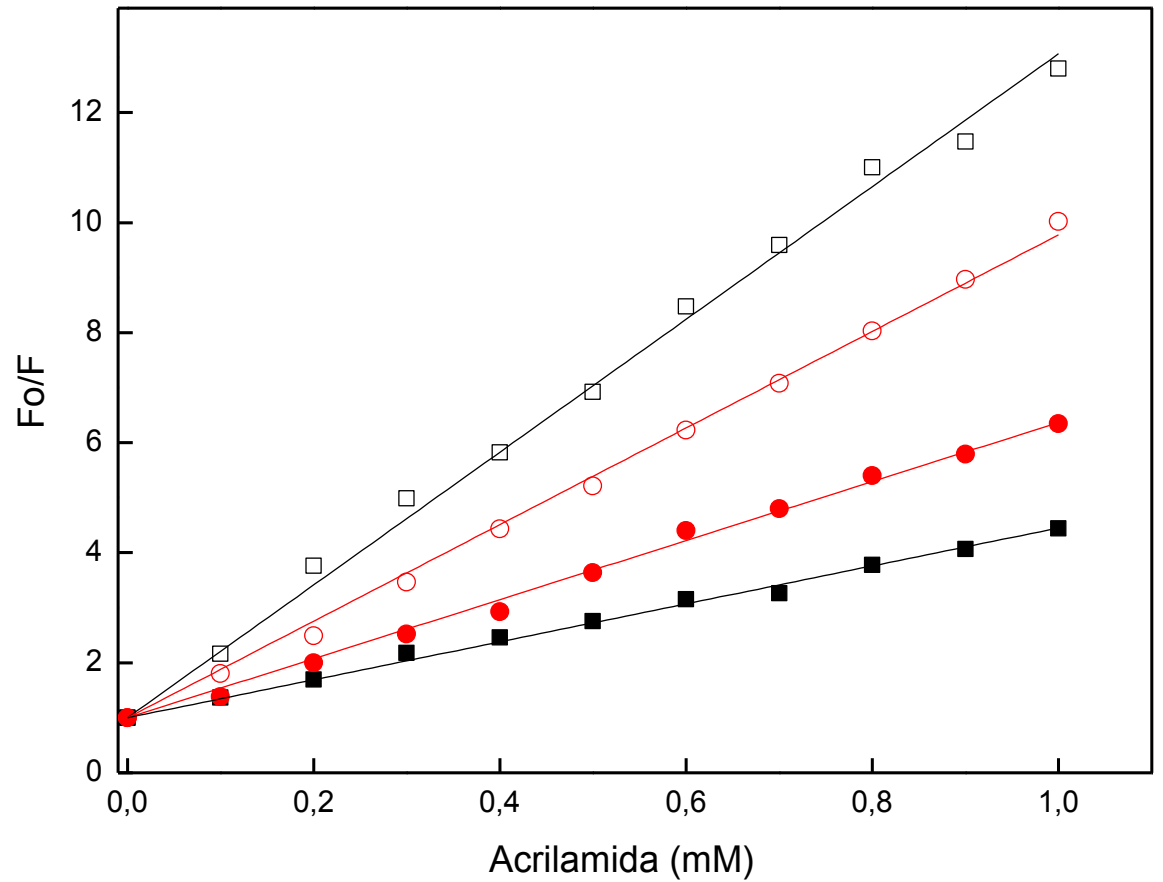

Figura 31: Supressão da fluorescência dos triptofanos presentes nos peptídeos Lo (匹) e $L_{1}$ (•), na ausência (símbolos abertos) e presença (símbolos preenchidos) de micelas de LPC, pH 7,0, conforme descrito em Materiais e Método.

TABELA 8. Valores de $\lambda \max$ e Ksv de Lo e $L_{1}$ na ausência (meio aquoso) e presença de micelas SDS ou LPC. Estes parâmetros foram obtidos das Figuras 28, 29, 30 e 31. Os experimentos foram realizados conforme descrito em Materiais e Métodos.

\begin{tabular}{|c|c|c|c|}
\hline \multirow[b]{2}{*}{ Condições } & \multirow[b]{2}{*}{ Parâmetros } & \multicolumn{2}{|c|}{ Peptídeos } \\
\hline & & $\mathrm{L}_{1}$ & Lo \\
\hline \multirow[b]{2}{*}{ Água } & $\lambda \max (\mathrm{nm})$ & 350 & 350 \\
\hline & $\operatorname{Ksv}\left(M^{-1}\right)$ & $8,8 \pm 0.3$ & $12,1 \pm 0.6$ \\
\hline \multirow[b]{2}{*}{ SDS } & $\lambda \max (\mathrm{nm})$ & 342 & 343 \\
\hline & $\operatorname{Ksv}\left(M^{-1}\right)$ & $1,8 \pm 0.1$ & $6,1 \pm 0.5$ \\
\hline \multirow[b]{2}{*}{ LPC } & $\lambda \max (\mathrm{nm})$ & 348 & 345 \\
\hline & $\operatorname{Ksv}\left(M^{-1}\right)$ & $5,4 \pm 0.2$ & $3,4 \pm 0.1$ \\
\hline
\end{tabular}




\subsubsection{Dicroísmo Circular do peptídeo em micelas}

Com o objetivo de investigar as mudanças conformacionais ocorridas nos peptídeos, devido à interação com micelas, foi utilizada a espectroscopia de CD na região do UVdistante $(190-250 \mathrm{~nm})$. O espectro de CD do Lo em meio aquoso, pH 7,0, possui uma banda negativa ao redor de $200 \mathrm{~nm}$ (Figura 32), que sugere uma estrutura não-ordenada. A adição de SDS provocou alterações no espectro de CD (Figura 32) de uma maneira dependente da concentração, gerando uma banda com máximo ao redor de $210 \mathrm{~nm}$.

A cadeia lateral do aminoácido triptofano, grupo indol, apresenta quatro bandas de $\mathrm{CD}$ (Ia, Ib, Ba e Bb). As bandas $\mathrm{La}$ e $\mathrm{Lb}$ representam transições de menor energia e aparecem na região de $280 \mathrm{~nm}$, portanto, não são visíveis no UV-distante. As bandas Ba e Bb correspondem a transições de maior energia. Dependendo da conformação e localização dos resíduos de triptofano, estas bandas pode ter sinal positivo ou negativo (GRISHINA e WOODY, 1994).

O espectro do $\mathrm{L}_{1}$ em água, $\mathrm{pH}$ 7,0, apresenta uma banda negativa ao redor de $198 \mathrm{~nm}$ e outra positiva em $224 \mathrm{~nm}$, característico de estrutura "ao acaso" (LADOKHIN et al., 2000). Esta banda positiva provavelmente corresponde ao acoplamento da transição Bb da cadeia lateral do triptofano com a transição da cadeia principal do peptídeo ou cadeia lateral de outro triptofano. A banda da região 180-210 nm representa uma transição Ba, é menos intensa que $\mathrm{Bb}$ e não pode ser visualizada devido a forte banda do $\mathrm{L}_{1}$ na mesma região (Figura 33). A adição de diferentes concentrações de SDS mudou o espectro de CD do $\mathrm{L}_{1}$ : um máximo ao redor de 194 nm e um mínimo em aproximadamente 218 nm, correspondente à conformação folha- $\beta$ (Figura 33). Esta alteração resultou provavelmente da interação $\mathrm{L}_{1^{-}}$ micelas, que separou os resíduos de triptofano, resultando na perda da banda em $225 \mathrm{~nm}$ (ANDERSSON et al., 2001; SFORÇA et al., 2005; WOODY, 1996), devido à mudança conformacional do $\mathrm{L}_{1}$. 


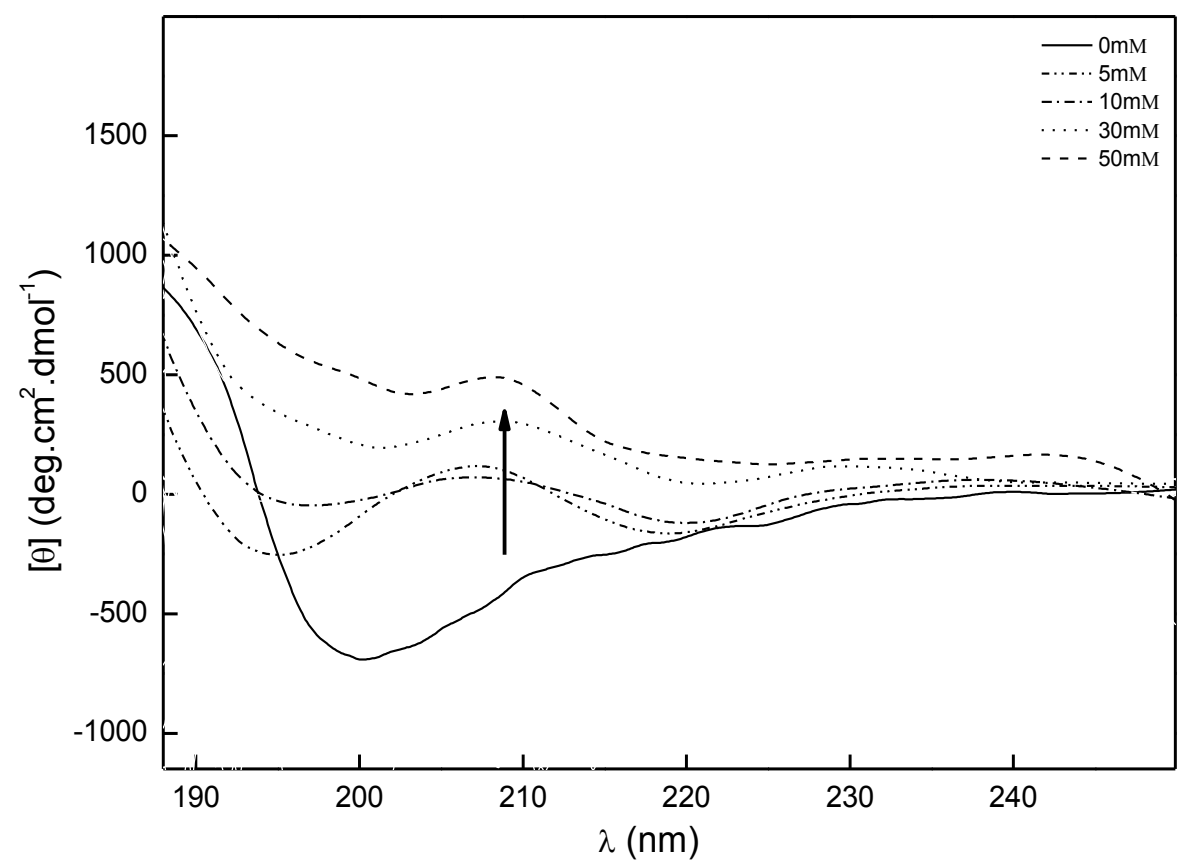

Figura 32: Espectro de CD do peptídeo Lo em diferentes concentrações de SDS (0 a 50 $\mathrm{mM}$ ), em meio aquoso, $\mathrm{pH}$ 7,0. O espectro de $\mathrm{CD}$ foi obtido conforme descrito em Materiais e Métodos.

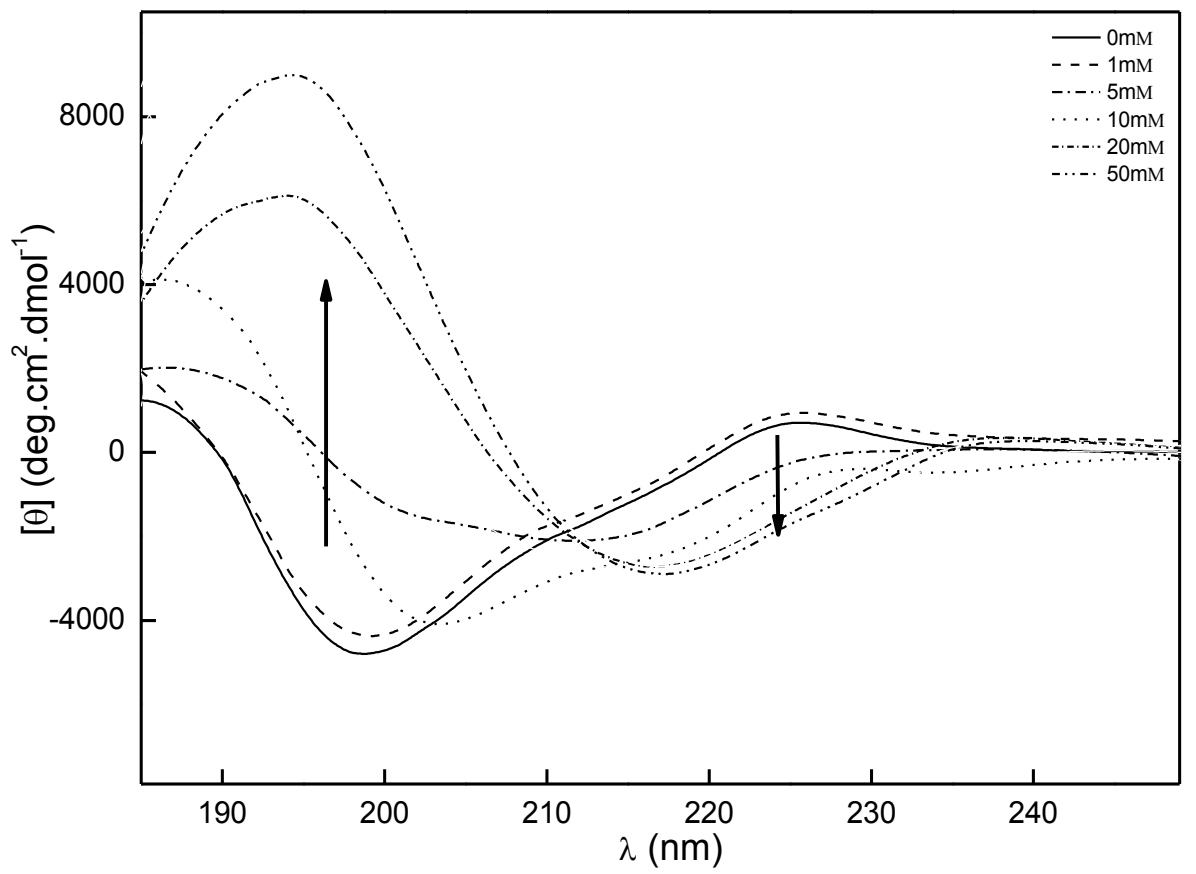

Figura 33: Espectro de CD do peptídeo $\mathrm{L}_{1}$ em diferentes concentrações de $\mathrm{SDS}(0$ a 50 $\mathrm{mM}$ ), em meio aquoso, $\mathrm{pH}$ 7,0. O espectro de $\mathrm{CD}$ foi obtido conforme descrito em Materiais e Métodos. 
Um estudo semelhante foi realizado na presença de micelas de LPC (Figura 32 e 33). Foram detectadas mudanças conformacionais em ambos os peptídeos devido à interação peptídeo-LPC. O espectro de CD do peptídeo Lo em meio aquoso, pH 7,0, apresenta uma banda negativa ao redor de $200 \mathrm{~nm}$; após a adição de LPC uma banda positiva em $213 \mathrm{~nm}$ foi gerada, mostrando-se dependente da concentração (Figura 32). O tamanho e a estrutura cíclica do Lo confere uma grande restrição conformacional, no entanto houve expressivas modificações em baixas concentrações de detergente, próximo à CMC. O peptídeo Lo exibiu espectros de CD diferentes em SDS e LPC (Figuras 32 e 34), evidenciando que experimentaram diferentes conformações em micelas aniônicas e zwitteriônicas.

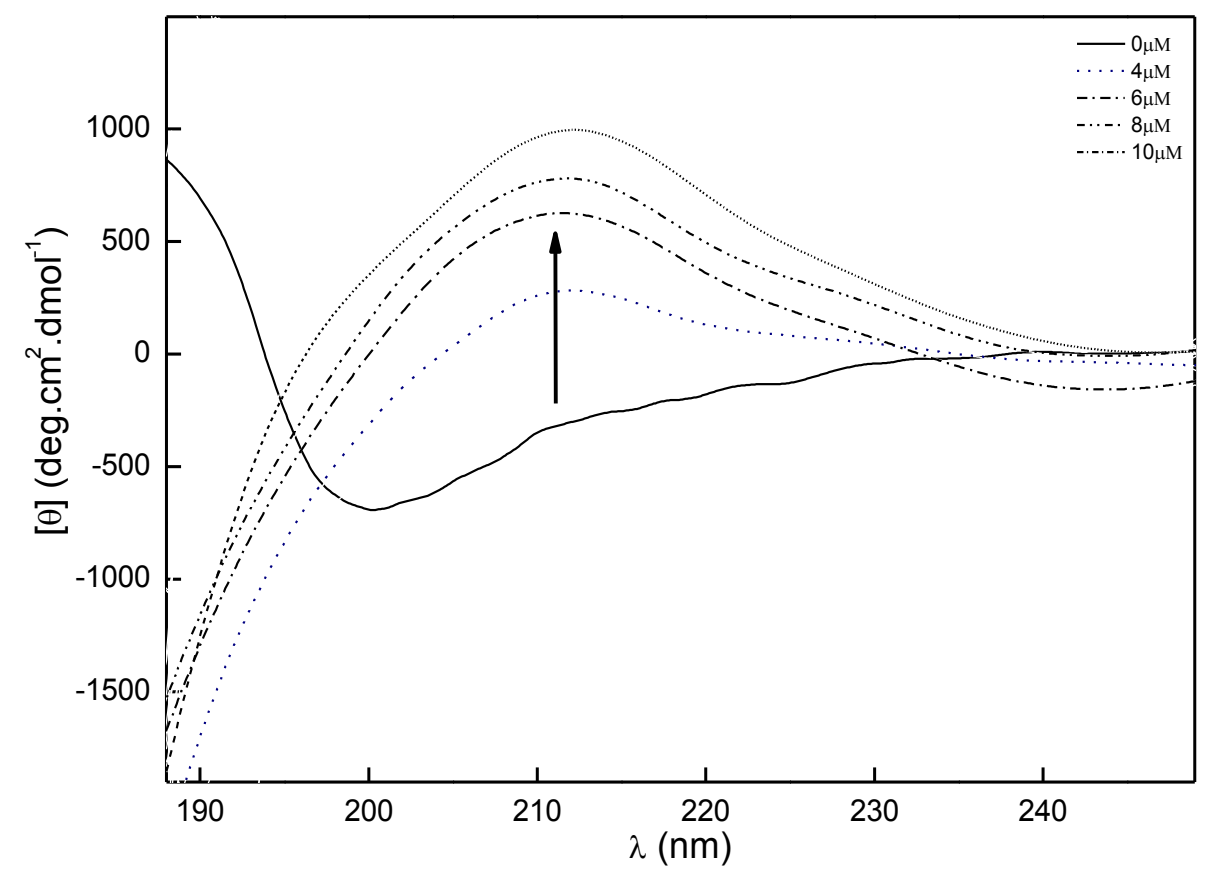

Figura 34: Espectro de CD do peptídeo Lo em diferentes concentrações de LPC (0 a 10 $\mu \mathrm{M}$ ), em meio aquoso, pH 7,0. O espectro de CD foi obtido conforme descrito em Materiais e Métodos. 
Com relação a $\mathrm{L}_{1}$ em micelas de $\mathrm{LPC}, \mathrm{pH}$ 7,0, uma banda com máximo ao redor de $224 \mathrm{~nm}$ desapareceu (Figura 35), fato também observado em SDS (Figura 33). $\mathrm{L}_{1}$ apresenta uma banda negativa em $230 \mathrm{~nm}$ e uma banda positiva ao redor de $194 \mathrm{~nm}$. Ele também mostrou um ombro em torno de $220 \mathrm{~nm}$.

Estes resultados demonstram que diferentes conformações podem ocorrer em ambos os peptídeos, Lo e $\mathrm{L}_{1}$, na presença de LPC ou SDS, evidenciando que as superfícies aniônicas e zwitteriônicas são fatores importantes para a interação (hidrofóbica ou eletrostática). Além disso, sugerem que o caráter lipídico da membrana é determinante na formação da estrutura ativa (SANI et al., 2012).

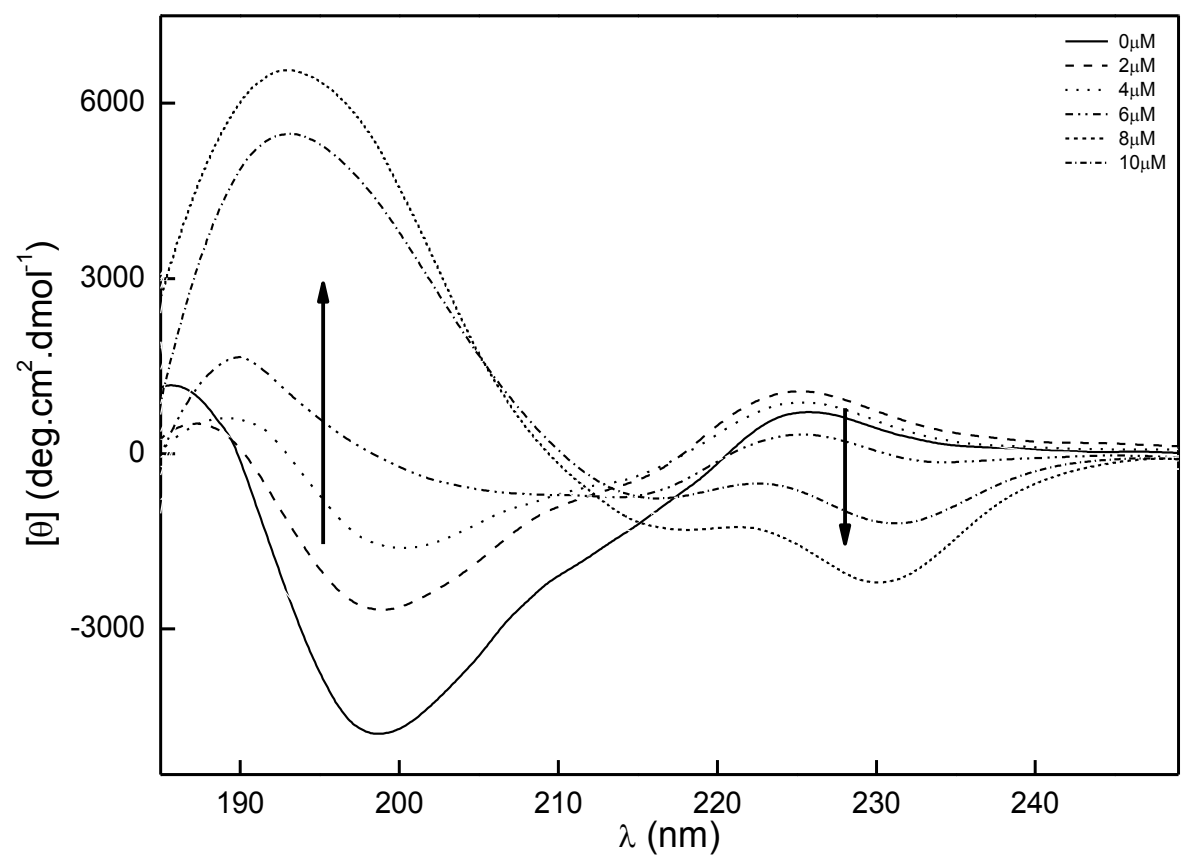

Figura 35: Espectro de CD do peptídeo $\mathrm{L}_{1}$ em diferentes concentrações de LPC (0 a 10 $\mu \mathrm{M}$ ), em meio aquoso, $\mathrm{pH}$ 7,0. O espectro de CD foi obtido conforme descrito em Materiais e Métodos. 


\subsubsection{Simulação por Dinâmica Molecular (DM): interação do peptídeo com micelas}

Os resultados das simulações através do modelo de representação das moléculas Coarse-Grained (CG) - demonstraram que os peptídeos Lo e $\mathrm{L}_{1}$, inicialmente dispersos em solução aquosa, são dirigidos espontaneamente para as imediações da micela. Usando um campo de força, com detalhes atômicos, ambos os peptídeos também permaneceram nas micelas. Foi calculado o desvio médio da raiz quadrada (RMSD) para os átomos de $\mathrm{C}_{\alpha}$ dos peptídeos em relação às estruturas iniciais obtidas nas simulações com SDS (RMSD $\left.{ }_{\mathrm{SDS}}\right)$.

Conforme observado, Figura 36A, o comportamento do $\mathrm{RMSD}_{\mathrm{SDS}}$ mostra que houve alterações na cadeia principal no início das simulações, indicando que as estruturas dos peptídeos Lo e $\mathrm{L}_{1}$, obtidos com as simulações $\mathrm{CG}$, foram reorganizadas a nível atômico, conforme observado por dicroísmo circular. Após, não ocorreram grandes mudanças na $\mathrm{RMSD}_{\mathrm{SDS}}$, evidenciando que as estruturas não sofreram maiores modificações durante as simulações com SDS. O mesmo efeito foi também observado por espectrometria de fluorescência.

Também foram monitoradas as posições dos átomos dos peptídeos nas micelas de SDS por meio da função de distribuição radial, $\mathrm{g}_{\mathrm{SDS}}(\mathrm{r})$, de todos os átomos de ambos os peptídeos, Lo e $\mathrm{L}_{1}$, em relação ao centro de massa da micela $(\mathrm{CM})$ (Figura 36B). O g gDs $(\mathrm{r})$ das moléculas de água também é representado na Figura 36B. Foi possível notar que a água pode penetrar até cerca de 1,2 $\mathrm{nm}$ do $\mathrm{CM}$ das micelas, lembrando que o núcleo da micela de SDS é cerca de 1,6 nm e que a cabeça polar é de 0,5 nm de espessura (ITRI e Amaral, 1993). Os perfis da $g_{S D S}(r)$ para $L_{1}$ e Lo iniciaram em 0,25 e $0,80 \mathrm{~nm}$, respectivamente, revelando que $\mathrm{L}_{1}$ insere parte de seus átomos mais profundamente na micela que o peptídeo cíclico, Lo.

A distância média entre o CM de cada resíduo e o CM da micela de SDS, $\mathrm{d}_{\mathrm{SDS}}$ (Figura 36C) evidenciou que a região $\mathrm{N}$-terminal do $\mathrm{L}_{1}$, bem como todos os resíduos, até 
Ile8 (isoleucina da posição 8), estão mais inseridos na região hidrofóbica da micela do que os mesmos resíduos do peptídeo Lo. O resíduo mais inserido na micela de SDS é o triptofano da posição 2 (Trp2), sugerindo que este aminoácido conduz a inserção do peptídeo $\mathrm{L}_{1}$ na região $\mathrm{N}$-terminal da micela de SDS. Estes resultados explicam os dados de fluorescência e supressão da fluorescência, mostrando que $\mathrm{L}_{1}$ está mais inserido nas micelas de SDS do que o Lo (Figura 28, Tabela 8). Estes dados também permitiram observar que os resíduos de Trp5 de ambos dos peptídeos, Lo e $\mathrm{L}_{1}$, estão localizados em similar ambiente da micela; portanto, as diferenças observadas nos espectros de fluorescência são devido à maior inserção do resíduo Trp2 do peptídeo $\mathrm{L}_{1}$.

Com o objetivo de enfatizar essa maior interação do $\operatorname{Trp} 2$ do $\mathrm{L}_{1}$ com a região hidrofóbica da micela de SDS, foi calculada a média da função de distribuição radial $\mathrm{g}_{\text {Trp- }}$ SDS $(r)$ dos pares formados entre os átomos de $\mathrm{C}$ ou $\mathrm{N}$ da cadeia lateral do triptofano e os átomos de carbono das cadeias hidrofóbicas das moléculas de SDS (Figura 36D). O primeiro pico, bem definido, da $\mathrm{g}_{\operatorname{Trp}-\mathrm{SDS}}(\mathrm{r})$ do $\operatorname{Trp} 2$ do $\mathrm{L}_{1}$, em $0,48 \mathrm{~nm}$, indica que a cadeia lateral do triptofano está rodeado por átomos de carbono do núcleo hidrofóbico. Por isso, o Trp2 do $\mathrm{L}_{1}$ está localizado em um ambiente mais apolar.

Com relação às micelas LPC, os valores do $\mathrm{RMSD}_{\mathrm{LPC}}$ (Figura 37A) indicam que a cadeia principal do peptídeo Lo teve uma variação muito pequena com o tempo: as alterações foram em torno de $0,15 \mathrm{~nm}$ durante a simulação. Maiores modificações ocorreram na cadeia principal do $\mathrm{L}_{1}$, em torno de $0,48 \mathrm{~nm}$ em $30 \mathrm{~ns}$; um comportamento convergente foi alcançado apenas em 50 ns. Assim, a utilização de um campo de força com todos os detalhes atômicos leva a uma estrutura desigual do peptídeo linear na micela LPC quando comparado com a simulação de CG. A Figura 37B mostra a função de distribuição radial $\mathrm{g}_{\mathrm{LPC}}(\mathrm{r})$ entre peptídeos e água em relação ao CM da micela de LPC. Como pode ser visto, o máximo valor da $\mathrm{g}(\mathrm{r})$ é $1,4 \mathrm{~nm}$ e $1,5 \mathrm{~nm}$ para $\mathrm{L}_{1}$ e Lo, respectivamente, ou seja, está 
localizado perto da interface apolar/polar, isto é, da cabeça polar zwitteriônica (BARBOSA et al., 2006). Além disso, os resultados da $d_{\text {LPC }}$ (Figura 37C) evidenciam que as maiores diferenças na localização dos peptídeos ocorreram nas regiões contendo os resíduos 1-2 e 57, regiões que incluem os triptofanos, justificando, assim, os blue-shift do $\lambda$ max, detectado através dos experimentos de emissão da fluorescência (Figuras 29 e Tabela 8).

Para avaliar as diferenças entre o comportamento dos resíduos de triptofano do $\mathrm{L}_{1} \mathrm{e}$ Lo foi calculada a interação deles com micelas de LPC. As cadeias laterais aromática dos resíduos de triptofano do $\mathrm{L}_{1}$ exibiram picos ligeiramente mais intensos para a $\mathrm{g}_{\text {Trp-LPC }}(\mathrm{r})$ entre os átomos de $\mathrm{C}$ e $\mathrm{N}$ da cadeia lateral e átomos de carbono das cadeias hidrofóbicas do LPC (Figura 37D). Os picos apareceram em 0,48 nm, como observado nos resultados de SDS, indicando que há contatos com os átomos de carbono da cadeia, embora em menor extensão que no caso do SDS (Figura 36D). Isto acontece porque os resíduos de triptofano não inseriram profundamente na micela LPC, conforme observado em micelas de SDS.

Portanto, houve maior inserção do peptídeo $\mathrm{L}_{1}$, que do Lo, nas micelas aniônicas de SDS, assim como observado com monocamada aniônica de DPPC:DPPS (8:2). Isso sugere que essa interação ocorre devido à interação eletrostática. Além disso, nas duas micelas, SDS e LPC, o peptídeo $\mathrm{L}_{1}$ apresenta uma conformação cujos resíduos de triptofano estão pareados (Figura 38), tal como observado através do CD (Figuras 33 e 35). Portanto, ambos os peptídeos, $\mathrm{L}_{1}$ e Lo, sofreram mudanças conformacionais ao interagir com as micelas.

Os resultados de DM divergem dos obtidos através da supressão da fluorescência, quando analisados na presença de LPC. Segundo os experimentos in vitro, o peptídeo Lo está mais inserido, que o peptídeo $\mathrm{L}_{1}$, nestas micelas; já através da DM, eles estão igualmente inseridos. Essa diferença pode ter ocorrido devido aos algoritmos utilizados na simulação, os detalhes atômicos e ao campo de força. Analogamente, em monocamada de 
DPPC foi observada maior interação do peptídeo Lo em menores pressões, fase em que o filme está mais hidratado, assim como o lipossomo.

Portanto, os resíduos de triptofano tem grande afinidade pelo meio hidrofóbico, sendo os aminoácidos mais inseridos no mimético de membrana. Isso valida ainda mais o estudo de fluorescência, já que o grau de inserção do peptídeo, por essa técnica, é avaliado através da sonda triptofano ( LAKOWICZ, 2006).
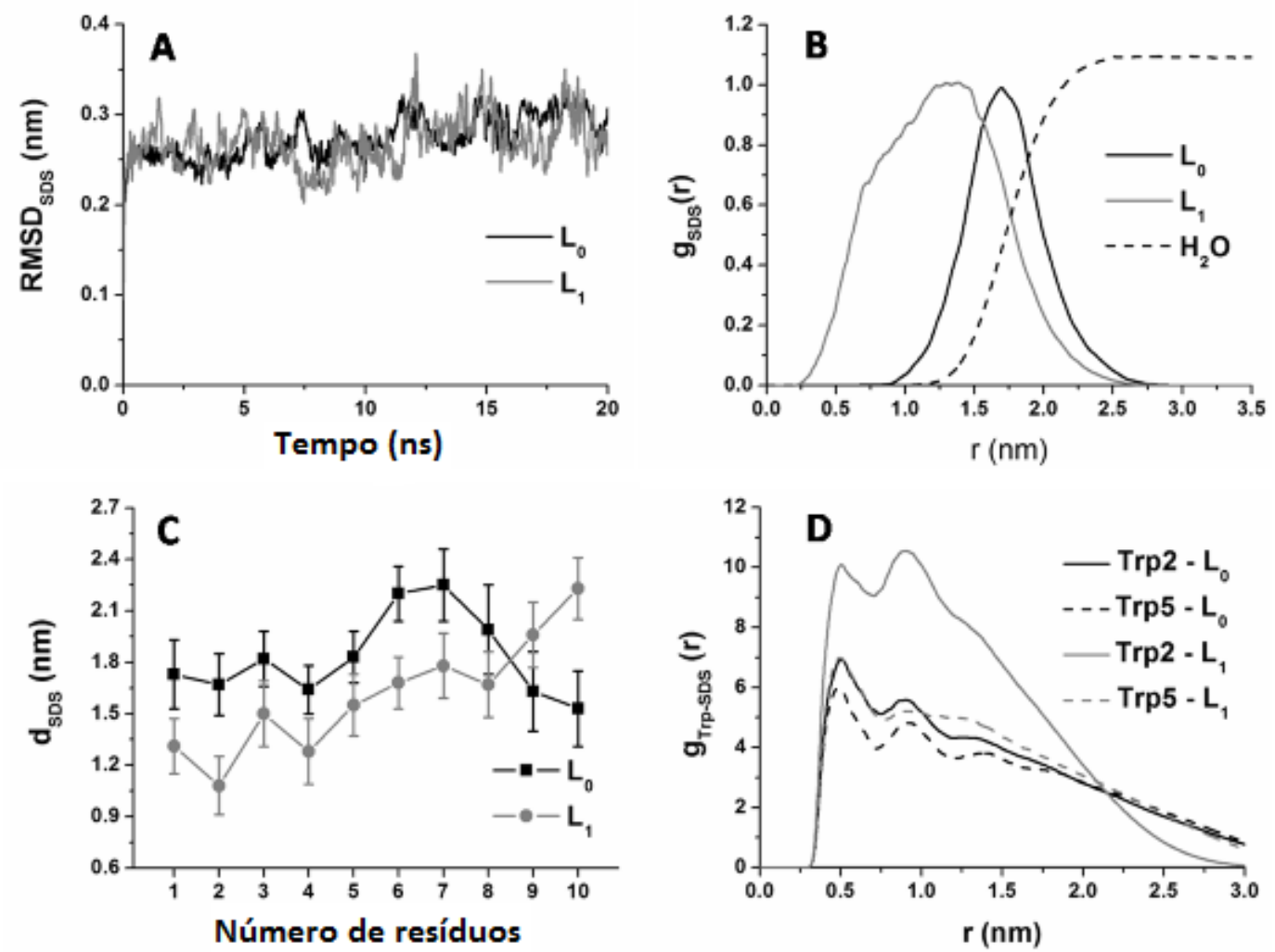

Figura 36: (A) RMSD $\mathrm{SDS}_{\text {do }}$ Lo e $\mathrm{L}_{1}$. Mostra os desvios da estrutura em relação à estrutura inicial, ao longo do tempo. (B) gSDS $(r)$ dos peptídeos e molécula de água em relação ao CM das micelas de SDS. A g $\mathrm{g}_{\mathrm{SDS}}(\mathrm{r})$ de cada peptídeo foi normalizada dividindo os valores pelo valor máximo do pico. (C) Distância entre o CM dos resíduos e a CM da micela. (D) $\mathrm{g}_{\text {Trp- }}$ SDS $(\mathrm{r})$ médio entre os átomos de $\mathrm{C}$ ou $\mathrm{N}$ das cadeias laterais dos triptofanos e os átomos de carbono da cadeia principal do SDS. Os dados contidos em A, B, e C foram calculados de 10 a $20 \mathrm{~ns}$. 

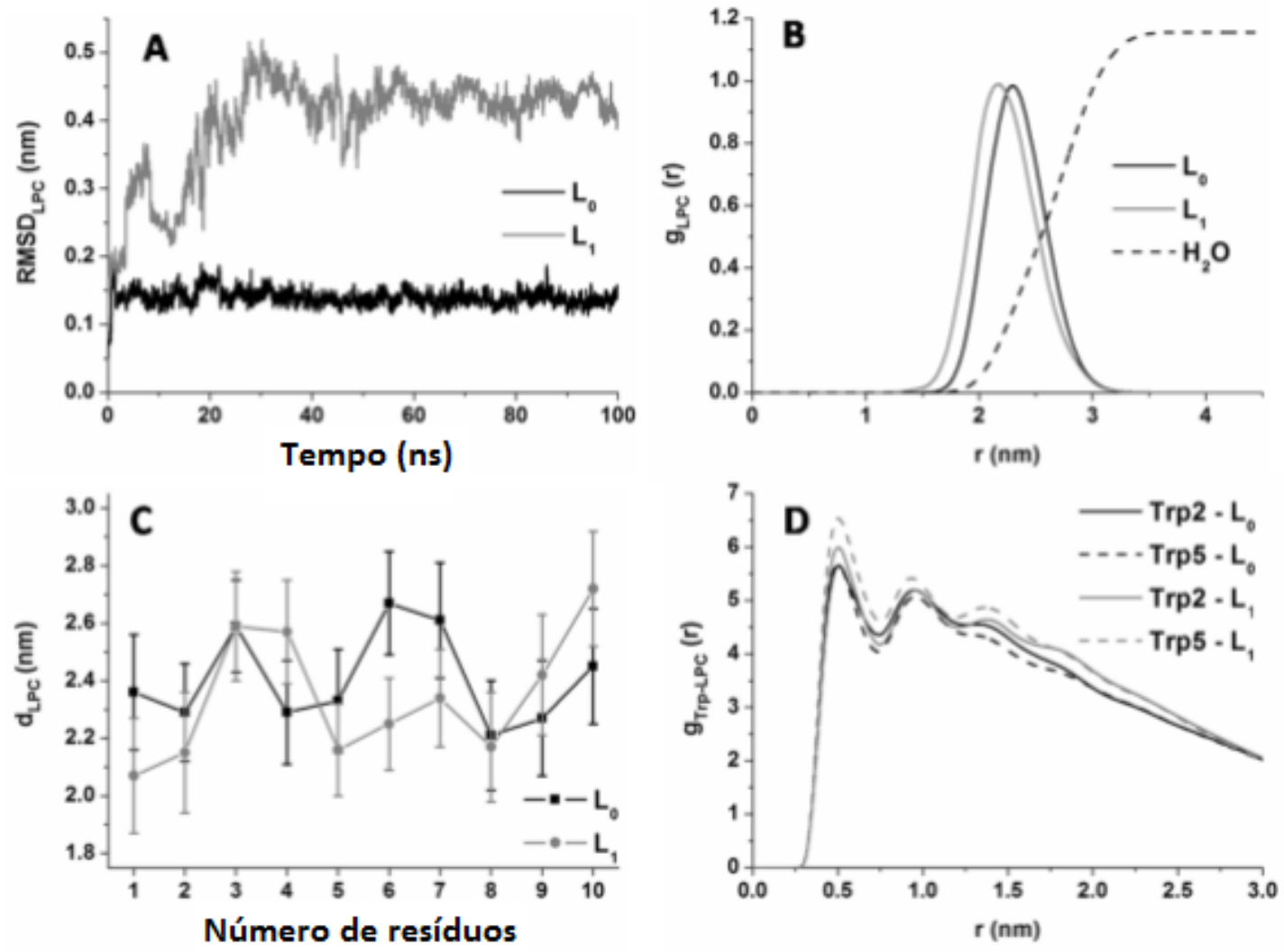

Figura 37: (A) RMSD $\mathrm{LPC}_{\mathrm{LP}}$ do Lo e $\mathrm{L}_{1}$. Mostra os desvios da estrutura em relação à estrutura inicial, ao longo do tempo. (B) $\mathrm{g}_{\mathrm{LPC}}(\mathrm{r})$ dos peptídeos e molécula de água em relação ao CM das micelas de LPC. A $g_{\text {LPC }}(r)$ de cada peptídeo foi normalizada dividindo os valores pelo valor máximo do pico. (C) Distância entre o CM dos resíduos e a CM da micela. (D) $\mathrm{g}_{\text {Trp- }}$ LPC(r) médio entre os átomos de $\mathrm{C}$ ou $\mathrm{N}$ das cadeias laterais dos triptofanos e os átomos de carbono da cadeia principal do LPC. Os dados contidos em A, B, e C foram calculados de 50 a $100 \mathrm{~ns}$. 

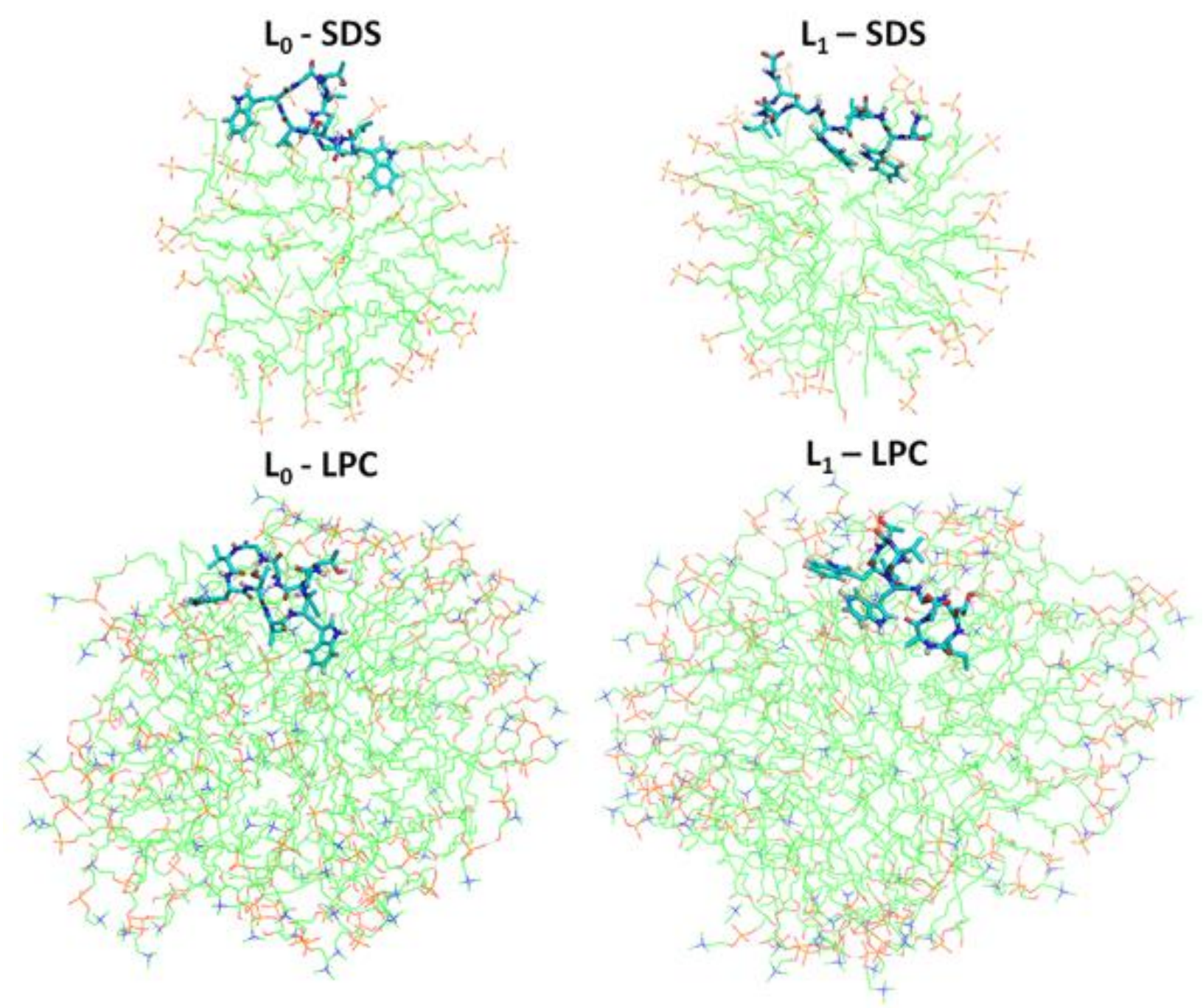

Figure 38: Configurações finais do peptídeo Lo e $\mathrm{L}_{1}$ ao interagir com micelas (SDS em cima e LPC embaixo) usando campo de força, conforme descrito em Materiais e Métodos. As moléculas de água e íons foram removidas para melhor visualização. 


\subsubsection{Lipossomos}

Lipossomos são sistemas esféricos compostos por lipídios que mimetizam a membrana biológica. Difere das micelas por formar bicamada. Eles podem conter uma única bicamada lipídica ou bicamadas múltiplas em torno do compartimento aquoso interno. Seu tamanho varia entre 20-5000 nm (DEMICHELI et al., 2005).

Os lipossomos, além de mimético de membrana, podem ser usados como vesículas para administração de nutrientes e carreadores de drogas (BATISTA et al., 2007; HYODO et al., 2013).

A interação de ambos os peptídeos, Lo e $\mathrm{L}_{1}$, com sistemas de DPPC foi estudada por Barbosa et al. (2011) através das técnicas: espectrometria de fluorescência, supressão da fluorescência, DLS, calorimetria (DSC) e dicroísmo circular. Foi observada interação de ambos os peptídeos com o lipossomo, no entanto, Lo inseriu mais que $\mathrm{L}_{1}$. Também, através do dicroísmo circular, observamos que em meio aquoso o peptídeo Lo possui conformação não-ordenada e $\mathrm{L}_{1}$ estrutura ao acaso. Ao interagir com lipossomos constituídos por DPPC, ambos os peptídeos sofreram alteração conformacional. $\mathrm{L}_{1}$ perdeu a banda positiva em 224 nm, devido ao distanciamento entre os resíduos de triptofano. Já Lo apresentou estrutura não-ordenada em ambos os meios, porém com alterações conformacionais. Através dos estudos termodinâmicos (DSC) foi observado um aumento da entalpia e diminuição da cooperatividade, pra ambos os peptídeos, conforme o aumento da concentração de peptídeo. Essas alterações ocorreram, possivelmente, devido à interação peptídeo-mimético de membrana.

\subsubsection{Efeito da concentração do peptídeo no diâmetro do lipossomo}

Através do espalhamento de luz foi avaliada a mudança do diâmetro hidrodinâmico dos diferentes lipossomos $(1 \mathrm{mg} / \mathrm{mL})$, após incubado por 2 horas com diferentes soluções 
peptídicas, em diferentes razões molares (L/P), conforme descrito em Materiais e Métodos (Figura 39).

Houve aumento do diâmetro de todas as composições lipídicas DPPC, DPPC:Chol (9:1), DPPC:DPPS (8:2) conforme a redução da razão molar L/P (aumento da concentração de peptídeo). Este comportamento ocorreu tanto em lipossomos com concentração lipídica de $1 \mathrm{mg} / \mathrm{mL}$, quanto em $5 \mathrm{mg} / \mathrm{mL}$ (Figura 39 e 40). Isso demonstra que o efeito foi causado pelo peptídeo.

Em lipossomos com concentração lipídica de $1 \mathrm{mg} / \mathrm{mL}$, conforme a redução da razão molar L/P (20-60) houve aumento do diâmetro médio dos lipossomos constituídos por DPPC. Esse aumento foi cerca de 1,6 vezes na presença do Lo, e 1,3 vezes na presença do $\mathrm{L}_{1}$ (Figura 39A). Em DPPC:Chol (9:1) o aumento foi cerca de 2,2 vezes na presença do Lo e 1,8 na do $\mathrm{L}_{1}$ (Figura 39B). Em DPPC:DPPS (8:2) o aumento foi cerca de 1,3 vezes na presença do Lo e 1,6 na do $\mathrm{L}_{1}$ (Figura 39C). Isso ocorreu, provavelmente, devido à agregação e/ou fusão dos sistemas vesiculares conforme o aumento da concentração de peptídeo (diminuição da razão L/P).

Além disso, em todos os lipossomos estudados a redução da relação L/P, além de causar aumento do diâmetro médio dos lipossomos, é acompanhado por aumento do índice de polidispersão (IP), atingindo valores de até 0,7. A associação destes dois parâmetros reforça a hipótese de formação de agregados e/ou fusão (OYEWUMI et al., 2010; STIMAC, 2012). Outros estudos devem ser realizados com intuito de avaliar a extensão da perturbação causada pelo peptídeo. 


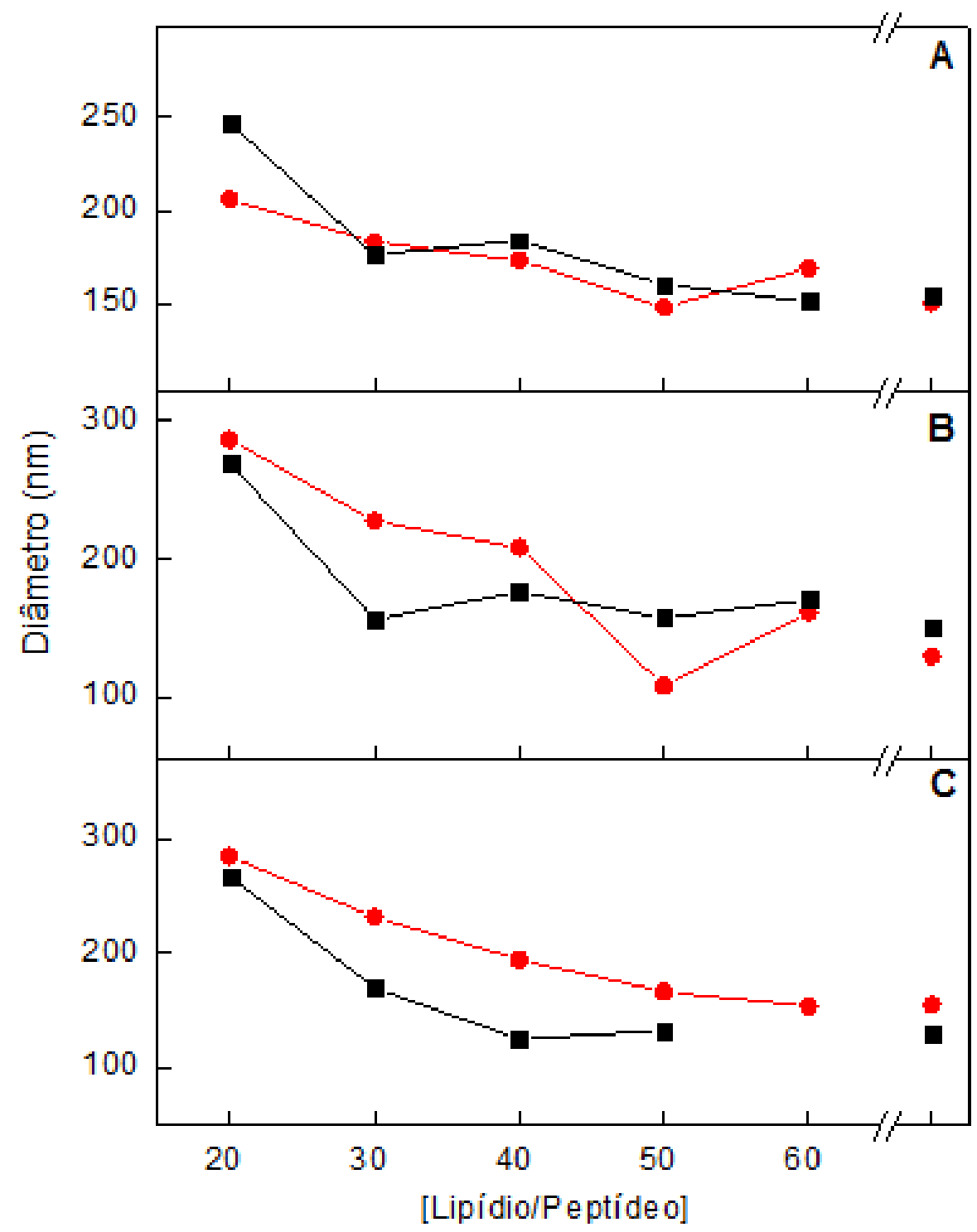

Figura 39: Variação do diâmetro dos lipossomos $(1 \mathrm{mg} / \mathrm{mL})$ na presença dos peptídeos Lo (घ) e $\mathrm{L}_{1}(\bullet)$ : (A) DPPC, (B) DPPC:Chol (9:1), (C) DPPC:DPPS (8:2). O ponto sem razão molar L/P corresponde ao lipossomo puro. Os peptídeos foram encubados com os lipossomos, em diferentes razões molares L/P (20 - 60), separadamente, por 2 horas, conforme descrito em Materiais e Métodos. 
Também foi avaliada a alteração do diâmetro hidrodinâmico dos lipossomos constituídos por lipídios na concentração $5 \mathrm{mg} / \mathrm{mL}$, após incubados por 2 horas com diferentes soluções peptídicas, conforme descrito em Materiais e Métodos (Figura 40). Como pode ser observado, os peptídeos Lo e $\mathrm{L}_{1}$ causaram perturbação no sistema, aumentando o diâmetro médio dos lipossomos constituídos por DPPC em cerca de 2,1 vezes na presença do peptídeo Lo e 1,6 vezes na presença do $\mathrm{L}_{1}$ (Figura 40A). Em DPPC:Chol (9:1) o diâmetro do lipossomo aumentou em cerca de 1,7 vezes na presença do Lo e 2,2 vezes na presença do $\mathrm{L}_{1}$ (Figura 40B). Em DPPC:DPPS (8:2) o diâmetro do lipossomo aumentou em cerca de 1,8 vezes na presença do Lo e 2,0 vezes na presença do $L_{1}$ (Figura 40C).

Portanto, nas duas concentrações lipídicas (1 e $5 \mathrm{mg} / \mathrm{mL}$ ) avaliadas houve maior perturbação, ou seja, aumento do diâmetro dos lipossomos constituídos por DPPC devido à presença do peptídeo Lo do que do $\mathrm{L}_{1}$. Já nos lipossomos constituídos por DPPC:Chol (9:1) e DPPC:DPPS (8:2), a perturbação foi maior na presença do $\mathrm{L}_{1}$. Possivelmente, esse aumento está relacionado com a interação peptídeo-lipossomo, e isso pode estar causando agregação e/ou fusão dos sistemas vesiculares, conforme já mencionado. 


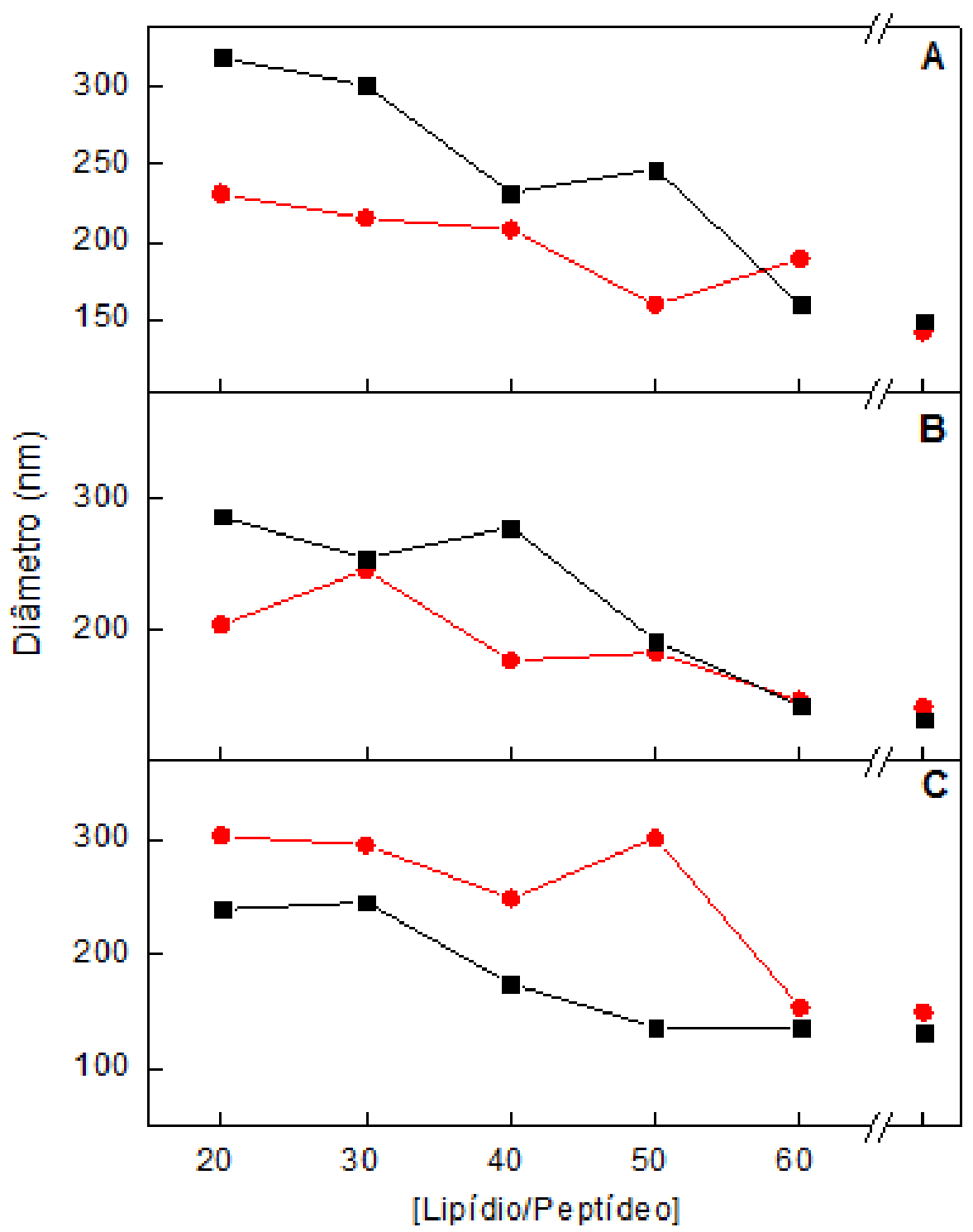

Figura 40: Variação do diâmetro dos lipossomos $(5 \mathrm{mg} / \mathrm{mL})$ na presença dos peptídeos Lo (匹) e $\mathrm{L}_{1}(\bullet)$ : (A) DPPC, (B) DPPC:Chol (9:1), (C) DPPC:DPPS (8:2). O ponto sem razão molar L/P corresponde ao lipossomo puro. Os peptídeos foram encubados com os lipossomos, em diferentes razões molares L/P (20 - 60), separadamente, por 2 horas, conforme descrito em Materiais e Métodos. 


\subsubsection{Espectrometria de Fluorescência em Lipossomos}

Complementando os estudos de interação, os peptídeos Lo e $\mathrm{L}_{1}$ foram analisados através da fluorescência utilizando lipossomos constituídos por DPPC, DPPC:Chol (9:1) e DPPC:DPPS (8:2). A interação peptídeo-lipossomo, em todas as composições, foi acompanhada por um decaimento da intensidade de fluorescência e deslocamento do $\lambda$ max de emissão para menores comprimento de onda (blue-shift), conforme a diminuição da razão molar L/P (Figura 41). Mudanças conformacionais podem ocorrer nestas moléculas ao interagir com lipídios, provocando maior ou menor aproximação das cadeias laterais do peptídeo em relação ao triptofano, agindo como supressores (VAN DER WEL et al., 2007). Portanto, esse decaimento da intensidade de fluorescência pode ser atribuído às alterações conformacionais sofridas pelo peptídeo (CHEN e BARKLEY, 1998; LADOKHIN et al.,2000), e o blue-shift à migração da sonda triptofano para um ambiente menos polar (PARK et al., 1995; LADOKHIN et al., 2000; AZIMI et al., 2011), conforme mencionado anteriormente nos estudos com micelas.

A interação dos peptídeos Lo e $\mathrm{L}_{1}$ com DPPC (Figura 41A) é caracterizada por um blue-shift, variando 8 e $4 \mathrm{~nm}$ (Tabela 9), respectivamente. Isso demonstra que os resíduos de triptofano do Lo estão em um ambiente mais apolar que os do $\mathrm{L}_{1}$. Isso ocorre, possivelmente, porque o DPPC possui carga líquida zero, favorecendo interação com moléculas hidrofóbicas.

$\mathrm{Na}$ presença de DPPC:Chol (9:1) (Figura 41B) os peptídeos Lo e $\mathrm{L}_{1}$ também apresentaram blue-shift, variando 4 e $6 \mathrm{~nm}$ (Tabela 9), respectivamente. Portanto, os resíduos de triptofano do $\mathrm{L}_{1}$ estão em um ambiente ligeiramente mais apolar que os do peptídeo Lo. Isso demonstra que embora a bicamada esteja mais rígida, o peptídeo linear apresentou maior interação, possivelmente, devido à interação eletrostática com o grupo hidroxila do colesterol, localizado na interface da bicamada. 
Em DPPC:DPPS (8:2) os peptídeos Lo e $\mathrm{L}_{1}$ apresentaram blue-shift de 3 e $11 \mathrm{~nm}$, respectivamente (Figura 41C). Devido à presença de cargas terminais o peptídeo $\mathrm{L}_{1}$ sofreu interação eletrostática com o lipídio aniônico, DPPS, favorecendo sua inserção no lipossomo. Similar comportamento foi observado no estudo com micelas aniônicas de SDS (Figura 28).

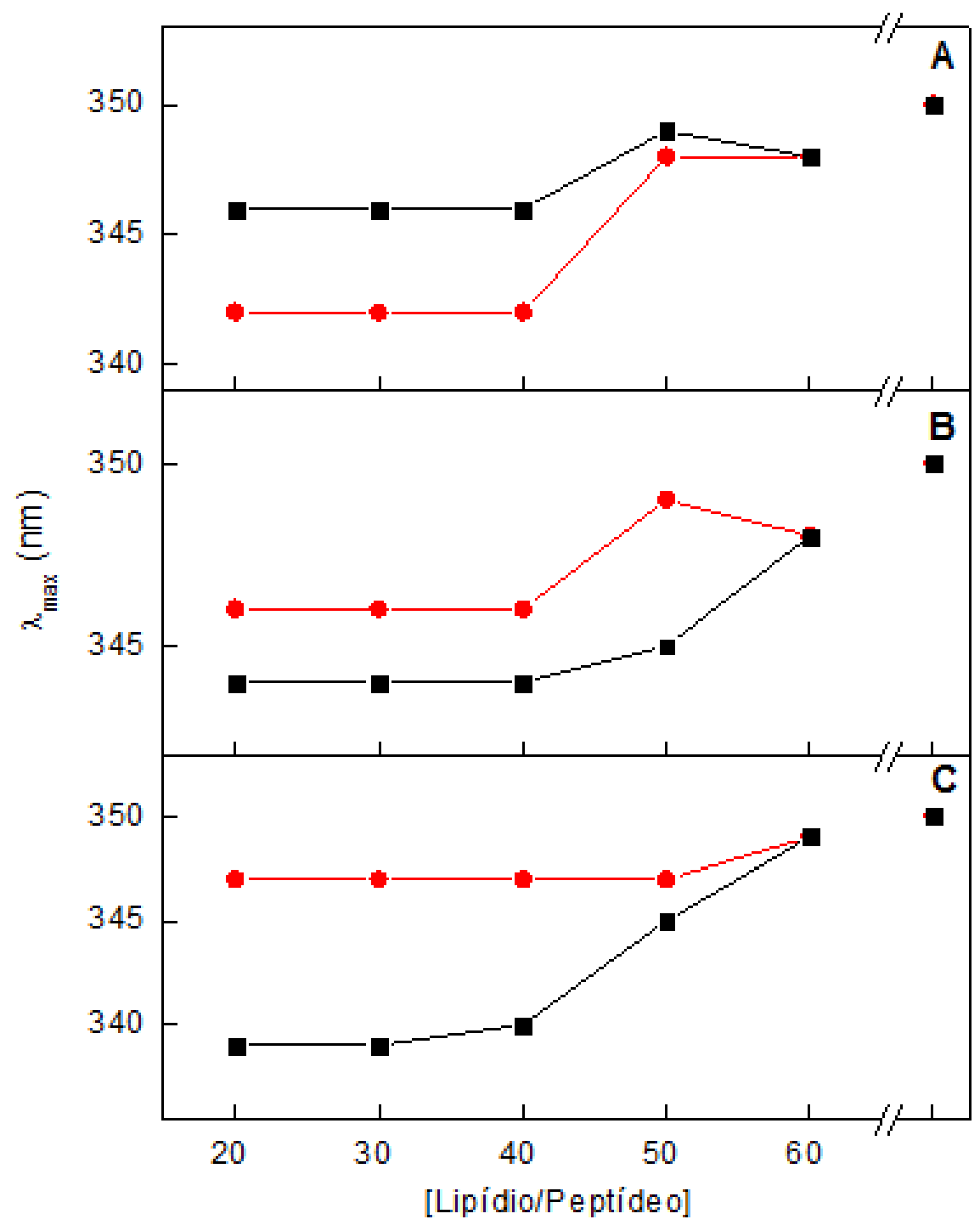

Figura 41: Variação do $\lambda \max$ de emissão da fluorescência dos triptofanos presentes nos peptídeos, Lo (ロ) e L $\mathrm{L}_{1}(\bullet)$, na presença ((A) DPPC, (B) DPPC:Chol (9:1), (C) DPPC:DPPS (8:2)) e ausência de lipossomo (ponto isolado). Diferentes razões molares L/P (20 - 60), separadamente, foram incubadas por 2 horas, conforme descrito em Materiais e Métodos. 


\subsubsection{Supressão da Fluorescência em Lipossomos}

A supressão da fluorescência dos triptofanos foi medida a partir da obtenção da constante de Stern-Volmer (Ksv) para cada peptídeo, tanto no microambiente lipídico, quanto no microambiente aquoso (EFTINK e GHIRON, 1976). O Ksv é um parâmetro obtido a partir da tangente da curva de supressão, dada pelo valor inicial da intensidade de fluorescência em relação aos valores pontuais obtidos $(\mathrm{Fo} / \mathrm{F})$ na presença de concentrações crescentes de acrilamida (DEVA e BEHERE, 1999).

Assim, foi estudada a interação dos lipossomos constituídos por DPPC, DPPC:Chol (9:1) e DPPC:DPPS (8:2), com Lo e $\mathrm{L}_{1}$. Em meio aquoso (Tabela 9) os resíduos de triptofano do peptídeo Lo $\left(14,2 \mathrm{M}^{-1}\right)$ estão mais expostos que os resíduos de triptofano do $\mathrm{L}_{1}$ $\left(11,1 \mathrm{M}^{-1}\right)$ (Figura 42, 43 e 44). Após a interação com os diferentes lipossomos, DPPC, DPPC:Chol (9:1) e DPPC:DPPS (8:2), foi observada uma redução nos valores de Ksv, revelando que os resíduos de triptofano dos peptídeos Lo e $\mathrm{L}_{1}$ tornaram-se menos expostos ao supressor, sugerindo interação com as diferentes bicamadas. A supressão da fluorescência, na faixa de concentração analisada, foi retilínea (Figuras 42, 43 e 44), sugerindo que os resíduos de triptofano $\left(2^{\circ}\right.$ e $\left.5^{\circ}\right)$ estão igualmente acessíveis ao supressor $[35,40,41]$.

De acordo com a Figura 42, e também com os valores de Ksv (Tabela 9), na presença de DPPC os triptofanos do peptídeo $\mathrm{L}_{1}\left(5,1 \mathrm{M}^{-1}\right)$ estão mais acessíveis ao supressor acrilamida que os do peptídeo Lo $\left(3,8 \mathrm{M}^{-1}\right)$. Portanto, os triptofanos do Lo estão em um ambiente mais apolar (Tabela 9). Já na presença de DPPC:Chol (9:1), o peptídeo $\mathrm{L}_{1}\left(3,5 \mathrm{M}^{-}\right.$ $\left.{ }^{1}\right)$ está ligeiramente mais inserido em um ambiente hidrofóbico que o Lo $\left(7,6 \mathrm{M}^{-1}\right)$, assim como observado nos estudos de fluorescência (blue-shift) (Figura 43, Tabela 9). Na presença de DPPC:DPPS (8:2), o peptídeo $\mathrm{L}_{1}\left(3,0 \mathrm{M}^{-1}\right)$ está mais acessível ao supressor acrilamida que o peptídeo Lo (10,1 $\left.\mathrm{M}^{-1}\right)$ (Figura 44, Tabela 9). 
Assim, os resultados sugerem que o peptídeo Lo apresenta maior interação com DPPC, que o $\mathrm{L}_{1}$, devido à interação hidrofóbica. Em lipossomos de DPPC:Chol (9:1) e DPPC:DPPS (8:2), o peptídeo $\mathrm{L}_{1}$ interage mais que o Lo, devido à interação eletrostática.

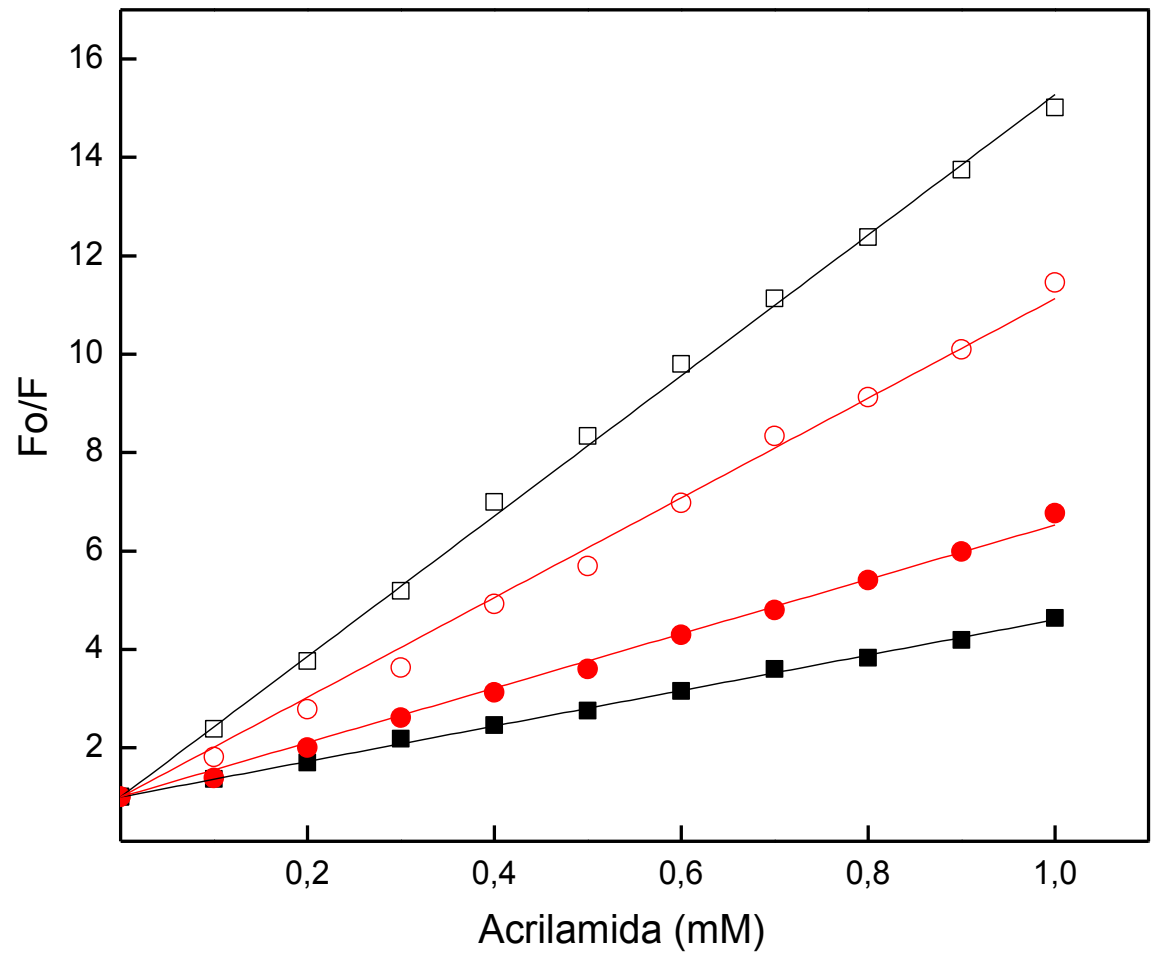

Figura 42: Supressão da fluorescência dos triptofanos presentes nos peptídeos Lo (ם) e $\mathrm{L}_{1}$ (•), na ausência (símbolos abertos) e presença (símbolos preenchidos) de lipossomos de DPPC, $\mathrm{pH} 7,0$, conforme descrito em Materiais e Método. 


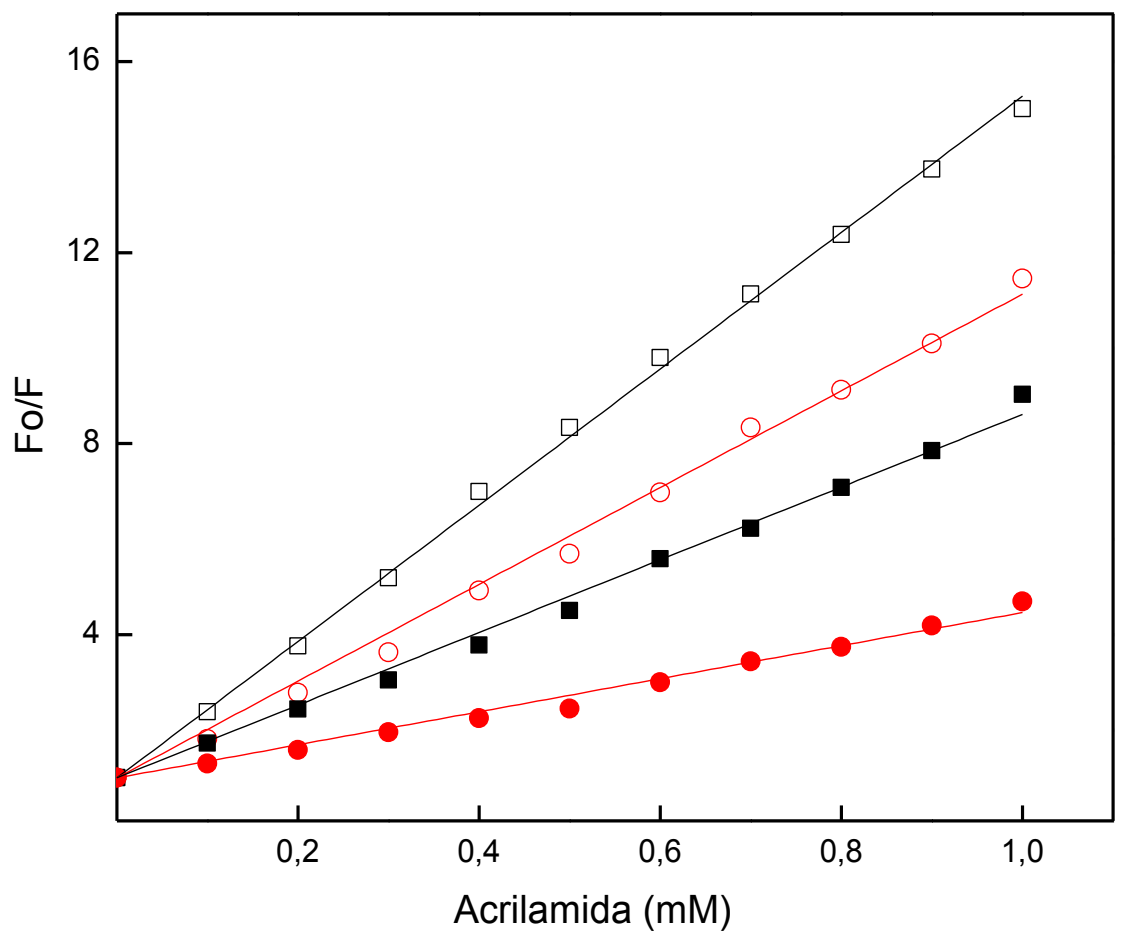

Figura 43: Supressão da fluorescência dos triptofanos presentes nos peptídeos Lo (匹) e $\mathrm{L}_{1}$ $(\bullet)$, na ausência (símbolos abertos) e presença (símbolos preenchidos) de lipossomos de DPPC:Chol (9:1), pH 7,0, conforme descrito em Materiais e Método.

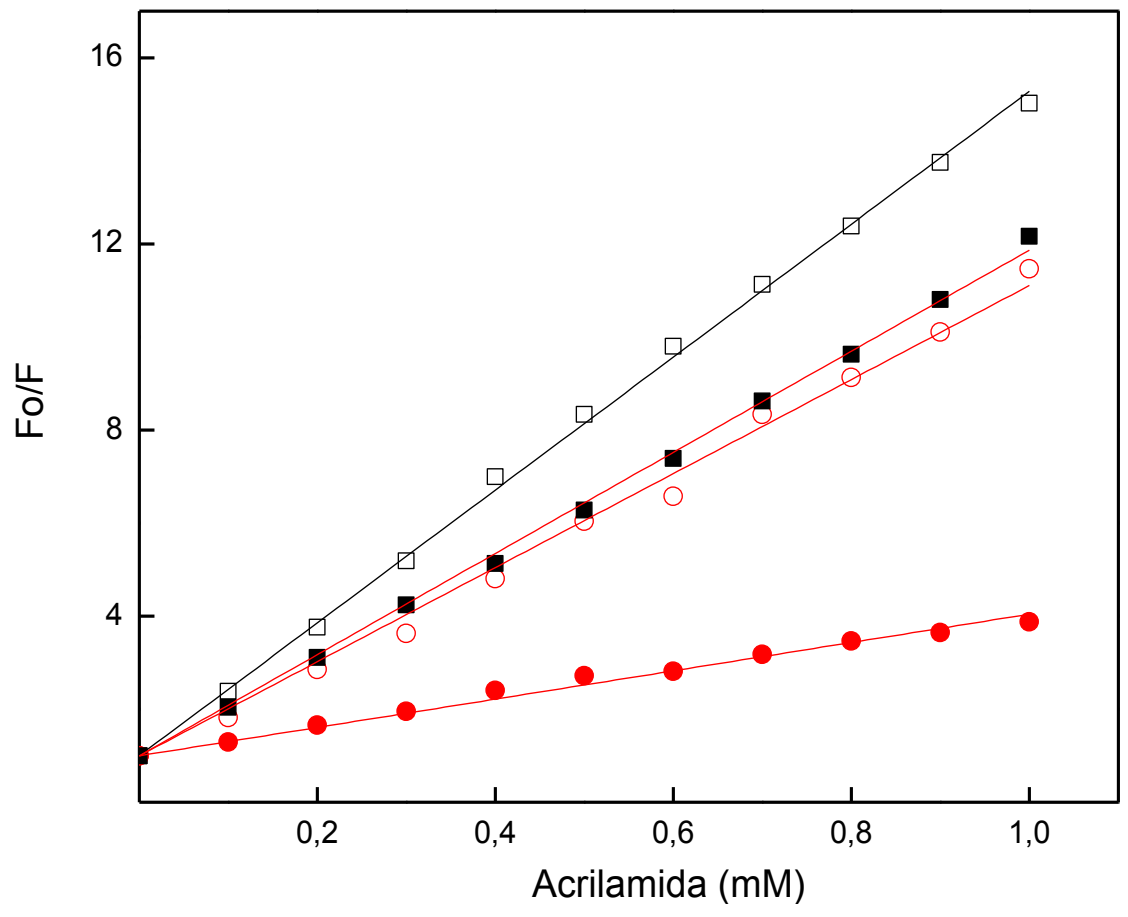

Figura 44: Supressão da fluorescência dos triptofanos presentes nos peptídeos Lo (匹) e $\mathrm{L}_{1}$ (•), na ausência (símbolos abertos) e presença (símbolos preenchidos) de lipossomos de DPPC:DPPS (8:2), pH 7,0, conforme descrito em Materiais e Método. 
Tabela 9: Valores de $\lambda \max$ e $\mathrm{Ksv}$ do Lo e $\mathrm{L}_{1}$, na ausência (meio aquoso) e presença de lipossomos constituídos por DPPC, DPPC:Chol (9:1) e DPPC:DPPS (8:2). Estes parâmetros foram obtidos a partir das Figuras 41, 42, 43 e 44. Os experimentos foram realizados conforme descrito em Materiais e Métodos.

\begin{tabular}{|c|c|c|c|}
\hline \multirow{2}{*}{ Condições } & \multirow{2}{*}{ Parâmetros } & \multicolumn{2}{|c|}{ Peptídeos } \\
\hline & & $\mathrm{L}_{1}$ & Lo \\
\hline \multirow[b]{2}{*}{ Água } & $\lambda \max (\mathrm{nm})$ & 350 & 350 \\
\hline & $\operatorname{Ksv}\left(M^{-1}\right)$ & $11,1 \pm 0.2$ & $14,2 \pm 0.1$ \\
\hline \multirow[b]{2}{*}{ DPPC } & $\lambda \max (\mathrm{nm})$ & 346 & 342 \\
\hline & $\operatorname{Ksv}\left(M^{-1}\right)$ & $5,1 \pm 0.3$ & $3,8 \pm 0.2$ \\
\hline \multirow[b]{2}{*}{ DPPC:Chol (9:1) } & $\lambda \max (\mathrm{nm})$ & 344 & 346 \\
\hline & $\operatorname{Ksv}\left(M^{-1}\right)$ & $3,5 \pm 0.3$ & $7,6 \pm 0.1$ \\
\hline \multirow[b]{2}{*}{ DPPC:DPPS (8:2) } & $\lambda \max (\mathrm{nm})$ & 339 & 347 \\
\hline & $\operatorname{Ksv}\left(M^{-1}\right)$ & $3,0 \pm 0.1$ & $10,1 \pm 0.1$ \\
\hline
\end{tabular}

Deve ser destacado que a susceptibilidade da bicamada depende da concentração de peptídeo na superfície da membrana. Em geral, após atingir uma razão limite entre peptídeo e lipídio (L/P) ocorre a inserção do peptídeo na bicamada. Isso está diretamente relacionado com a composição lipídica (HUANG, 2000). Estudos demonstram que além de influenciar na inserção, a composição lipídica também influencia na orientação e profundidade do peptídeo em relação à superfície da membrana (MATSUZAKI e MURASE, 1994). 


\subsubsection{Dicroísmo Circular em Lipossomos}

As mudanças conformacionais devido à interação peptídeo-membrana são essenciais para o entendimento do mecanismo de ação e regulação da atividade biológica das moléculas (KELLY et al., 2005).

Foram observadas mudanças conformacionais em ambos os peptídeos na presença de DPPC (Figuras 45 e 46). O Lo em meio aquoso, pH 7,0, apresenta uma extensa banda negativa ao redor de $207 \mathrm{~nm}$ (Figura 45). Essa banda negativa localizada entre 198 e $220 \mathrm{~nm}$ sugere que o peptídeo está predominantemente não-ordenado, conforme descrito por outros autores (YANG et al., 1994). A adição de DPPC provocou alterações no espectro de CD do Lo, de uma maneira dependente da concentração, gerando uma banda com máximo ao redor de $210 \mathrm{~nm}$.

O $\mathrm{L}_{1}$ em meio aquoso, $\mathrm{pH}$ 7,0, apresenta um mínimo ao redor de $197 \mathrm{~nm}$ e um máximo ao redor de $224 \mathrm{~nm}$, característico de estrutura ao acaso (LADOKHIN et al., 2000). Esta banda positiva provavelmente corresponde ao acoplamento da transição $\mathrm{Bb}$ da cadeia lateral do triptofano com a transição da cadeia principal do peptídeo ou cadeia lateral de outro triptofano (YANG, 1994). A banda da região 180-210 nm representa uma transição $\mathrm{Ba}$, é menos intensa que $\mathrm{Bb}$ e não pode ser visualizada devido a forte banda do $\mathrm{L}_{1}$ na mesma região (Figura 46). Após a interação com DPPC houve um pequeno deslocamento da banda negativa, passando de 197 para 203 nm. Também foi observado o desaparecimento da banda positiva em $224 \mathrm{~nm}$, provavelmente, devido à interação do peptídeo com a bicamada lipídica, resultando no distanciamento dos triptofanos (SFORÇA et al., 2005). 


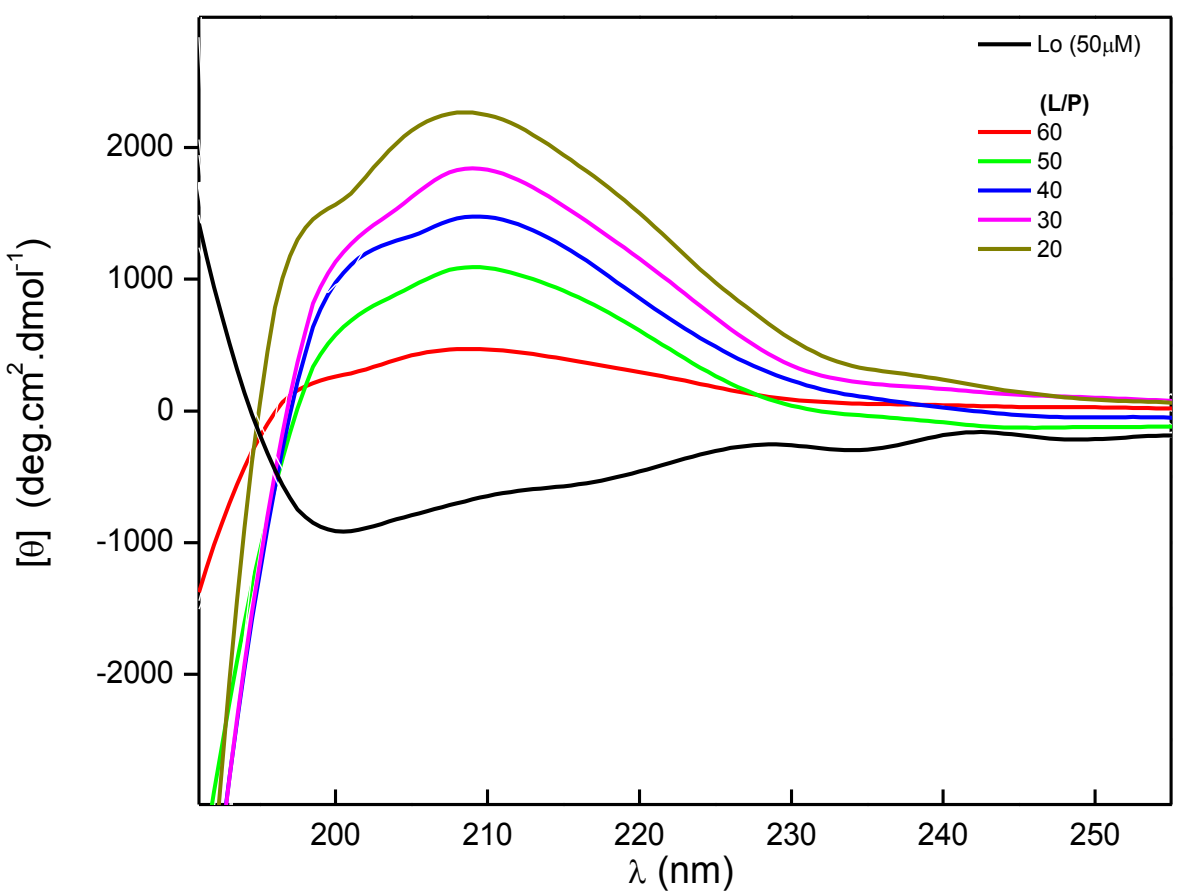

Figura 45: Espectros de CD do peptídeo Lo em meio aquoso $(50 \mu \mathrm{M})$ e na presença de lipossomos constituídos por DPPC, em diferentes razões molares (L/P), pH 7,0, obtidos conforme descrito em Materiais e Métodos.

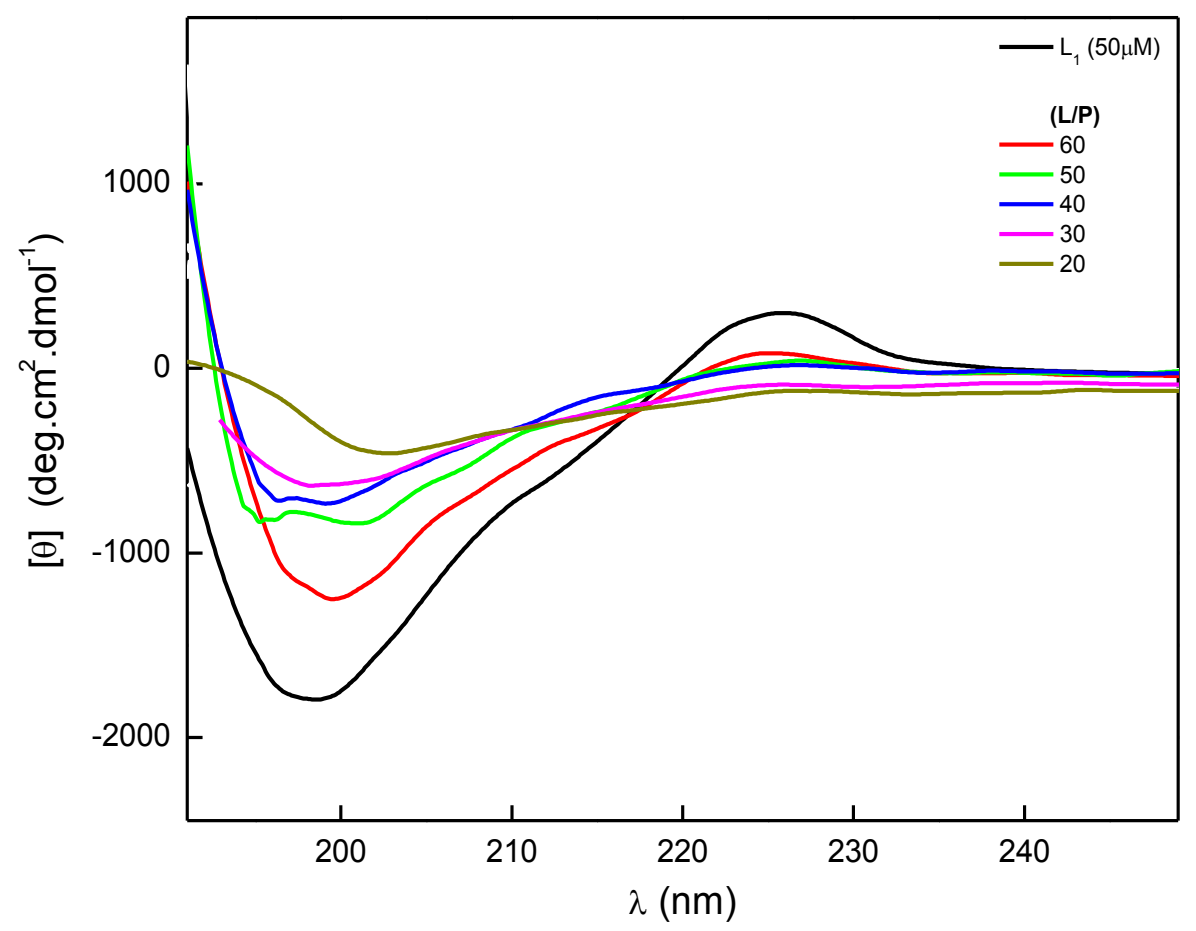

Figura 46: Espectros de $\mathrm{CD}$ do peptídeo $\mathrm{L}_{1}$ em meio aquoso $(50 \mu \mathrm{M})$ e após interagir com lipossomos constituídos por DPPC, em diferentes razões molares (L/P), pH 7,0, obtidos conforme descrito em Materiais e Métodos. 
Os peptídeos Lo e $\mathrm{L}_{1}$ também apresentaram mudanças conformacionais após interação com DPPC:Chol (9:1) (Figuras 47 e 48). Para Lo, a presença do lipídio causou deslocamento da banda negativa, passando de $207 \mathrm{~nm}$, em meio aquoso, para $215 \mathrm{~nm}$ (Figura 47); entretanto, nos dois meios encontrou-se não-ordenado. Já o peptídeo $\mathrm{L}_{1}$, em meio aquoso, apresenta estrutura ao acaso (Figura 48), conforme mencionado anteriormente. A adição de DPPC:Chol (9:1) provocou um deslocamento da banda negativa em $197 \mathrm{~nm}$ para $202 \mathrm{~nm}$ e desaparecimento da banda positiva em $224 \mathrm{~nm}$, provavelmente devido ao distanciamento entre os triptofanos (SFORÇA et al., 2005).

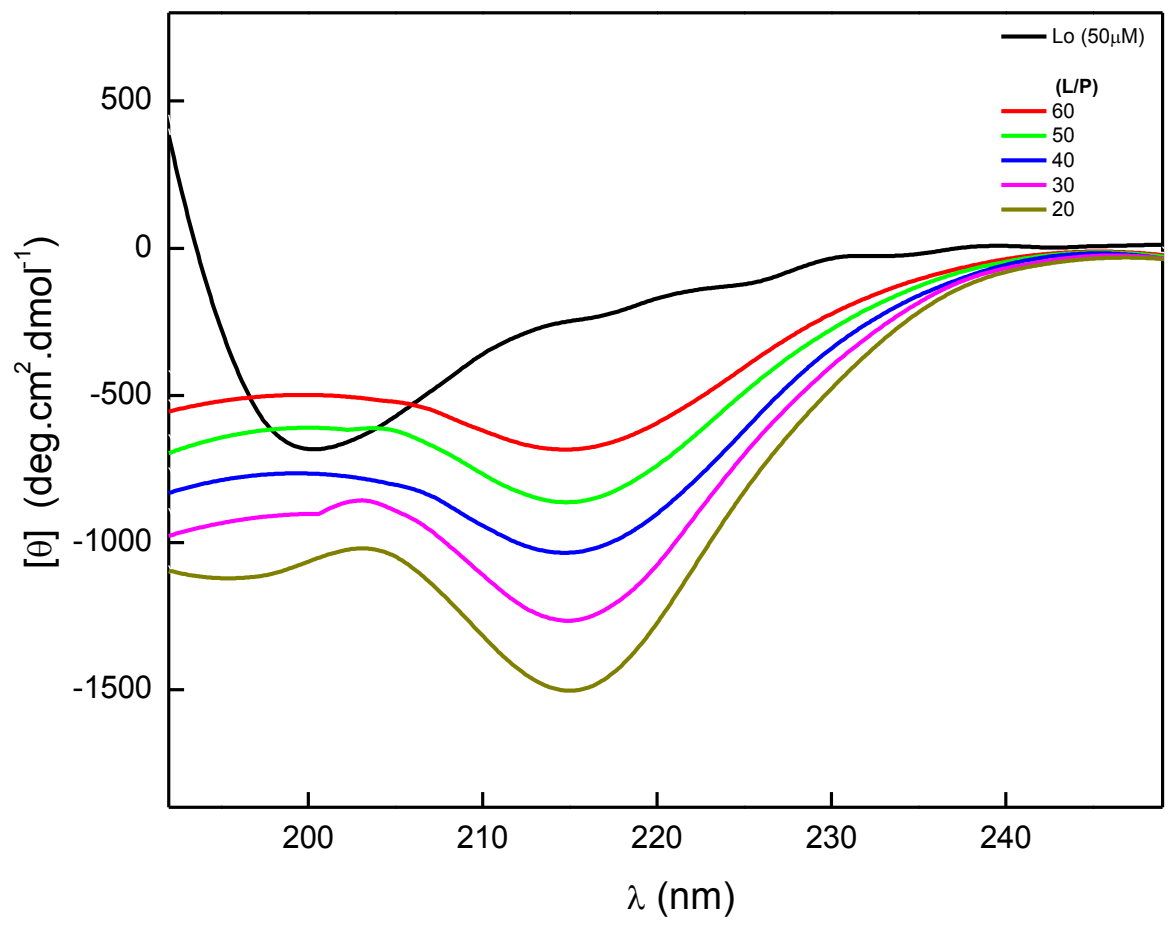

Figura 47: Espectros de CD do peptídeo Lo em meio aquoso $(50 \mu \mathrm{M})$ e após interagir com lipossomos constituídos por DPPC:Chol (9:1), em diferentes razões molares (L/P), pH 7,0, obtidos conforme descrito em Materiais e Métodos. 


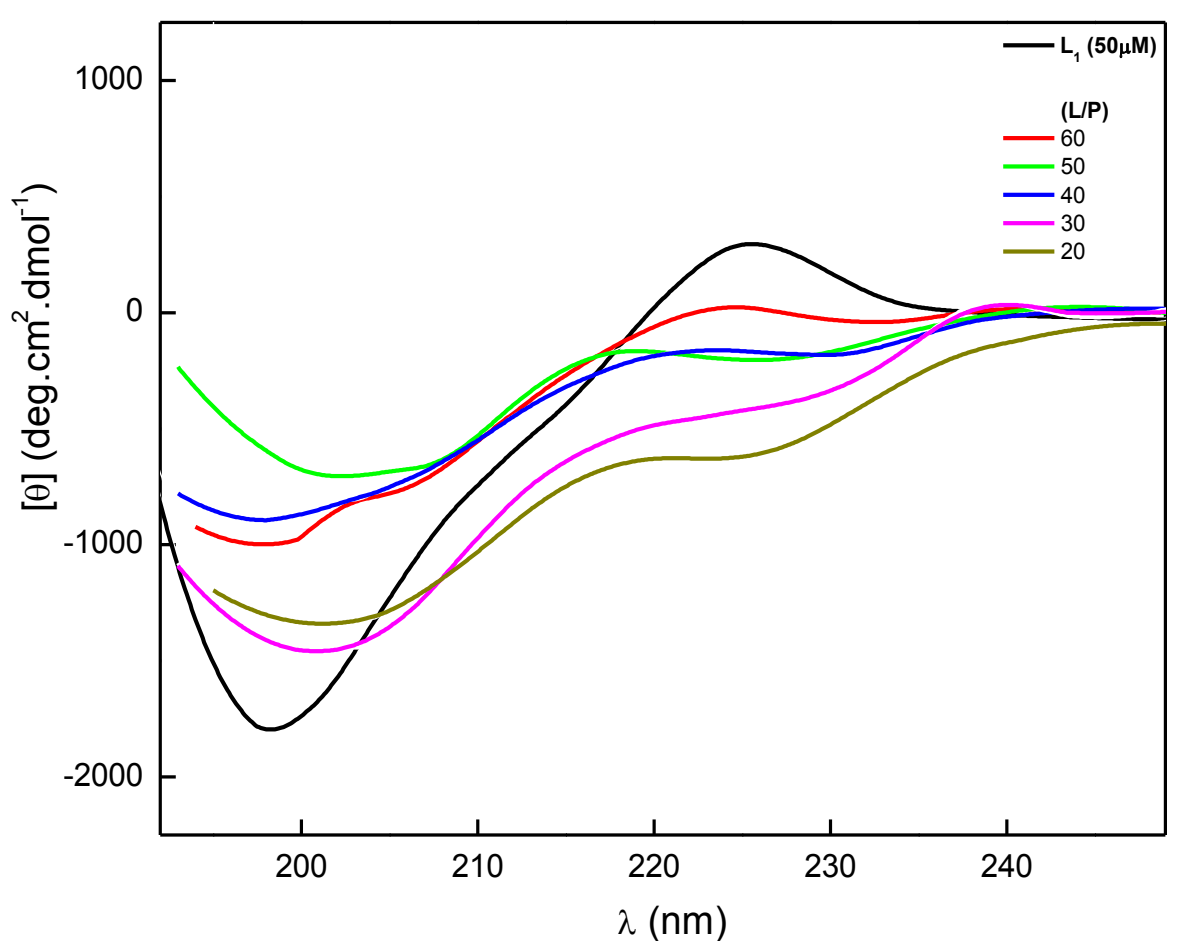

Figura 48: Espectros de $\mathrm{CD}$ do peptídeo $\mathrm{L}_{1}$ em meio aquoso $(50 \mu \mathrm{M})$ e após interagir com lipossomos constituídos por DPPC:Chol (9:1), em diferentes razões molares (L/P), pH 7,0, obtidos conforme descrito em Materiais e Métodos.

O peptídeo Lo, na presença de DPPC:DPPS (8:2), pH 7.0, também apresentou alteração conformacional. Em meio aquoso, conforme já mencionado, possui uma banda negativa em 207 nm, e após interação com DPPC:DPPS (8:2) apresentou uma ampla banda positiva ao redor de 203 nm (Figura 49); ambas conformações são não-ordenadas. Conforme o aumento da concentração de peptídeo (redução da razão L/P) não houve alteração na forma dos espectros, sugerindo não haver mais alteração conformacional.

A adição de DPPC:Chol (9:1) provocou alteração conformacional no peptídeo L1, apresenta um máximo em 193 nm e um mínimo em aproximadamente 219 nm, característico de conformação $\beta$-folha (Figura 50). Esta interação resultou provavelmente na separação dos resíduos de triptofano, identificada através do desaparecimento da banda em $224 \mathrm{~nm}$ (BARBOSA et al., 2011). Este efeito é concentração dependente, ou seja, ocorre alteração conformacional no peptídeo conforme o aumento da concentração de peptídeo. 


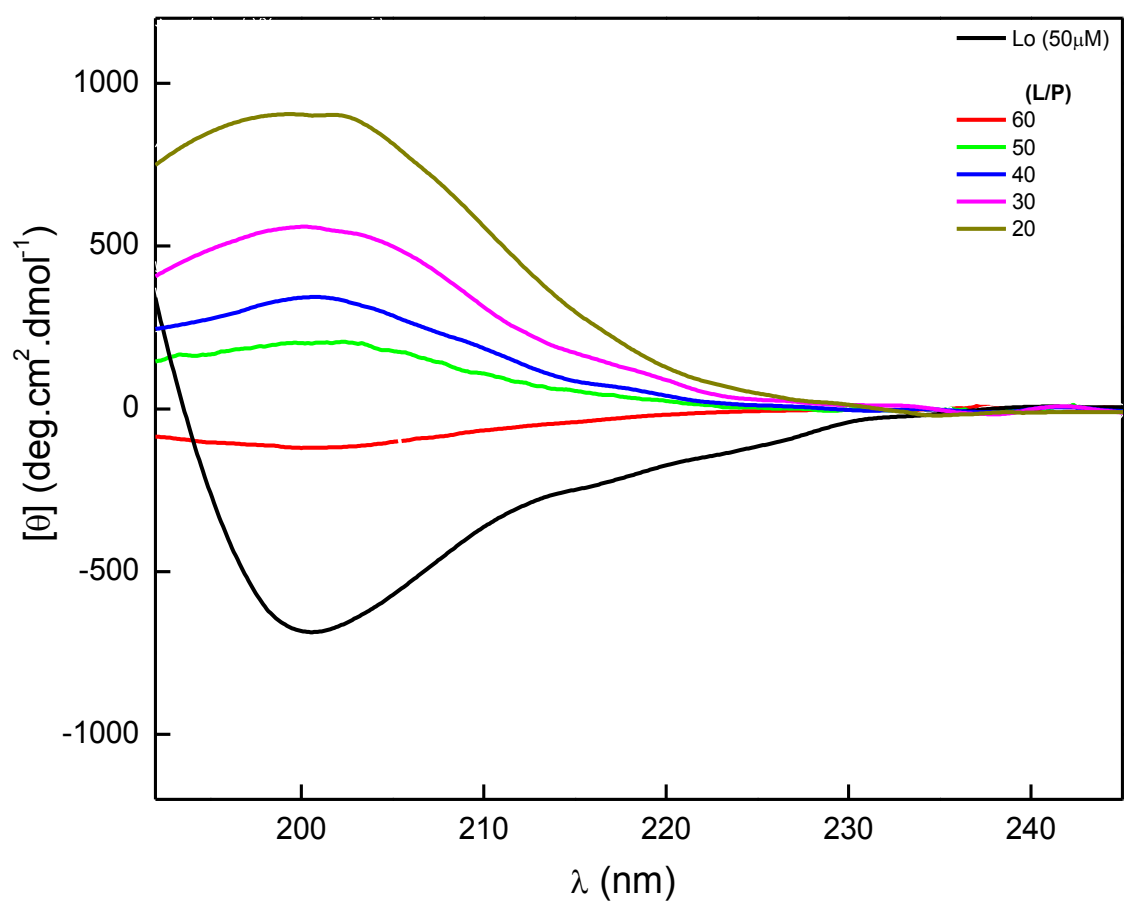

Figura 49: Espectros de CD do peptídeo Lo em meio aquoso $(50 \mu \mathrm{M})$ e após interagir com lipossomos constituídos por DPPC:DPPS (8:2), em diferentes razões molares (L/P), pH 7,0, obtidos conforme descrito em Materiais e Métodos.

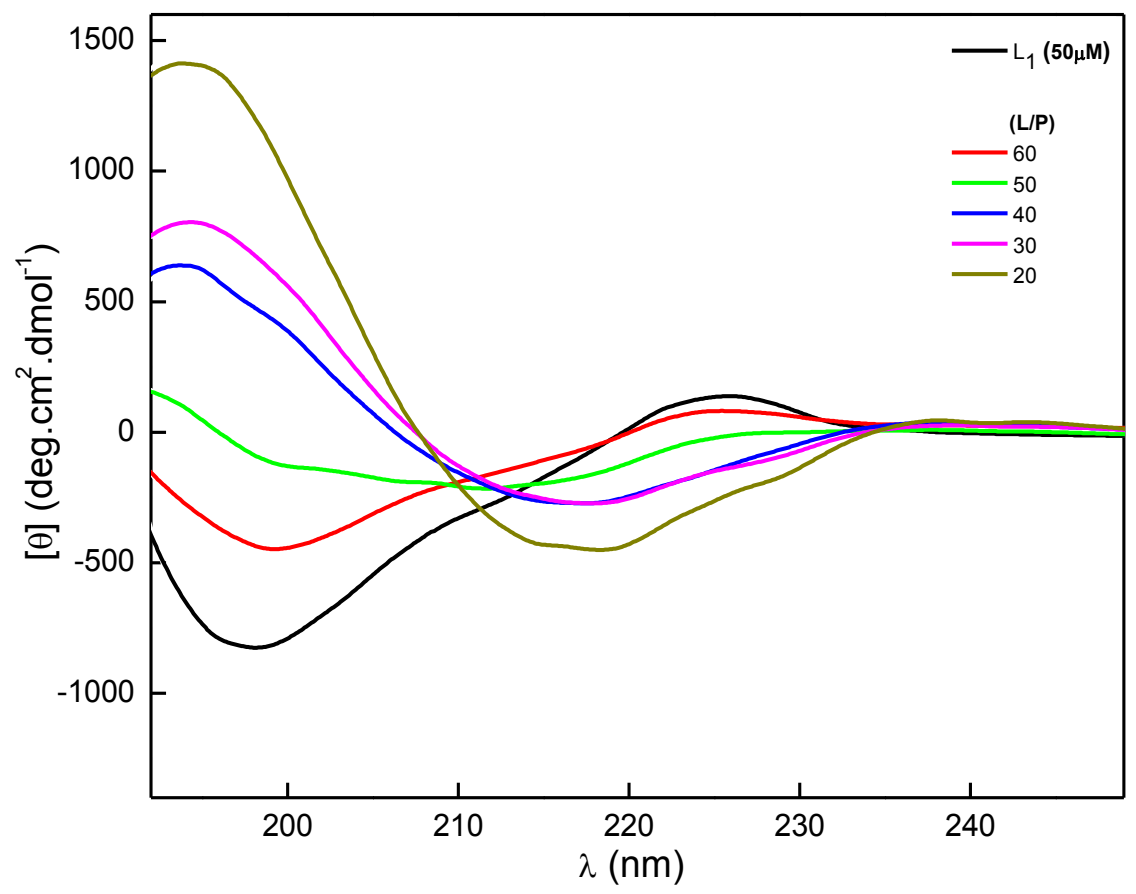

Figura 48: Espectros de $\mathrm{CD}$ do peptídeo $\mathrm{L}_{1}$ em meio aquoso $(50 \mu \mathrm{M})$ e após interagir com lipossomos constituídos por DPPC:DPPS (8:2), em diferentes razões molares (L/P), pH 7,0, obtidos conforme descrito em Materiais e Métodos. 
Portanto, Lo e $\mathrm{L}_{1}$ apresentaram mudanças conformacionais conforme a alteração da composição lipídica. A diferente curvatura da micela e do lipossomo não demonstrou interferir na atividade do peptídeo cíclico (Lo), no entanto, aparenta interferir na do peptídeo linear $\left(\mathrm{L}_{1}\right)$, pois este apresenta diferente conformação na presença de LPC e DPPC. A alteração conformacional muda a natureza anfipática da molécula, que por sua vez altera as propriedades físico-químicas da mesma (URUSHIBARA e HICKS, 2013). Isso demonstra que a restrição conformacional, devido à estrutura cíclica, é um importante requisito para a seletividade (CHEN e MARK, 2011), proporcionando estabilidade e menor entropia.

\subsubsection{Calorimetria diferencial de varredura (DSC)}

DSC é uma poderosa técnica termodinâmica que fornece informações sobre a natureza da interação lipídio-lipídio e lipídio-peptídeo (DAVE et al., 2005). A adsorção na superfície, inserção na membrana e ligação específica do peptídeo são frequentemente acompanhados por mudanças na energia do sistema, que pode ser convenientemente medida por esta técnica. Nesse estudo foram avaliadas as perturbações sofridas pelos lipídios, devido à presença dos peptídeos Lo e $\mathrm{L}_{1}$, separadamente, variando-se a temperatura à pressão constante.

O DPPC puro apresentou dois picos: um referente à temperatura de transição principal, Tm, em $41,1^{\circ} \mathrm{C}$, e outro referente à temperatura de pré-transição, em $32,1^{\circ} \mathrm{C}$ (Figura 50, Tabela 10 e 11), similar ao observado na literatura (OKORO, 2013). Estudos demonstram que a organização molecular da bicamada se altera conforme a variação da temperatura. Como observado, esse sistema formado por apenas um lipídio (DPPC), em temperatura abaixo da Tm a bicamada lipídica encontra-se ordenada, fase gel (So); acima da Tm a bicamada está fluida e desordenada, fase líquido-cristalina (Lc). Entretanto, o DPPC 
apresenta uma fase intermediária entre So e Lc, denominada ripple”. Essa fase é referente à pré-transição, e é assim denominada devido à forma ondulada que os lipídios se organizam.

A adição de quantidades crescentes do peptídeo Lo (redução da razão L/P) nos lipossomos constituídos por DPPC, Figura 50 e Tabela 10 (os parâmetros termodinâmicos da tabela 10 foram calculados à partir da Figura 50), não induziu mudanças significativas na temperatura de transição principal desse lipídio. Similar comportamento foi observado na presença do $\mathrm{L}_{1}$ (Figura 51 e Tabela 11).

Apesar da pré-transição do DPPC não ser visualizada no gráfico apresentado, devido ao seu tamanho reduzido, na presença de ambos os peptídeos (diminuição da razão molar $\mathrm{L} / \mathrm{P}$ ) ela variou de 32,1 para 33,5 e $33,3^{\circ} \mathrm{C}$, na presença de Lo e $\mathrm{L}_{1}$, respectivamente (Tabelas 10 e 11). Essa variação observada é consequência da rotação dos grupos cabeça do fosfolipídio ou mudança conformacional ocorrida na estrutura da bicamada lipídica, induzida pelo peptídeo presente na interface (BIRUSS et al., 2007). Similar comportamento foi observado ao interagir o peptídeo Melitina com lipossomos constituídos por DPPC. Neste estudo, a interação causou o desaparecimento do pico de pré-transição (OKORO, 2013).

Também houve redução da cooperatividade lipídica, $\Delta \mathbf{t}_{1 / 2}$, devido à presença dos peptídeos. Esse parâmetro corresponde a medida da largura do pico na meia altura. Esse efeito foi maior na presença do peptídeo Lo $\left(1,6-2,0{ }^{\circ} \mathrm{C}\right)$, que do $\mathrm{L}_{1}\left(1,6-1,8{ }^{\circ} \mathrm{C}\right)$, provavelmente devido à maior incorporação do peptídeo na cadeia hidrofóbica do lipídio DPPC, dificultando o empacotamento da bicamada (OKORO, 2013).

Através da integração do pico principal obteve-se a entalpia de transição de fase $(\Delta \mathrm{H})$. Ao avaliar os $\Delta \mathrm{Hs}$, obtidos nas diferentes razões molares $\mathrm{L} / \mathrm{P}$, foi observado que tanto Lo (Tabela 10) quanto $\mathrm{L}_{1}$ (Tabela 11) apresentaram grande variação no $\Delta \mathrm{H}$, sugerindo a inserção dos peptídeos na bicamada. Além disso, o calor absorvido durante a interação 
peptídeo-lipídio demonstra que o processo é endotérmico. Essa variação da entalpia foi maior na presença do peptídeo Lo que do $L_{1}$, chegando a 65,2 e 30,7 kcal/mol, respectivamente, sugerindo maior interação do Lo com a bicamada de DPPC. Nos estudos com micelas o peptídeo Lo também demonstrou maior interação com micelas de LPC, análogo ao DPPC (Tabela 8). Isso ocorreu porque esses miméticos de membrana apresentam carga líquida neutra, favorecendo interação hidrofóbica com o peptídeo cíclico, Lo.

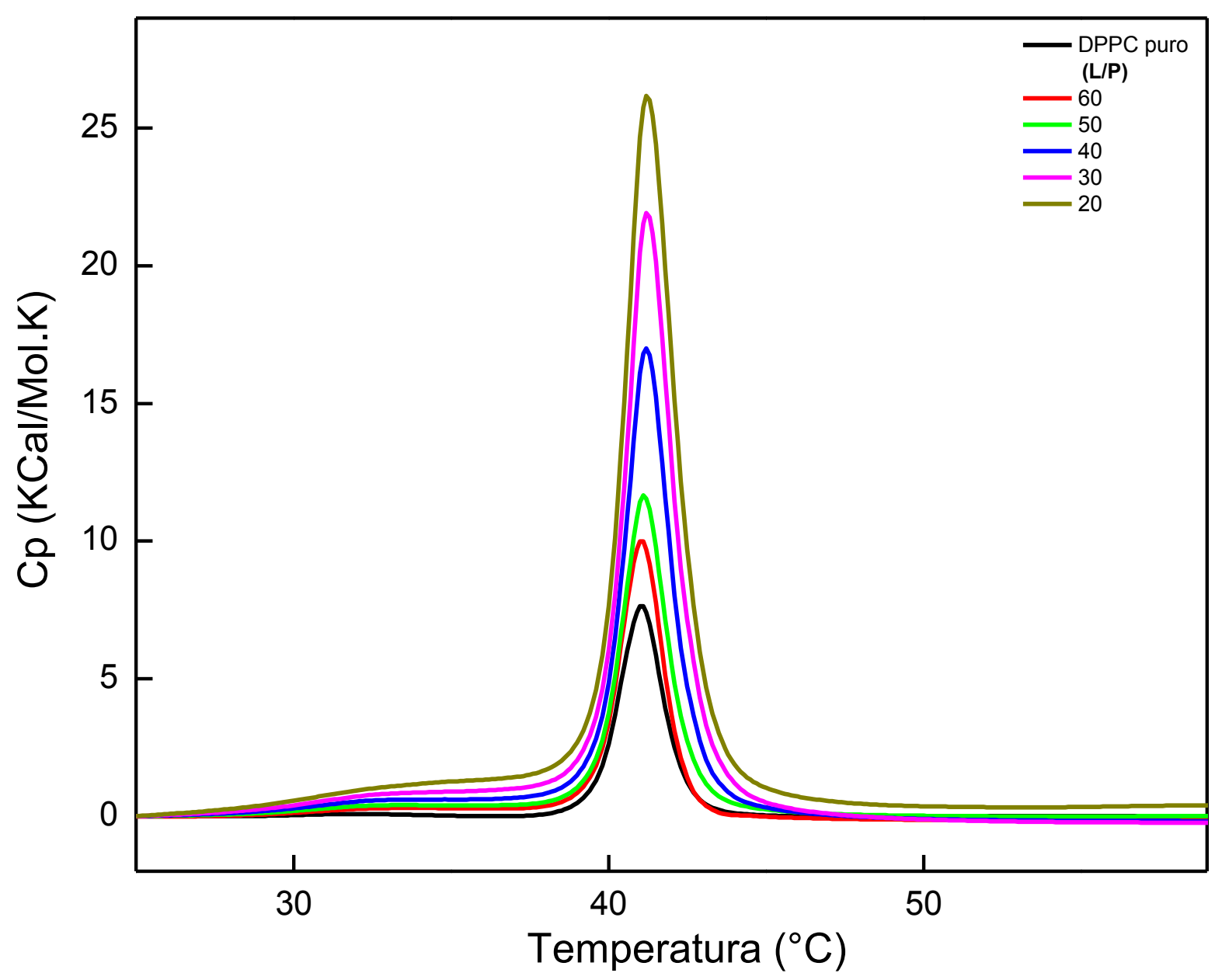

Figura 50: Termograma $\mathrm{Cp}(\mathrm{kcal} / \mathrm{K} . \mathrm{mol})$ vs. $\mathrm{T}\left({ }^{\circ} \mathrm{C}\right)$ para a interação do peptídeo Lo (em diferentes razões L/P) com lipossomos constituídos de DPPC (5 mg/mL). Os valores de Cp e $\mathrm{T}$ foram registrados utilizando-se o aparelho Nano-DSC II: Differential Scanning Calorimeter (CSC), conforme descrito em Materiais e Métodos. 


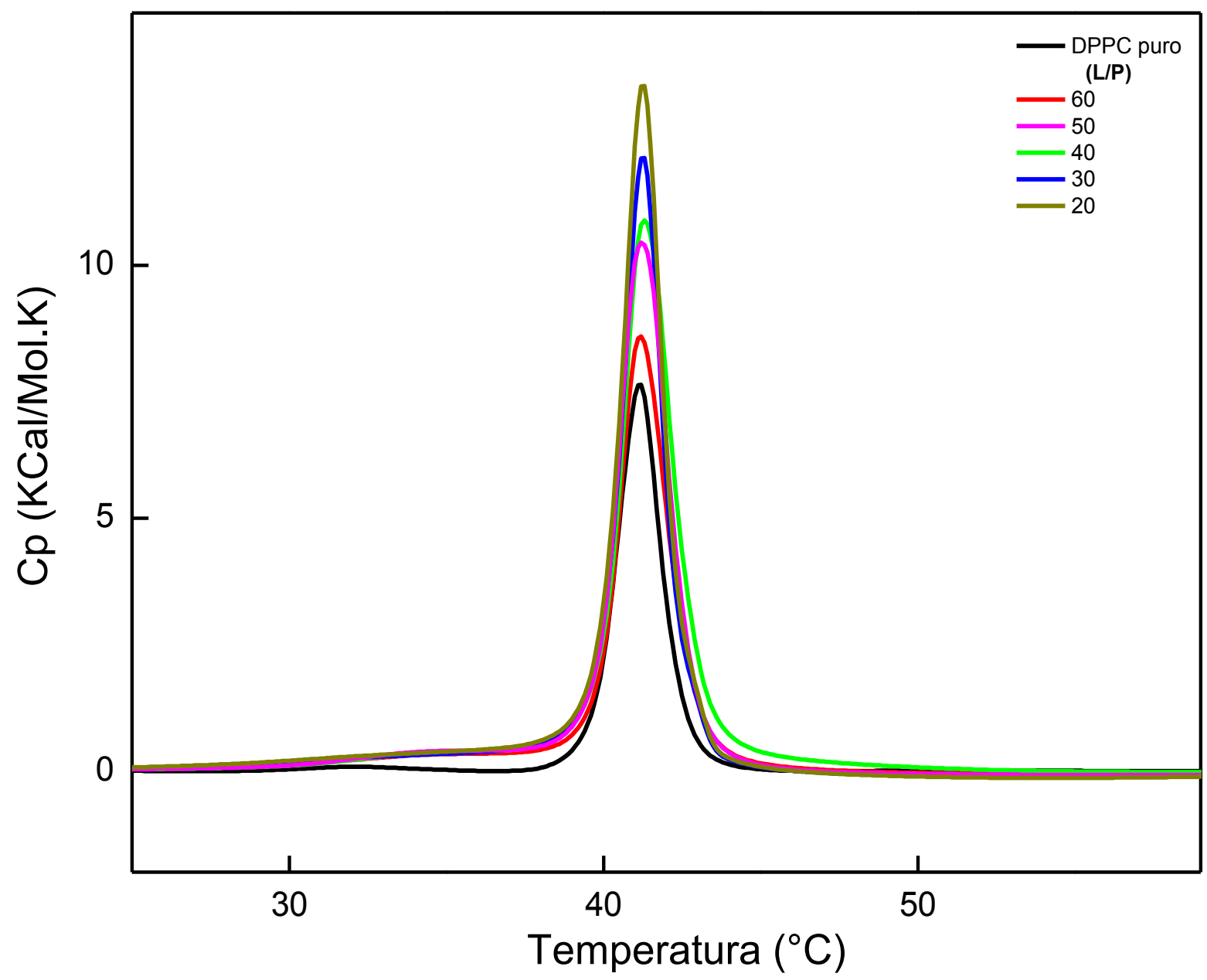

Figura 51: Termograma $\mathrm{Cp}(\mathrm{kcal} / \mathrm{K} . \mathrm{mol})$ vs. $\mathrm{T}\left({ }^{\circ} \mathrm{C}\right)$ para a interação do peptídeo $\mathrm{L}_{1}$ (em diferentes razões L/P) com lipossomos constituídos de DPPC (5 mg/mL). Os valores de Cp e $\mathrm{T}$ foram registrados utilizando-se o aparelho Nano-DSC II: Differential Scanning Calorimeter (CSC), conforme descrito em Materiais e Métodos. 
TABELA 10: Parâmetros termodinâmicos determinados por DSC para a interação do peptídeo Lo com lipossomos constituídos de DPPC na concentração de $5 \mathrm{mg} / \mathrm{mL}$, determinados conforme descrito em Materiais e Métodos.

\begin{tabular}{|c|c|c|c|}
\hline$(\mathbf{L} / \mathbf{P})$ & $\begin{array}{c}\Delta \mathbf{H} \\
(\mathrm{kcal} / \mathrm{mol})\end{array}$ & $\begin{array}{l}\mathrm{Tm} \\
\left({ }^{\circ} \mathrm{C}\right)\end{array}$ & $\Delta \mathbf{t}_{1 / 2}$ \\
\hline \multirow{2}{*}{ DPPC } & $0,9^{*}$ & $32,1^{*}$ & - \\
\hline & 14,9 & 41,1 & 1,6 \\
\hline \multirow[b]{2}{*}{60} & $1,9 *$ & $32,3^{*}$ & - \\
\hline & 23,7 & 41,2 & 1,7 \\
\hline \multirow[b]{2}{*}{50} & $2,3^{*}$ & $32,6^{*}$ & - \\
\hline & 28,9 & 41,2 & 1,8 \\
\hline \multirow[b]{2}{*}{40} & $3,9 *$ & $32,8^{*}$ & - \\
\hline & 43,1 & 41,3 & 1,9 \\
\hline \multirow[b]{2}{*}{30} & $4,5^{*}$ & $33,1^{*}$ & - \\
\hline & 57,6 & 41,3 & 1,9 \\
\hline \multirow[b]{2}{*}{20} & $4,7 *$ & $33,5^{*}$ & - \\
\hline & 65,2 & 41,4 & 2,0 \\
\hline
\end{tabular}


TABELA 11: Parâmetros termodinâmicos determinados por DSC para a interação do peptídeo $\mathrm{L}_{1}$ com lipossomos constituídos de DPPC na concentração de $5 \mathrm{mg} / \mathrm{mL}$, determinados conforme descrito em Materiais e Métodos.

\begin{tabular}{|c|c|c|c|}
\hline$(\mathbf{L} / \mathbf{P})$ & $\begin{array}{c}\Delta \mathbf{H} \\
\text { (kcal/mol) }\end{array}$ & $\begin{array}{l}\mathrm{Tm} \\
\left({ }^{\circ} \mathrm{C}\right)\end{array}$ & $\Delta \mathbf{t}_{1 / 2}$ \\
\hline \multirow{2}{*}{ DPPC } & $0,9^{*}$ & $32,1^{*}$ & - \\
\hline & 14,9 & 41,1 & 1,6 \\
\hline \multirow{2}{*}{60} & $1,41^{*}$ & $32,3 *$ & - \\
\hline & 22,9 & 41,3 & 1,6 \\
\hline \multirow[b]{2}{*}{50} & $2,4^{*}$ & $32,4 *$ & - \\
\hline & 27,4 & 41,2 & 1,8 \\
\hline \multirow{2}{*}{40} & $3,6^{*}$ & $32,5^{*}$ & - \\
\hline & 28,2 & 41,4 & 1,8 \\
\hline \multirow{2}{*}{30} & $5,7 *$ & $32,9 *$ & - \\
\hline & 29,9 & 41,3 & 1,5 \\
\hline \multirow[b]{2}{*}{20} & $6,1^{*}$ & $33,3^{*}$ & - \\
\hline & 30,7 & 41,2 & 1,7 \\
\hline
\end{tabular}

Foi observado que na presença de colesterol (Figuras 52 e 53) o termograma de DPPC perdeu a pré-transição $\left(32,1^{\circ} \mathrm{C}\right)$. Isso ocorre porque o colesterol apresenta pequena cabeça polar, uma hidroxila, e ao se inserir entre as fosfatidilcolinas reduz a área interfacial e, consequentemente, o nível de hidratação da bicamada (KARMAKAR et al., 2006; BIRUSS et al., 2007).

Nessa concentração de colesterol utilizada (razão molar 9:1) não houve formação de domínios lipídicos, apresentando um único pico. Entretanto, o colesterol causou redução no Tm do DPPC, variando de 41,1 para 40,6 ${ }^{\circ} \mathrm{C}$ (MULLEN e ELHANEY, 1997). Além disso, também houve redução da entalpia (de 14,9 para $3,2 \mathrm{kcal} / \mathrm{mol}$ ), indicando desestabilização 
da bicamada devido a alterações no empacotamento.

A adição de quantidades crescentes do peptídeo Lo (redução da razão L/P) nos lipossomos constituídos por DPPC:Chol (9:1) (Figura 52, Tabela 12) não induziu mudanças significativas na temperatura de transição principal dessa mistura lipídica. Similar comportamento foi observado na presença do $\mathrm{L}_{1}$ (Figura 53, Tabela 13).

Nenhuma redução na cooperatividade da mistura lipídica foi observada, $\Delta \mathbf{t}_{\mathbf{1} / 2}$, devido à presença dos peptídeos, tanto para o peptídeo Lo $\left(0,6-0,8{ }^{\circ} \mathrm{C}\right)$, quanto para $\mathrm{L}_{1}(0,6-0,7$ ${ }^{\circ} \mathrm{C}$ ), sugerindo que ambos os peptídeos estão apenas adsorvidos na interface da bicamada (OKORO, 2013).

Ao avaliar o $\Delta \mathrm{H}$, os resultados demonstram que a diminuição da razão molar L/P (aumento da concentração de peptídeo) causou um aumento na entalpia de ambos os peptídeos. Entretanto, esse efeito é um pouco maior na presença do $\mathrm{L}_{1}$ que do Lo (Tabelas 12 e 13), chegando a 8,1 e $9,2 \mathrm{kcal} / \mathrm{mol}$, respectivamente, sugerindo maior interação do peptídeo Lo.

Os resultados demonstram que o colesterol reduziu a fluidez, dificultando a interação de ambos os peptídeos com o lipossomo constituído por DPPC:Chol (9:1). Entretanto, o grupo hidroxila do colesterol, presente na interface (VANEGAS et al., 2012), favoreceu maior adsorção do peptídeo linear $\left(\mathrm{L}_{1}\right)$, devido interação eletrostática. $\mathrm{O}$ mesmo resultado foi observado no estudo com monocamada. 


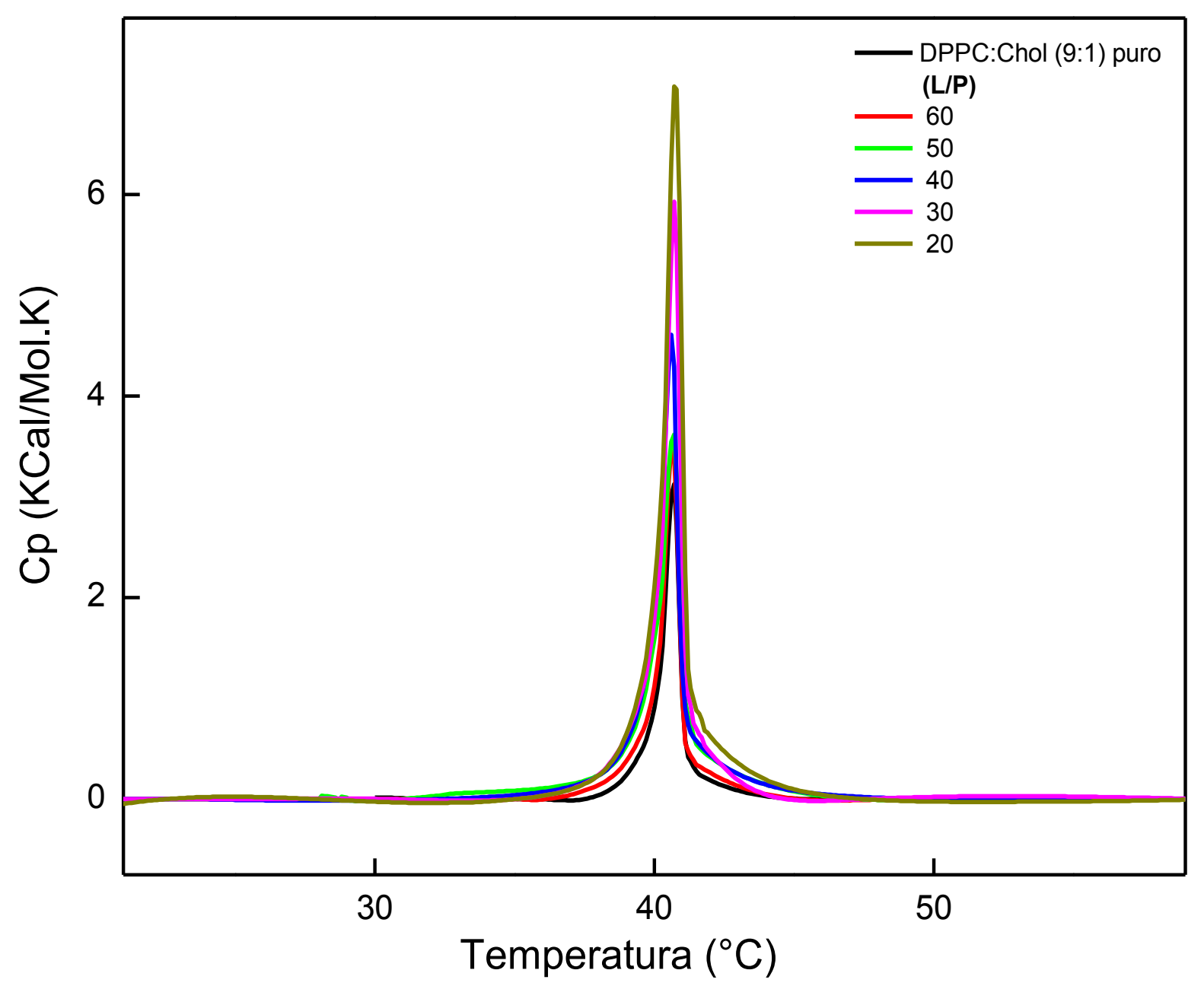

Figura 52: Termograma $\mathrm{Cp}(\mathrm{kcal} / \mathrm{K} . \mathrm{mol}) v s . \mathrm{T}\left({ }^{\circ} \mathrm{C}\right)$ para a interação do peptídeo $\mathrm{L}_{1}$ (em diferentes conecntrações) com lipossomos constituídos de DPPC:Chol (9:1), $5 \mathrm{mg} / \mathrm{mL}$. Os valores de $\mathrm{Cp}$ e $\mathrm{T}$ foram registrados utilizando-se o aparelho Nano-DSC II: Differential Scanning Calorimeter (CSC), conforme descrito em Materiais e Métodos. 


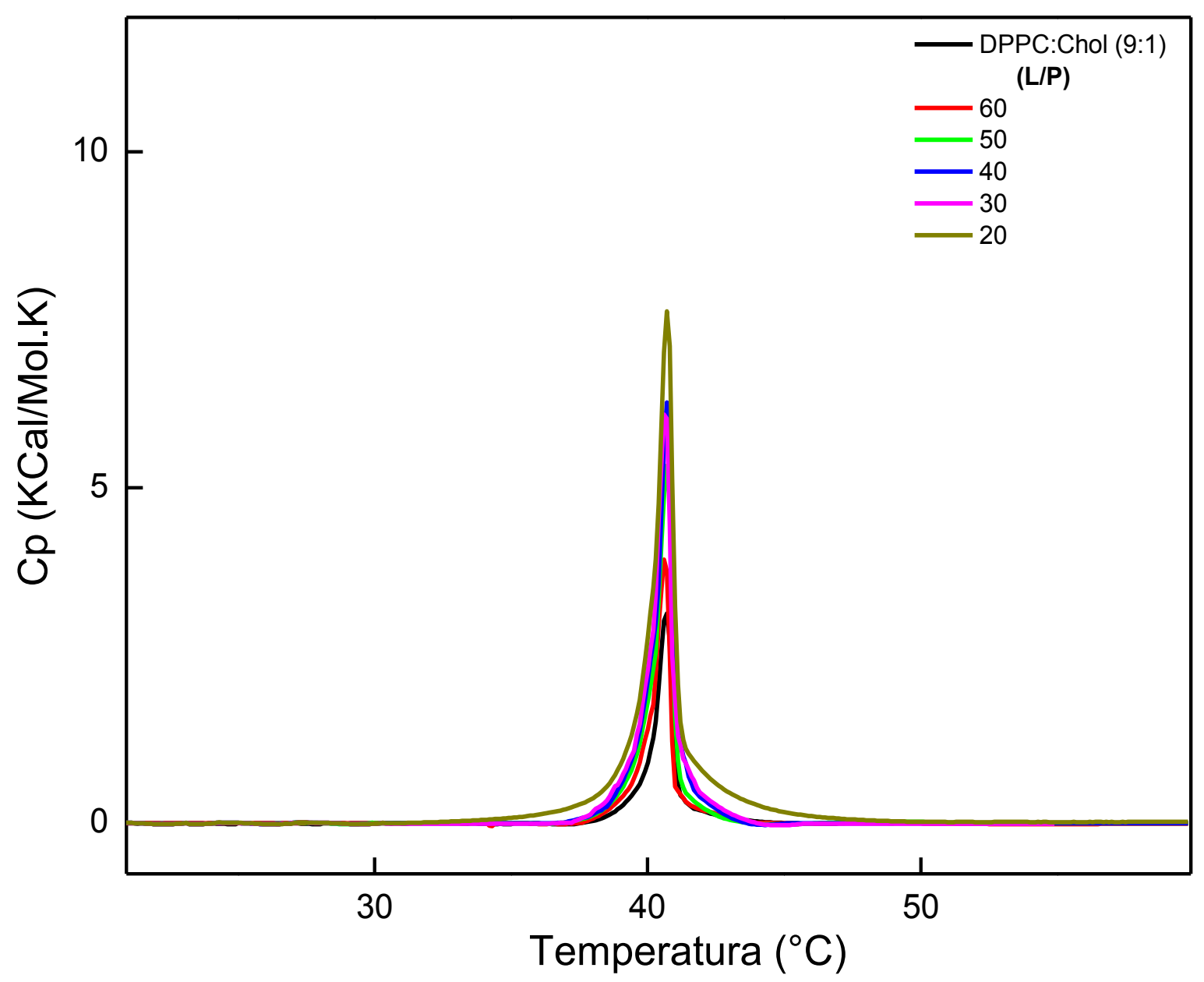

Figura 53: Termograma $\mathrm{Cp}(\mathrm{kcal} / \mathrm{K} . \mathrm{mol})$ vs. $\mathrm{T}\left({ }^{\circ} \mathrm{C}\right)$ para a interação do peptídeo $\mathrm{L}_{1}$ (em diferentes concentrações) com lipossomos constituídos de DPPC:Chol (9:1), $5 \mathrm{mg} / \mathrm{mL}$. Os valores de $\mathrm{Cp}$ e $\mathrm{T}$ foram registrados utilizando-se o aparelho Nano-DSC II: Differential Scanning Calorimeter (CSC), conforme descrito em Materiais e Métodos. 
TABELA 12: Parâmetros termodinâmicos determinados por DSC para a interação do peptídeo Lo com lipossomos constituídos de DPPC:Chol (9:1) na concentração de $5 \mathrm{mg} / \mathrm{mL}$, determinados conforme descrito em Materiais e Métodos.

\begin{tabular}{cccc}
\hline (L/P) & $\begin{array}{c}\Delta \mathbf{H} \\
(\mathbf{k c a l} / \mathbf{m o l})\end{array}$ & $\begin{array}{c}\mathbf{T m} \\
\left({ }^{\mathbf{0}} \mathbf{C}\right)\end{array}$ & $\Delta \mathbf{t}_{\mathbf{1} / \mathbf{2}}$ \\
\hline DPPC:Chol (9:1) & 3,2 & 40,6 & 0,6 \\
60 & 3,8 & 40,6 & 0,6 \\
50 & 5,2 & 40,6 & 0,9 \\
40 & 5,6 & 40,5 & 0,8 \\
30 & 6,5 & 40,6 & 0,8 \\
20 & 8,1 & 40,7 & 0,8 \\
\hline
\end{tabular}

TABELA 13: Parâmetros termodinâmicos determinados por DSC para a interação do peptídeo $\mathrm{L}_{1}$ com lipossomos constituídos de DPPC:Chol (9:1) na concentração de $5 \mathrm{mg} / \mathrm{mL}$, determinados conforme descrito em Materiais e Métodos.

\begin{tabular}{cccc}
\hline (L/P) & $\begin{array}{c}\Delta \mathbf{H} \\
(\mathbf{k c a l} / \mathbf{m o l})\end{array}$ & $\begin{array}{c}\mathbf{T m} \\
\left({ }^{\mathbf{0}} \mathbf{C}\right)\end{array}$ & $\Delta \mathbf{t}_{\mathbf{1} / \mathbf{2}}$ \\
\hline DPPC:Chol (9:1) & 3,2 & 40,6 & 0,6 \\
60 & 3,9 & 40,5 & 0,4 \\
50 & 5,6 & 40,6 & 0,6 \\
40 & 6,9 & 40,6 & 0,6 \\
30 & 7,0 & 40,6 & 0,7 \\
20 & 9,2 & 40,6 & 0,7 \\
\hline
\end{tabular}


A mistura DPPC:DPPS (8:2) é composta por dois lipídios que possuem diferentes Tm, 41 e $53{ }^{\circ} \mathrm{C}$, respectivamente (SERGELIUS et al., 2013; OKORO, 2013). Neste estudo foi utilizado DPPS na razão molar 8:2, obtendo-se um pico uniforme, sem formação de domínios.

A presença do DPPS resultou na perda da pré-transição do lipídio DPPC, pois os lipídios de cabeça pequena são pouco hidratados, ou seja, alto $\operatorname{Tm}\left(\mathrm{Tm}>45^{\circ} \mathrm{C}\right)$. A mistura DPPC:DPPS (8:2) causou uma significativa redução da área interfacial, reduzindo a hidratação (KARMAKAR et al., 2006). Além disso, a transição principal do DPPC (41,3 $\left.{ }^{\circ} \mathrm{C}\right)$ sofreu pequeno deslocamento $\left(41,5^{\circ} \mathrm{C}\right)$, devido à presença do DPPS.

Conforme observado na Figura 54 e Tabela 14, a presença do peptídeo Lo nos lipossomos constituídos por DPPC:DPPS (8:2) não induz novas transições de fase. Similar comportamento foi observado na presença do $\mathrm{L}_{1}$ (Figura 55 e Tabela 15).

Houve redução da cooperatividade da mistura lipídica, $\Delta \mathbf{t}_{1 / 2}$, na presença de ambos os peptídeos, devido ao alargamento do pico. Essa redução foi maior na presença do peptídeo Lo $\left(1,1-1,7^{\circ} \mathrm{C}\right)$, que do $\mathrm{L}_{1}\left(1,1-1,2^{\circ} \mathrm{C}\right)$, sugerindo maior interação do Lo com a bicamada (OKORO, 2013).

Os resultados demonstram que conforme a diminuição da razão molar L/P (aumento da concentração de peptídeo) houve um aumento na variação da entalpia, tanto na presença do Lo, quanto na do $\mathrm{L}_{1}$. Entretanto, esse efeito é maior na presença do $\mathrm{L}_{1}$ que do Lo (Tabelas 14 e 15), chegando a 18,3 e 27,4 kcal/mol, respectivamente.

Portanto, esses resultados sugerem, conforme já esperado, maior interação do peptídeo $\mathrm{L}_{1}$ nos lipossomos constituídos por DPPC:DPPS (8:2). Isso ocorreu, provavelmente, devido à presença de cargas terminais no peptídeo linear, $\mathrm{L}_{1}$, que favoreceu a interação eletrostática com o lipossomo aniônico. Resultados similares foram observados nos estudos com micelas aniônicas de SDS (Tabela 8) e com monocamada de Langmuir. 


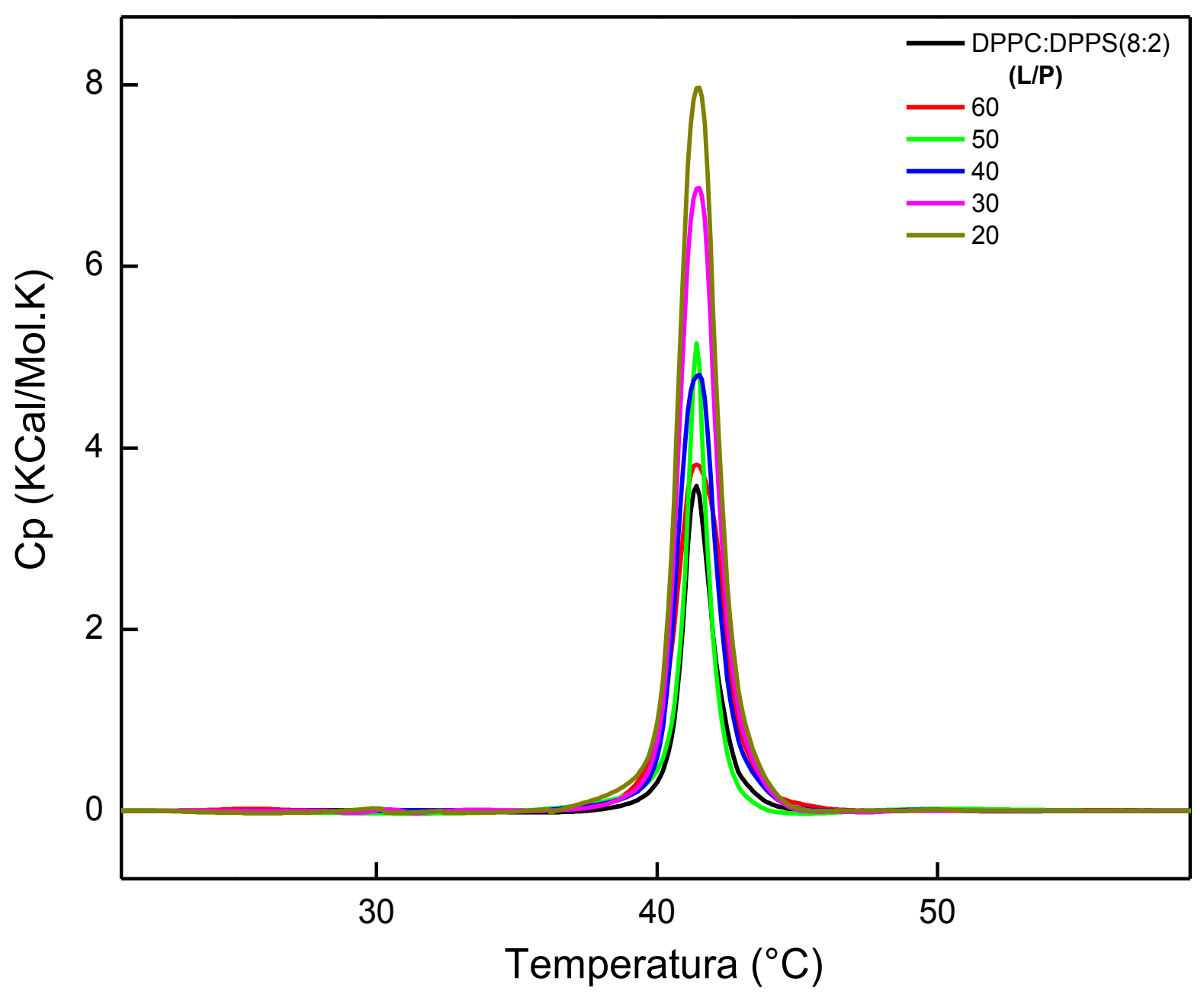

Figura 54: Termograma $\mathrm{Cp}(\mathrm{kcal} / \mathrm{K} . \mathrm{mol}) v s . \mathrm{T}\left({ }^{\circ} \mathrm{C}\right)$ para a interação do peptídeo Lo (em diferentes concentrações) com lipossomos constituídos de DPPC:DPPS (8:2), $5 \mathrm{mg} / \mathrm{mL}$. Os valores de $\mathrm{Cp}$ e $\mathrm{T}$ foram registrados utilizando-se o aparelho Nano-DSC II: Differential Scanning Calorimeter (CSC), conforme descrito em Materiais e Métodos. 


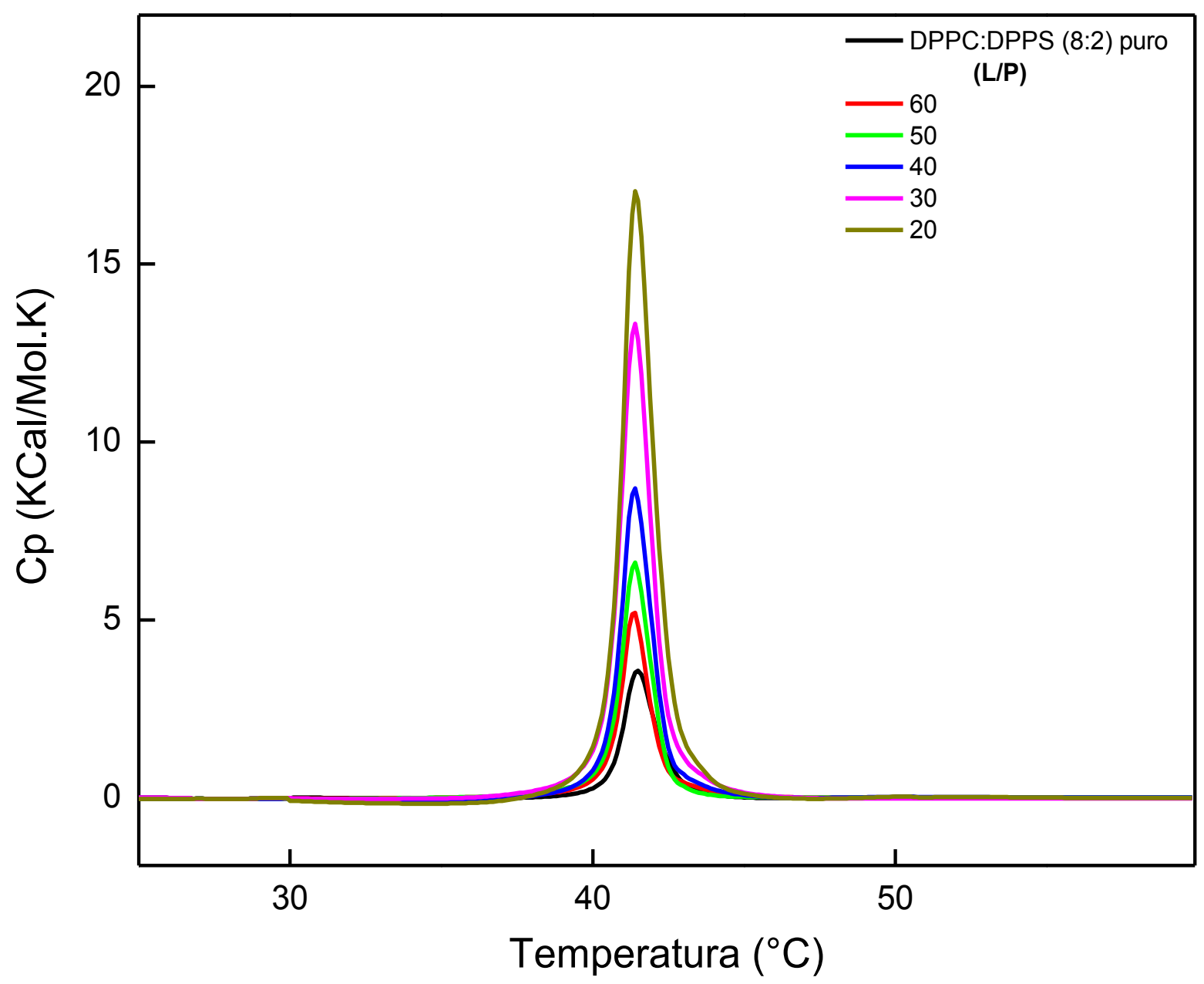

Figura 55: Termograma $\mathrm{Cp}(\mathrm{kcal} / \mathrm{K} . \mathrm{mol})$ vs. $\mathrm{T}\left({ }^{\circ} \mathrm{C}\right)$ para a interação do peptídeo $\mathrm{L}_{1}$ (em diferentes concentrações) com lipossomos constituídos de DPPC:DPPS (8:2), $5 \mathrm{mg} / \mathrm{mL}$. Os valores de $\mathrm{Cp}$ e $\mathrm{T}$ foram registrados utilizando-se o aparelho Nano-DSC II: Differential Scanning Calorimeter (CSC), conforme descrito em Materiais e Métodos. 
TABELA 14: Parâmetros termodinâmicos determinados por DSC para a interação do peptídeo $\mathrm{L}_{1}$ com lipossomos constituídos de DPPC:DPPS (8:2) na concentração de 5 $\mathrm{mg} / \mathrm{mL}$, determinados conforme descrito em Materiais e Métodos.

\begin{tabular}{cccc}
\hline (L/P) & $\begin{array}{c}\Delta \mathbf{H} \\
(\mathbf{k c a l} / \mathbf{m o l})\end{array}$ & $\begin{array}{c}\mathbf{T m} \\
\left({ }^{\mathbf{0}} \mathbf{C}\right)\end{array}$ & $\Delta \mathbf{t}_{\mathbf{1} / \mathbf{2}}$ \\
\hline DPPC:DPPS (8:2) & 6,5 & 41,5 & 1,1 \\
60 & 10,9 & 41,5 & 1,1 \\
50 & 7,9 & 41,4 & 1,2 \\
40 & 11,2 & 41,4 & 1,2 \\
30 & 15,5 & 41,5 & 1,2 \\
20 & 18,3 & 41,5 & 1,2 \\
\hline
\end{tabular}

TABELA 15: Parâmetros termodinâmicos determinados por DSC para a interação do peptídeo $\mathrm{L}_{1}$ com lipossomos constituídos de DPPC:DPPS (8:2) na concentração de 5 $\mathrm{mg} / \mathrm{mL}$, determinados conforme descrito em Materiais e Métodos.

\begin{tabular}{cccc}
\hline (L/P) & $\begin{array}{c}\Delta \mathbf{H} \\
(\mathbf{k c a l} / \mathbf{m o l})\end{array}$ & $\begin{array}{c}\mathbf{T m} \\
\left({ }^{\mathbf{0}} \mathbf{C}\right)\end{array}$ & $\Delta \mathbf{t}_{\mathbf{1} / \mathbf{2}}$ \\
\hline DPPC:DPPS (8:2) & 6,5 & 41,5 & 1,1 \\
60 & 8,3 & 41,4 & 1,7 \\
50 & 10,8 & 41,4 & 1,6 \\
40 & 14,8 & 41,4 & 1,4 \\
30 & 19,4 & 41,4 & 1,6 \\
20 & 27,4 & 41,5 & 1,7 \\
\hline
\end{tabular}

Em todos os meios estudados houve um aumento progressivo da capacidade calorífica na transição de fase, conforme o aumento da concentração de peptídeo no meio. Isso ocorreu, principalmente, devido às variações da cooperatividade de um grande número de moléculas de lipídio, causado pela inserção do peptídeo na bicamada (OKORO, 2013). 


\section{Conclusões}

O método de síntese, Fmoc/tBu, foi adequado e possibilitou a obtenção do peptídeo linear, com bom rendimento. A ciclização utilizada permitiu a obtenção da Labaditina (Lo). A purificação dos peptídeos foi eficiente, obtendo-se os materiais com pureza acima de $95 \%$.

A interação peptídeo-mimético de membrana foi realizada utilizando diferentes técnicas. Através dos estudos com monocamada de Langmuir foi possível observar que ambos os peptídeos apresentam atividade superficial em meio aquoso, ou seja, ocorre migração para a interface ar-água conforme o aumento da compressão.

Além disso, os estudos em monocamada de DPPC demonstraram que peptídeo Lo tem maior afinidade pela monocamada à baixa pressão superficial, enquanto $\mathrm{L}_{1} \mathrm{em}$ alta pressão. Este resultado, muito provavelmente, está relacionado com a conformação de ambas as estruturas dos peptídeos, cíclica e linear. O peptídeo linear deve ocupar menor área, e, por tal motivo, ser capaz de permanecer incorporado ao filme, mesmo ao longo da compressão. Já a estrutura cíclica pode ter sido expulsa por ocupar maior área. Portanto, esses resultados sugerem que a adsorção e/ou inserção do peptídeo Lo em monocamada de DPPC diminui em monocamadas mais compactas.

Através da isoterma $\pi$-A com DPPC:Chol (9:1), na ausência de peptídeo, foi possível constatar um aumento na compactação da monocamada, causado pelo colesterol. Isso foi identificado através da redução da área mínima por molécula do DPPC (46 $\mathrm{A}^{2} /$ moléc.). Não foi observada atividade superficial induzida pelo peptídeo Lo nessa faixa de concentração analisada, possivelmente devido à maior compactação. Já $\mathrm{L}_{1}$ foi adsorvido na monocamada à partir de 0,059 $\mu \mathrm{M}$. Nas isotermas $\pi$-A de DPPC:Chol (9:1), o peptídeo $\mathrm{L}_{1}$ apresentou maior afinidade que o Lo, entretanto a diferença não é grande. Isso ocorre, provavelmente, porque os anéis hidrofóbicos do colesterol se inserem entre as cadeias 
apolares, causando enrijecimento da monocamada, diminuindo a fluidez. Sobretudo, o grupo hidroxila do colesterol está posicionado na interface, favorecendo a interação eletrostática com o $\mathrm{L}_{1}$.

A monocamada de DPPC:DPPS (8:2) é mais compactada do que a de DPPC puro. Foi observado maior incorporação do peptídeo $\mathrm{L}_{1}$ que do Lo, possivelmente devido à condensação das cadeias hidrofóbicas, aumento da densidade da membrana e ao caráter aniônico do DPPS, favorecendo a interação eletrostática. Isso confirma que o peptídeo Lo tem menor afinidade por membrana compactada, e também aniônica.

Portanto, alguns fatores dirigem esse processo de adsorção, principalmente conformação e hidrofobicidade. A diferença estrutural dos peptídeos Lo e $\mathrm{L}_{1}$, cíclica e linear, respectivamente, confere diferentes hidrofobicidades, contribui para a conformação.

Nos estudos com micelas foi observada a migração dos aminoácidos triptofanos para um ambiente mais apolar. Em micela aniônica, SDS, isso foi maior na presença do peptídeo $\mathrm{L}_{1}$, e em LPC a migração foi maior na presença do Lo. Através da supressão da fluorescência, os resultados demostraram que os resíduos de triptofano do peptídeo $\mathrm{L}_{1}$ (Ksv =1,8) estão menos expostos em SDS, portanto o peptídeo Lo $(\mathrm{Ksv}=6,1)$ está localizado mais próximo à região da interface que o $\mathrm{L}_{1}$. Já em micelas de LPC os resultados demonstraram que os resíduos de triptofano do peptídeo Lo $(\mathrm{Ksv}=3,4)$ estão mais inseridos na micela que os do $\mathrm{L}_{1}(\mathrm{Ksv}=5,4)$, provavelmente devido à interação hidrofóbica com o lipídio zwitteriônico.

O estudo de supressão da fluorescência dos triptofanos de ambos os peptídeos, realizado em meio aquoso, confirmou a maior restrição conformacional do peptídeo Lo devido à estrutura cíclica, conforme esperado.

Os estudos de CD demonstraram que todos os peptídeos sofreram alteração conformacional após mudança de meio. O Lo, tanto em meio aquoso quanto na presença de 
micelas de SDS e LPC, está não-ordenado, no entanto, com diferenças. Já o peptídeo $\mathrm{L}_{1}$, em meio aquoso apresenta estrutura ao acaso com uma banda positiva em $224 \mathrm{~nm}$, devido à interação entre triptofanos; em SDS sofreu alteração para $\beta$-folha, e em LPC apresenta uma banda negativa ao redor de $230 \mathrm{~nm}$ e outra banda positiva ao redor de $194 \mathrm{~nm}$. Também apresenta um ombro em torno de $220 \mathrm{~nm}$. Portanto, o caráter aniônico e zwitteriônico das superfícies são fatores importantes para a interação (hidrofóbico ou eletrostático). Sobretudo, a composição lipídica dessa membrana é determinante para a formação da estrutura ativa.

Baseado no estudo por DM, em micelas de SDS houve maior inserção do peptídeo $\mathrm{L}_{1}$, conforme observado no estudo in vitro. Além disso, o triptofano da posição 2 é o resíduo mais inserido. Já o peptídeo Lo, embora não tenha sido a molécula mais inserida na micela de SDS, a região da molécula mais inserida no mimético de membrana também contém o triptofano da posição 2 , além dos resíduos das posições 1,9 , e 10 . O triptofano é altamente hidrofóbico, tem grande afinidade com membrana, e demonstrou ser o responsável pela inserção dos peptídeos na região hidrofóbica. Por isso, acredita-se que está diretamente envolvido com o mecanismo de ação dos peptídeos. Devido à sua maior inserção os outros resíduos de aminoácido se reorganizam na membrana, de tal forma que permita o menor gasto de energia, buscando maior afinidade com os lipídios. Por isso, mudanças conformacionais ocorrem, e depende da composição lipídica da membrana.

Em LPC, a utilização de um campo de força com todos os detalhes atômicos levou a uma estrutura desigual do LPC, quando comparada à obtida por Coarse-Grained. Isso possivelmente afetou os resultados, já que divergem do observado in vitro. Segundo a DM, ambos os peptídeos estão igualmente inseridos na região da interface da micela.

Já nos estudos com lipossomos foi possível observar um aumento no diâmetro hidrodinâmico dos lipossomos após interagir com crescentes concentrações de peptídeo 
(redução da razão L/P). Em DPPC e DPPC:Chol (9:1) esse aumento foi maior na presença de Lo; e em DPPC:DPPS (8:2) foi maior em $\mathrm{L}_{1}$. O mecanismo de agregação e/ou fusão desses lipossomos não é conhecido, o que impossibilita determinar quem apresentou maior interação com os peptídeos, devido à diferença estrutural dos peptídeos. Portanto, estudos complementares são necessários. Sobretudo, o aumento do PI indicou que esse acréscimo no diâmetro do lipossomo não foi homogêneo, havendo uma população de diferentes tamanhos em solução. Foi observado que essa população cresce conforme o aumento da concentração de peptídeo em solução, reforçando que os peptídeos podem induzir fusão e/ou agregação dos sistemas.

Esses lipossomos também foram estudados através da espectrometria de fluorescência e supressão da fluorescência. Os resultados obtidos são similares aos observados nos estudos com monocamada de Langmuir, e análogo aos obtidos com micelas. Em DPPC houve maior inserção dos triptofanos do peptídeo Lo que do $\mathrm{L}_{1}$. Em DPPC:Chol (9:1) os triptofanos do peptídeo $\mathrm{L}_{1}$ estão mais inseridos que os do Lo. E em DPPC:DPPS (8:2) os triptofanos do peptídeo $\mathrm{L}_{1}$ estão mais inseridos que os do Lo.

No estudo de CD com lipossomos também foi observado mudanças conformacionais mediante a interação peptídeo-mimético de membrana. O peptídeo Lo, tanto em meio aquoso quanto na presença dos diferentes lipossomos, está não-ordenado, no entanto essas conformações são diferentes. Já o peptídeo $\mathrm{L}_{1}$, tanto em meio aquoso quanto em DPPC apresenta estrutura ao acaso, no entanto, na presença do lipídio não apresenta a banda positiva referente à interação entre triptofanos, em $224 \mathrm{~nm}$. Em DPPC:Chol e DPPC:DPPS (8:2) devido à restrição conformacional, o peptídeo Lo permanece não-ordenado, no entanto, essas conformações são diferentes. Já o peptídeo $\mathrm{L}_{1}$ na presença de colesterol apresenta estrutura ao acaso, com perda da banda positiva referente à interação entre triptofanos. E na 
presença de DPPS o peptídeo linear sofreu alteração conformacional, estruturando-se em forma de $\beta$-folha.

Ao comparar os resultados obtidos com membranas similares, DPPC e LPC, foi possível observar distintos comportamentos. O peptídeo Lo não apresentou significante alteração conformacional ao interagir com estas estruturas de diferente raio de curvatura e hidratação, porém $\mathrm{L}_{1}$ mudou. Portanto, a estrutura cíclica do Lo restringe sua conformação, impedindo a obtenção de uma conformação mais estável conforme a variação do ambiente lipídico (composição, hidratação, curvatura).

Essas alterações conformacionais causaram mudanças na energia do sistema. Isso foi avaliado através da variação da entalpia. Em todo os meios lipídicos (DPPC, DPPC:Chol (9:1) e DPPC:DPPS (8:1)), a interação peptídeo-lipossomo foi endotérmica. Quanto maior a interação do peptídeo com a bicamada, maior a variação da entalpia, e menor a cooperatividade $\left(t_{1 / 2}\right)$.

Assim, baseado nesse estudo, um provável mecanismo de interação do peptídeo Lo com membrana consiste inicialmente na adsorção do peptídeo na superfície lipídica. Em seguida, ocorre a interação hidrofóbica membrana-peptídeo, acompanhada pela inserção da região do triptofano da posição 2 na parte mais profunda da membrana, induzindo modificações na conformação mediante a interação, dos outros resíduos, com a membrana.

Deve-se ressaltar que o efeito de interação mostrou ser dependente da concentração. Por isso, outros estudos devem ser realizados com intuito de obter informações quanto à organização dessas moléculas na bicamada e entre si (peptídeo-peptídeo). 
Referências Bibliográficas

\section{Referências Bibliográficas}

ALBERTS, B.; JOHNSON, A.; LEWIS, J.; RAFF, M.; ROBERTS, K.; WALTER, P. (2002) Molecular Biology of the Cell. 4th edition. Garland Science, New York.

ANDERSSON, D.; CARLSSON, U.; FRESKGARD, P. (2001) Contribution of tryptophan residues to the $\mathrm{CD}$ spectrum of the extracellular domain of human tissue factor. European Journal of Biochemistry, 268:1118-1128.

ATTWOOD, S. J.; CHOI, Y.; LEONENKO, Z. (2013) Preparation of DOPC and DPPC Supported Planar Lipid Bilayers for Atomic Force Microscopy and Atomic Force Spectroscopy. International Journal of Molecular, 14:3514-3539.

AZIMI, O.; EMAMI, Z.; SALARI, H.; CHAMANI, J. (2011) Probing the Interaction of Human Serum Albumin with Norfloxacin in the Presence of High-Frequency Electromagnetic Fields: Fluorescence Spectroscopy and Circular Dichroism Investigations. Molecules, 16:9792-9818.

BACIA, K.; SCHWEIZER, J. (2005) Practical Course: Giant Unilamellar Vesicles. Institut für Biophysik.

BARAGUEY, C.; GUETTE, C. A.; BLOND, A.; CAVELIER, F.; LEZENVEN, F.; POUSSET, J. L.; BODO, B. (1998) Isolation, structure and synthesis of chevalierins A, $\mathrm{B}$ and $\mathrm{C}$, cyclic peptides from the latex of Jatropha chevalieri. Journal Chemical Society, 1:3033-3039.

BARBOSA, L. R.; CAETANO, W.; ITRI, R.; HOMEM-DE-MELLO, P.; SANTIAGO, P. S.; TABAK, M. (2006) Interaction of phenothiazine compounds with zwitterionic lysophosphatidylcholine micelles: Small angle X-ray scattering, electronic absorption spectroscopy, and theoretical calculations. Journal of Physical Chemistry B, 110:13086-13093.

BARBOSA, S. C.; CILLI, E. M.; DIAS, L. G.; STABELI, R. G.; CIANCAGLINI, P. (2011) Labaditin, a cyclic peptide with rich biotechnological potential: preliminary toxicological studies and structural changes in water and lipid membrane environment. Amino Acids, 40:135-144.

BATISTA, C. M.; CARVALHO, C. M. B.; MAGALHÃES, N. S. S. (2007) Lipossomas e suas aplicações terapêuticas: Estado da arte. Brazilian Journal of Pharmaceutical Sciences, 43:167-179.

BERENDSEN, H. J. C.; GRIGERA, J. R.; STRAATSMA, T. P. (1987) The Missing Term in Effective Pair Potentials. Journal of Physical Chemistry, 91:6269-6271.

BERMEJO, I. L., ARNULPHI, C., IBANEZ DE OPAKUA, A., ALONSO-MARINO, M., GONI, F. M., VIGUERA, A. R. (2013) Membrane partitioning of the pore-forming domain of colicin A. Role of the hydrophobic helical hairpin. Biophysical Journal, 105:1432-1443.

BERTHELOT, T.; GONÇALVES, M.; LAÏN, G.; ESTIEU-GIONNET, K.; DÉLÉRIS, G. (2006) New strategy towards the efficient solid phase synthesis of cyclopeptides. Tetrahedron, 62:1124-1130.

BIRUSS, B.; DIETL, R.; VALENTA, C. (2007) The influence of selected steroid hormones on the physicochemical behaviour of DPPC liposomes. Chemistry and Physics of Lipids, 148:84-90.

BOCKUS, A. T.; MCEWEN, C. M.; LOKEY, R. S. (2013) Form and Function in Cyclic Peptide Natural Products: A Pharmacokinetic Perspective. Current Topics in Medicinal Chemistry, 13:821-836.

BOKVIST, M.; LINDSTROM, F. (2004) Two types of Alzheimer's beta-amyloid (1-40) peptide membrane interactions: aggregation preventing transmembrane anchoring 
versus accelerated surface fibril formation. Journal of Molecular Biology, 335:10391049.

CHEN, R.; MARK, A. E. (2011) The effect of membrane curvature on the conformation of antimicrobial peptides: implications for binding and the mechanism of action. Journal European Biophysics, 40:545-553.

CHEN, Y.; BARKLEY, M. D. (1998) Toward understanding tryptophan fluorescence in proteins. Biochemistry, 37:9976-9982.

CHRISTIAENS, B.; SYMOENS, S.; VERHEYDEN, S.; ENGELBORGHS, Y.; JOLIOT, A.; PROCHIANTZ, A.; VANDEKERCKHOVE, J.; ROSSENEU, M.; VANLOO, B.; VANDERHEYDEN, S. (2002) Tryptophan fluorescence study of the interaction of penetratin peptides with model membranes. European Journal of Biochemistry, 269:2918-2926.

CRUSCA, E.; REZENDE, A. A.; MARCHETTO, R.; MENDES-GIANNINI, M. J.; FONTES, W.; CASTRO, M. S.; CILLI, E. M. (2011) Influence of N-terminus modifications on the biological activity, membrane interaction, and secondary structure of the antimicrobial peptide hylin-a1. Biopolymers, 96:41-48.

DARDEN, T.; YORK, D.; PEDERSEN, L. (1993) Particle Mesh Ewald-an N.Log(N) method for Ewald sums in large systems. Journal Chemical Physics, 98:10089-10092.

DAVE, P. C.; BILLINGTON, E.; PAN, Y.; STRAUS, S. K. (2005) Interaction of Alamethicin with Ether-Linked Phospholipid Bilayers: Oriented Circular Dichroism, 31P Solid-State NMR, and Differential Scanning Calorimetry Studies. Biophysical Journal, 89:2434-2442.

DEVA, M. S. Z. W.; BEHERE, D. V. (1999) Fluorescence and circular dichroism spectroscopic studies on bovine lactoperoxidase. BioMetals, 12:219-225.

EFTINK, M. R.; GHIRON, C. A. (1976) Fluorescence quenching of Indole and Model Micelle Systems. Journal of Physical Chemistry, 80:486-493.

EFTINK, M. R.; GHRION, C. A. (1976) Exposure of Tryptophanyl Residues in Protein. Quantitative Determination by Fluorescence Quenching Studies. Biochemistry, 15:672680.

FERREIRA, M.; CAETANO, W.; ITRI, R. (2005) Técnicas de Caracterização para Investigar Interações no Nível Molecular em Filmes de Langmuir e Langmuir-Blodgett (LB). Química Nova, 28:502-510.

GALDIERO, S.; FALANGA, A. (2013) Peptide-lipid interactions: experiments and applications. International Journal of Molecular Sciences, 14:18758-18789.

GIERASCH, L. M., LACY, J. E., THOMPSON, K. F., ROCKWELL, A. L., WATNICK, P. I. (1982) Conformations of model peptides in membrane-mimetic environments. Biophysical Journal, 37:275-284.

GOPAL, R.; LEE, J. H.; KIM, Y. G.; KIM, M. S.; SEO, C. H.; PARK, Y. (2013) The Role of Biophysical Parameters in the Antilipopolysaccharide Activities of Antimicrobial Peptides from Marine Fish. Marine drugs, 11:1836-1852.

GRIFFITHS, P. C.; CHEUNG, A. Y. F.; DAVIES, J. A.; PAUL, A.; TIPPLES, C. N.; WINNINGTON, A. L. (2002) Probing interactions within complex colloidal systems using PGSE-NMR. Magnetic Resonance in Chemistry, 40: 40-50.

GRISHINA, I. B.; WOODY, R. W. (1994) Contributions of Tryptophan Side Chains to the Circular Dichroism of Globular proteins: Exciton Couplets and coupled Oscillators. Faraday Discussion, 99:245-262. 
HESS, B.; BEKKER, H.; BERENDSEN, H. J. C.; FRAAJIE, J. G. E. M. (1997) LINCS: a linear constraint solver for molecular simulations. Journal of Computational Chemistry, 18:1463-1472.

HESS, B.; KUTZNER, C.; VAN DER SPOEL, D.; LINDAHL, E. (2008) GROMACS 4: Algorithms for highly efficient, load-balanced and scalable molecular simulation. Journal of Chemical Theory and Computation, 4:435-447.

HOCKNEY, R. W.; GOEL, S. P.; EASTWOOD, J. (1974) Quiet high-resolution computer models of a plasma. Journal of Computational Physics, 14:148-158.

http://employees.csbsju.edu/hjakubowski/classes/ch125/IB1_IMF_Lipid_Aggregates.

http://md.chem.rug.nl/marrink/coarsegrain.html

http://sunmil.epfl.ch/page-68954-en.html.

http://www.hipertrofia.org/forum/topic/90111-nutrition-101/page-4

HYODO, K.; YAMAMOTO, E.; SUZUKI, T.; KIKUCHI, H.; ASANO, M.; ISHIHARA, H. (2013) Challenges of Drug Delivery Systems That Contribute to Cancer Chemotherapy: Development of Liposomal Anticancer Drugs. Biological Pharmaceutical Bulletin, 36:703-707.

INNOVAGEN (1979) Peptide Property Calculator Disponível em: http://www.innovagen.se. Solid Phase Peptide Synthesis, $2^{\circ}$ Ed. Pierce.

ITRI, R., AMARAL, L. Q. (1993) Micellar-shape anisometry near isotropic-liquid-crystal phase transitions. Physical Review E, 47:2551-2557.

JALILI, S.; AKHAVAN, M. (2011) Study of the Alzheimer's A 440 peptide in SDS micelles using molecular dynamics simulations. Biophysical chemistry, 153:179-186.

JANA, S.; CHAUDHURI, T. K.; DEB, J. K. (2006) Effects of guanidine hydrochloride on the conformation and enzyme activity of streptomycin adenylyltransferase monitored by circular dichroism and fluorescence spectroscopy. Biochemistry, 71:1230-1237.

JELINEK, R.; SHEYNIS, T. (2010) Amyloid - membrane interactions: experimental approaches and techniques. Current Protein and Peptide Science, 11:372-384.

JIA, C.; QI, W.; HE, Z.; YANG, H.; QIAO, B. (2006) Synthesis of heptapeptides and analysis of sequence by tandem ion trap mass spectrometry. Central European Journal of Chemistry, 285-298.

KARMAKAR, S.; SARANGI, B. R.; RAGHUNATHAN, V. A. (2006) Phase behavior of lipid-cholesterol membranes. Solid State Communication. 139:630-634.

KING, D. S.; FIELDS, C. G.; FIELDS, G. B. (1990) A cleavage method which minimizes side reactions following Fmoc solid phase peptide synthesis. International Journal of Peptide and Protein Research, 36:255-266.

KITAMURA, A.; KIYOTA, T.; TOMOHIRO, M.; UMEDA, A.; LEE, S.; INOUE, T.; SUGIHARA, G. (1999) Morphological Behavior of Acidic and Neutral Liposomes Induced by Basic Amphiphilic a-Helical Peptides with Systematically Varied Hydrophobic-Hydrophilic Balance. Biophysical Journal, 76:1457-1468.

KOSASI, S.; VANDERSLUIS, W. G.; BOELENS, R.; THART, L.; LABADIE, R. P. L. (1989) Labaditin A novel cyclic decapeptide from the latex of jatrophamultifida (Euphorbiaceae). FEBS Lett, 256:91-96.

KUKOL, A. (2009) Lipid Models for United-Atom Molecular Dynamics Simulations of Proteins. Journal of Chemical Theory and Computation, 5:615-626.

KWON, Y. U., KODADEK, T. (2007) Quantitative comparison of the relative cell permeability of cyclic and linear peptides. Chemistry and Biology, 14:671-677. 
LADOKHIN, A. S.; JAYASINGHE, S.; WHITE, S. H. (2000) How to measure and analyze tryptopahn fluorescence in membranes properly, and why bother? Analytical Biochemistry, 285:235-245.

LAKOWICZ, J. R. (2006). Principles of fluorescence spectroscopy. Springer, New York.

LOURA, L. M. S.; ALMEIDA, R. F. M. (2004) Tópicos de Biofísica de Membranas. Sociedade Portuguesa de Química, 63:121-125.

MA, G.; ALLEN, H. C. (2006) DPPC Langmuir Monolayer at the Air-Water Interface: Probing the Tail and Head Groups by Vibrational Sum Frequency Generation Spectroscopy. Langmuir, 22:5341-5349.

MANIASSO, N. (2001) Ambientes micelares em química analítica. Quimica Nova, 24:8793.

MARRINK, S. J.; RISSELADA, H. J.; YEFIMOV, S.; TIELEMAN, D. P.; VRIES, A. H. (2007) The MARTINI force field: coarse grained model for biomolecular simulations. Journal Physical Chemistry B, 111:7812-7824.

MARSH, D. (1996) Lateral pressure in membranes. Biochimica et Biophysica acta, 1286:183-223.

MATSUZAKI, K.; MURASE, O. (1994) Orientational and aggregational states of magainin 2 in phospholipid bilayers. Biochemistry, 33:3342-3349.

MONTICELLI, L.; KANDASAMY, S. K.; PERIOLE, X.; LARSON, R. G.; TIELEMAN, D. P.; MARRINK, S. J. (2008) The MARTINI Coarse-Grained Force Field: Extension to Proteins. Journal of Chemical Theory and Computation, 4:819-834.

NAKANISHI, K.; SAKIYAMA, T.; IMAMURA, K. (2001) On the Adsorption of Proteins on Solid Surfaces, a Common but Kazuhiro tanaka Very Complicated Phenomenon. Journal of bioscience and bioengineering, 91:233-244.

NELSON, D. L.; COX, M. M. (2011) Princípios de bioquímica - Lehninger. 5. ed. Porto Alegre: Artmed.

NOBRE, T. M.; PAVINATTO, F. J.; COMINETTI, M. R.; SELISTRE DE-ARAÚJO, H. S.; ZANIQUELLI, M. E. D.; BELTRAMINI, L. M. (2010) The specificity of frutalin lectin using biomembrane models. Biochimica et Biophysica Acta, 1798:1547-1555.

OHE, C.; SASAKI, T.; NOI, M.; GOTO, Y.; ITOH, K. (2007) Sum frequency generation spectroscopic study of the condensation effect of cholesterol on a lipid monolayer. Analytical and Bioanalytical Chemistry, 388:73-79.

OKORO, L. N. (2013) Calorimetric determination of phospholipid melittin interaction. European Chemical Bulletin, 2:107-111.

OOSTENBRINK, C.; VILLA, A.; MARK, A. E.; VAN GUNSTEREN, W. F. (2004) A biomolecular force field based on the free enthalpy of hydration and solvation: the GROMOS force-field parameter sets 53A5 and 53A6, Journal of Computational Chemistry, 25:1656-1676.

OYEWUMI, O. M.; KUMAR, A.; CUI, Z. (2010) Nano-microparticles as immune adjuvants. Correlating particle sizes and the resultant immune responses 9:1095-1107.

PARK, N. G. (1995) Interaction of Mastoparan-B from venom of a hornet in Taiwan with phospholipid bilayer and its antimicrobial activity. Biopolymers, New York, 36:793801.

PICCHI, D. G.; ALTEI, W. F.; SAITO, M. S.; BOLZANI, V. S.; CILLI, E. M. (2009) Peptídeos cíclicos de biomassa vegetal: características, diversidade, biossíntese e atividades biológicas. Química Nova, 32:1262-1277. 
QIAN, Z.; LIU, T.; LIU, Y.; BRIESEWITZ, R.; BARRIOS, A. M.; JHIANG, S. M.; PEIA, D. (2013) Efficient Delivery of Cyclic Peptides into Mammalian Cells with Short Sequence Motifs. ACS Chemical Biology, 15:423-431.

REZAI, T.; BOCK, J. E.; ZHOU, M. V.; KALYANARAMAN, C.; LOKEY, R. S.; JACOBSON, M. P. (2006) Conformational Flexibility, Internal Hydrogen Bonding, and Passive Membrane Permeability: Successful in Silico Prediction of the Relative Permeabilities of Cyclic Peptides. Journal of the American Chemical Society, 128: 14073-14080.

ROSS, M.; STEINEM, C.; GALLA, H. J.; JANSHOFF, A. (2001) Visualization of Chemical and Physical Properties of Calcium-Induced Domains in DPPC/DPPS Langmuir-Blodgett Layers. Langmuir, 17:2437-2445.

ROWE, E. S., ZHANG, F., LEUNG, T. W., PARR, J. S., GUY, P. T. (1998) Thermodynamics of membrane partitioning for a series of $n$-alcohols determined by titration calorimetry: role of hydrophobic effects. Biochemistry, 37:2430-2440.

RZEPIELA, A. J.; SCHÄFER, L. V.; GOGA, N.; RISSELADA, H. J.; DE VRIES, A. H.; MARRINK, S. J. (2010) Reconstruction of atomistic details from coarse-grained structures. Journal of Computational Chemistry, 31:1333-1343.

SABANDAR, C. W., AHMAT, N., JAAFAR, F. M., SAHIDIN, I. (2013) Medicinal property, phytochemistry and pharmacology of several Jatropha species (Euphorbiaceae): a review. Phytochemistry 85:7-29.

SANI, M. A.; WHITWELL, T. C.; SEPAROVIC, F. (2012) Lipid composition regulates the conformation and insertion of the antimicrobial peptide maculatin 1.1. Biochimica et Biophysica Acta, 1818:205-211.

SANTOS, N. C.; CASTANHO, M. A. R. B. (2002) Lipossomas: a bala mágica acertou? Quimica Nova, 25:1181-1185.

SATO, H.; FEIX, J. B. (2006) Peptide-membrane interactions and mechanisms of membrane destruction by amphipathic alpha-helical antimicrobial peptides. Biochimica et Biophysica Acta, 1758:1245-1256.

SERGELIUS, C.; YAMAGUCHI, S.; YAMAMOTO, T.; ENGBERG, O.; KATSUMURA, S.; SLOTTE, J. P. (2013) Cholesterol's interactions with serine phospholipids - A comparison of N-palmitoyl ceramide phosphoserine with dipalmitoyl phosphatidylserine. Biochimica et Biophysica Acta, 1828:785-791.

SFORÇA, M. L.; MACHADO, A.; FIGUEREDO, R. C. R.; OYAMA, Jr. S.; SILVA, F. D.; MIRANDA, A.; DAFRE, S.; TERESA, M.; MIRANDA, M.; SPISNI, A.; PERTINHEZ, T. A. (2005) The micelle-bound Structure of na Antimicrobial Peptide Derived from the $\alpha$-Chain of Bovine hemoglobin Isolated from the Tick Boophilus microplus. Biochemistry, 44:6440-6451.

SHAW, D. J. (1992) Introdução à Química dos Colóides e de Superfícies, São Paulo, Editora Edgard Blucher e Editora da Universidade de São Paulo.

STEWART, J. M.; YOUNG, J. D. (1984) Solid Phase Peptide Synthesis. Pierce Chemical Company.

STEWART, J. M.; YOUNG, J. D. (2005) Interaction of alamethicin with Ether-linked phospholipid: Oriented Circular Dichroism 31P Solid-State NMR, and Differential Scanning Calorimetry Studies. Biophysical Journal, 89:2434-2442.

STIMAC, A.; SEGOTA, S.; SIKIRIC, M. D.; RIBIC, R.; FRKANEC, L.; SVETLICIC, V.; TOMIC, S.; VRANESIC, B.; FRKANEC, R. (2012) Surface modified liposomes by mannosylated conjugates anchored via the adamantly moiety in the lipid bilayer. Biochimica et Biophysica Acta, 1818:2252-2259. 
TAN, N. H.; ZHOU, J. (2006) Plant cyclopeptides. Chemical Reviews, 106:840-895.

TUMMALA, N. R.; STRIOLO, A. (2008) Role of counterion condensation in the selfassembly of SDS surfactants at the water-graphite interface. Journal of Physical Chemistry B, 112:1987-2000.

URUSHIBARA, T.; HICKS, R. (2013) Effect of Liposome Surface Charge and Peptide Side Chain Charge Density on Antimicrobial Peptide-Membrane Binding as Determined by Circular Dichroism and Nuclear Magnetic Resonance Spectroscopy. Journal Membrane Science Technology, 3:124.

VAN DER WEL, P. C. A.; REED, N. D.; GREATHOUSE, D. V.; KOEPPE, R. E. (2007) Orientation and motion of Thyptophan Interfacial Anchors in Membrane Spanning Peptides. Biochemistry, 46:7514-7524.

VANEGAS, J. M.; CONTRERAS, M. F.; FALLER, R.; LONGO, M. L. (2012) Role of Unsaturated Lipid and Ergosterol in Ethanol Tolerance of Model Yeast Biomembranes. Biophysical Journal, 102:507-516.

VIEIRA, R. F.; CASALLANOVO, F.; MARÍN, N.; PAIVA, A. C.; SCHREIER, S.; NAKAIE, C. R. (2009) Conformational properties of angiotensin II and its active and inactive TOAC-labeled analogs in the presence of micelles. Electron paramagnetic resonance, fluorescence, and circular dichroism studies. Biopolymers, 92:525-537.

WADE, J. D.; MATHIEU, M. N.; MACRIS, M.; TREGEAR, G. W. (1999) Baseinduced side reations in Fmoc-solid phase peptide synthesis: Minimization by use of piperazine as $\mathrm{N} \alpha$-deprotection reagent. Letters in Peptide Science, 7:107-112.

WIECEK, A.; DYNAROWICZ-LATKA, P.; VILA-ROMEU, N.; NIETO-SUAREZ, M.; FLASINSKI, M. (2008) Colloids surfaces A: Physicochem. Eng. Aspests 321:201-205.

WOODY, R. W. (1994) Contributions of tryptophan side chains to the far-ultraviolet circular dicroism of proteins. Journal European Biophysics, 23:253-262.

WOODY, R. W. (1996). Theory of circular dichroism of protein. New York: Plenum Press.

XIAO, Q.; PEI, D. (2007) High-Throughput synthesis and screening of cyclic peptide antibiotics. Journal of Medicinal Chemistry, 50:3132-3137.

YANG, J. J.; PITKEATHLY, M.; RADFORD, S. E. (1994) Far-UV Circular Dichroism Reveals a Conformational Switch in a Peptide Fragment from the $\beta$-Sheet of Hen Lysozyme. Biochemistry, 33:7345-7353.

ZHANG, C.; GAO, C.; MU, J. QIU, Z.; LI, L. (2013) Spectroscopic Studies on Unfolding Processes of Apo-Neuroglobin Induced by Guanidine Hydrochloride and Urea. BioMed Research International, 2013.

ZHANG, X. P.; ZHANG, M. L.; SU, A. H.; HUO, C. H.; GU, Y. C.; SHI, Q. W. (2009) Chemical constituents of the plants from genus Jatropha. Chemistry and Biodiversity, 6:2166-2183. 